\title{
ALTERNATIVE ENHANCED CHEMICAL CLEANING: BASIC STUDIES RESULTS FY09
}

February 2010

Savannah River National Laboratory Savannah River Nuclear Solutions Aiken, SC 29808

Prepared for the U.S. Department of Energy Under Contract Number DE-AC09-08SR22470

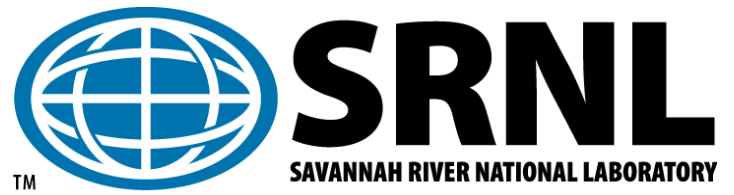




\section{DISCLAIMER}

This work was prepared under an agreement with and funded by the U.S. Government. Neither the U. S. Government or its employees, nor any of its contractors, subcontractors or their employees, makes any express or implied:

1. warranty or assumes any legal liability for the accuracy, completeness, or for the use or results of such use of any information, product, or process disclosed; or

2. representation that such use or results of such use would not infringe privately owned rights; or

3. endorsement or recommendation of any specifically identified commercial product, process, or service.

Any views and opinions of authors expressed in this work do not necessarily state or reflect those of the United States Government, or its contractors, or subcontractors.

This document was prepared in conjunction with work accomplished under Contract No. DE-AC09-08SR22470 with the U.S. Department of Energy.

Printed in the United States of America

Prepared For U.S. Department of Energy 
Key Words:

Sludge Heel

Oxalic Acid Cleaning

Retention: Permanent

Key References:

Technical Task Plan: WSRC-RP-2008-00613

\title{
ALTERNATIVE ENHANCED CHEMICAL CLEANING: BASIC STUDIES RESULTS FY09
}

\author{
W. D King, SRNL/E\&CPT \\ M. S. Hay, SRNL/E\&CPT
}

Issue Date: February 2010 


\section{TABLE OF CONTENTS}

$\begin{array}{lc}\text { LIST OF TABLES } & 3\end{array}$

$\begin{array}{ll}\text { LIST OF FIGURES } & 4\end{array}$

$\begin{array}{ll}\text { LIST OF ACRONYMS } & 5\end{array}$

$\begin{array}{ll}\text { 1.0 SUMMARY } & 6\end{array}$

$\begin{array}{ll}\text { 2.0 INTRODUCTION } & 7\end{array}$

$\begin{array}{ll}\text { 3.0 EXPERIMENTAL DETAILS } & 11\end{array}$

$\begin{array}{ll}\text { 4.0 EXPERIMENTAL RESULTS } & 19\end{array}$

4.1 SLUDGE CHARACTERIZATION

4.2 TANK 8F SLUDGE SIMULANT SOLUBILITY EVALUATIONS 19

4.3 SOLUBILITY TESTING WITH PURE ALUMINUM PHASES 20

4.4 METHOD DEVELOPMENT AND SUPPORTIVE DATA FOR IRON PHASE SOLUBILITY TESTING 22

4.5 SOLUBILITY TESTING WITH PURE IRON PHASES 23

5.0 THERMODYNAMIC MODELING OF SOLUBILITY TESTS 48

5.1 Model Predictions COMPared to EXPERIMENTAl Data 48

$\begin{array}{lr}\text { 6.0 CONCLUSIONS } & 62\end{array}$

$\begin{array}{ll}\text { 7.0 PATH FORWARD } & 65\end{array}$

$\begin{array}{lc}\text { 8.0 REFERENCES } & 66\end{array}$ 


\section{LIST OF TABLES}

TABLE 4.1 SUMMARY OF XRD ANALYSIS RESULTS FOR SRS TANK SLUDGE SAMPLES. ..................................27

TABLE 4.2 EXPERIMENTAL RESULTS - GIBBSITE SOLUBILITY IN 0.125 M ACIDS AT 25 AND $70^{\circ} \mathrm{C} \ldots \ldots \ldots \ldots \ldots . . . . . .28$

TABLE 4.3 EXPERIMENTAL RESULTS - BOEHMITE SOLUBILITY IN 0.125 M ACIDS AT 25 AND $70{ }^{\circ} \mathrm{C} \ldots \ldots \ldots \ldots \ldots . . .29$

TABLE 4.4 EXPERIMENTAL ReSULTS - Boehmite SOLUBILITY IN 1, 4, AND 8 WT. \% OXALIC ACID AT $50^{\circ} \mathrm{C}$

(TEST DURATION: 19 DAYS)............................................................................................

TABle 4.5 Experimental Results - Method Verification Testing With Ferrous Oxalate, Ferric

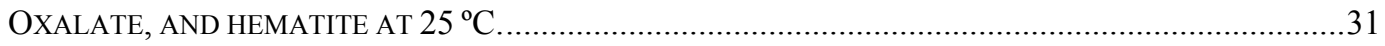

TABLE 4.6 EXPERIMENTAL RESULTS - FERRIC AND FERROUS OXALATE SOLUBILITIES IN OXALIC, NITRIC, AND

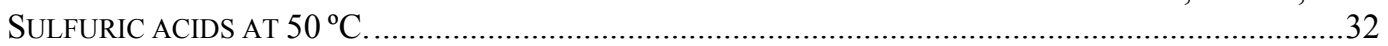

TABLE 4.7 EXPERIMENTAL RESULTS - MAGNETITE SOLUBILITY IN 0.125 M ACIDS AT 25 AND $70{ }^{\circ} \mathrm{C} \ldots \ldots \ldots \ldots . . . .33$

TABLE 4.8 EXPERIMENTAL RESULTS - HEMATITE SOLUBILITY IN 0.125 M ACIDS AT 25 AND $70^{\circ} \mathrm{C} \ldots \ldots . . . . . . . . . .34$

TABLE 4.9 EXPERIMENTAL RESUlTS - HEMATITE SOlUBILITY IN VARIOUS MinERAL ACID CONCENTRATIONS

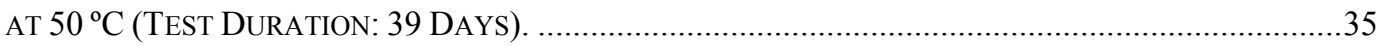

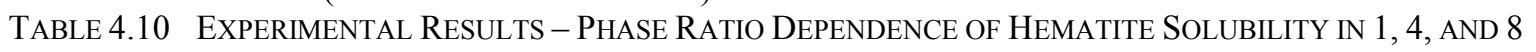
WT. \% OXALIC ACID AT $50{ }^{\circ} \mathrm{C}$ (TEST DURATION: 15 DAYS). .........................................................

TABLE 4.11 EXPERIMENTAL RESULTS - PH DEPENDENCE OF HEMATITE SOLUBILITY IN 1 wT. \% OXALIC ACID WITH $\mathrm{NANO}_{3}$ SALT BACKGROUND AT $50^{\circ} \mathrm{C}$ WITHOUT PH CONTROL (TEST DURATION: 30 DAYS). 37

TABLE 4.12 EXPERIMENTAL RESUlTS - PH DEPENDENCE OF HEMATITE SOlUBILITY IN 1 wT. \% OXALIC ACID

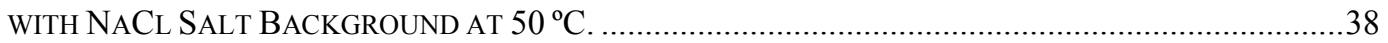

TABLE 5.1 COMPARISON OF EXPERIMENTAL DATA WITH MODELING RESUltS: HEMATITE SOLUBILITY IN 0.125

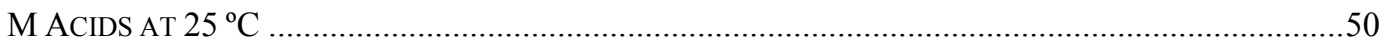

TABle 5.2 COMPARISON OF EXPERIMENTAL DATA With MODELING RESUltS: MAGNETITE SOLUBILITY IN

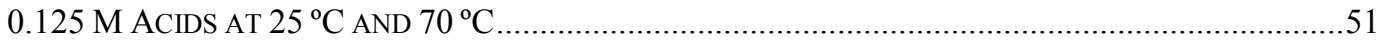

TABle 5.3 COMPARISON OF EXPERIMENTAL DATA With MODELING RESUltS: GibBSITE SOLUBiLity IN 0.125 M ACIDS AT $25^{\circ} \mathrm{C}$ AND $70^{\circ} \mathrm{C}$ .52

TABLE 5.4 COMPARISON OF EXPERIMENTAL DATA WITH MODELING RESULTS: BOEHMITE SOLUBILITY IN

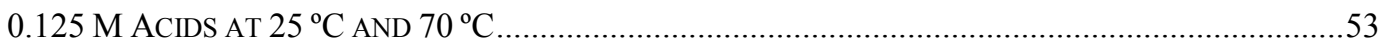

TABLE 5.5 COMPARISON OF EXPERIMENTAL DATA WITH MODELING RESULTS: HEMATITE SOLUBILITY IN

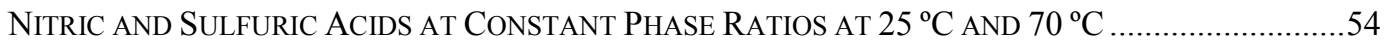

TABLE 5.6 COMPARISON OF EXPERIMENTAL DATA WITH MODELING RESUlTS: HEMATITE SOLUBILITY IN OXALIC ACID WITH VARYING PhaSe/MOlar Ratios at $50^{\circ} \mathrm{C}$ WITH AND WITHOUT PH CONTROL 55

TABLE 5.7 COMPARISON OF EXPERIMENTAL DATA WITH MODELING RESUlTS: HEMATITE SOLUBILITY IN 1 WT\% OXALIC ACID WITH $\mathrm{NANO}_{3}$ BACKGROUND SALT AND CONSTANT PHASE RATIO OVER A

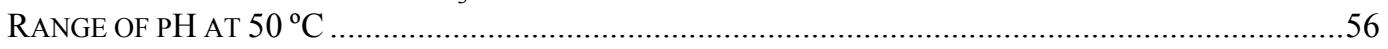

TABLE 5.8 COMPARISON OF EXPERIMENTAL DATA WITH MODELING RESULTS: HEMATITE SOLUBILITY IN 1

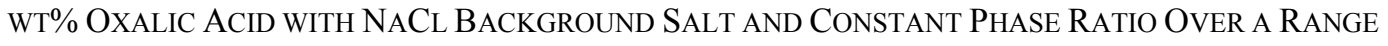
OF PH AT $50^{\circ} \mathrm{C}$ (WITH PH CONTROL). . .57

Table 6.1 Solubilities of Primary Metal Phases in OXalic, Nitric, AND Sulfuric ACIDS. ..................64 


\section{LIST OF FIGURES}

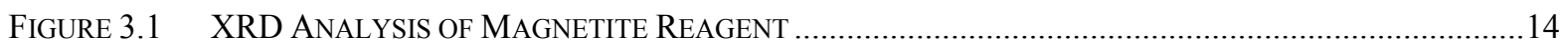

FIGURE 3.2 XRD ANALYSIS OF HEMATITE REAGENT ........................................................................... 15

FIGURE 3.3 XRD ANALYSIS OF FERRIC OXALATE REAGENT .................................................................... 16

FIGURE 3.4 XRD ANALYSIS OF FERROUS OXALATE REAGENT ............................................................... 17

FIGURE 3.5 XRD ANALYSIS OF TANK 8F SLUDGE SIMULANT ..................................................................18

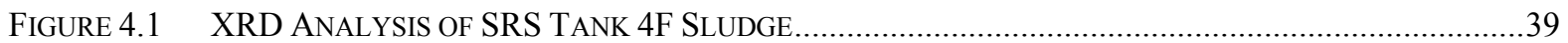

FIGURE 4.2 GIBBSITE SOLUBILITY IN 0.125 M ACIDS VERSUS TEMPERATURE. ................................................40

FIGURE 4.3 BOEHMITE SOLUBILITY IN 0.125 M ACIDS VERSUS TEMPERATURE. ...........................................41

FIgURE 4.4 XRD ANALYSIS OF RESIDUAL BOEHMITE SOLIDS AFTER CONTACT WITH 8 WT. \% OA ...............42

FIGURE 4.5 SOLIDS FORMED AFTER LIGHT EXPOSURE FROM FE $\mathrm{F}_{2}\left(\mathrm{C}_{2} \mathrm{O}_{4}\right)_{3}$ DISSOLVED IN WATER (LEFT AND

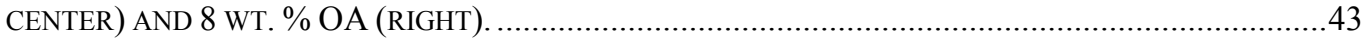

FIGURE 4.6 MAGNETITE SOLUBILITY IN VARIOUS ACIDS VERSUS TEMPERATURE.........................................44

Figure 4.7 HeMATITE SOLUBILITY IN VARIOUS ACIDS VERSUS CONCENTRATION AT $50^{\circ} \mathrm{C}$ WITHOUT PH

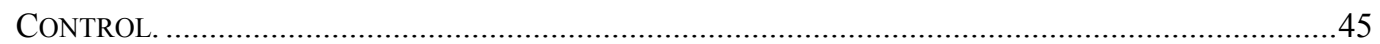

FIGURE 4.8 HEMATITE SOLUBILITY VERSUS PH IN 1 WT. \% OXALIC ACID ...................................................46

Figure 4.9 SOluble OXALATE:IRON MOLAR RATIO FOR HEMATITE VERSUS PH IN 1 wT. \% OXALIC ACID ...47

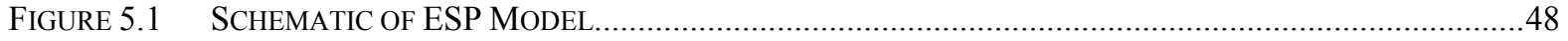

Figure 5.2 MOdEL PREDICTIONS OF HeMATITE SOLUBILITY IN 1 WT\% OXALIC ACID ...................................58

Figure 5.3 MOdEL PREDICTIONS OF HEMATITE SOLUBILITY IN 8 WT\% OXALIC ACID ...................................59

Figure 5.4 HeMATITE SOlUBILITY IN 1 WT\% OXALIC ACID-MODEL PREDICTIONS AND EXPERIMENTAL DATA-

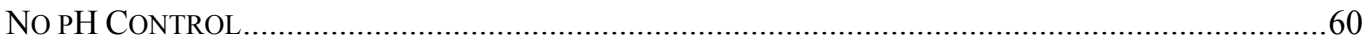

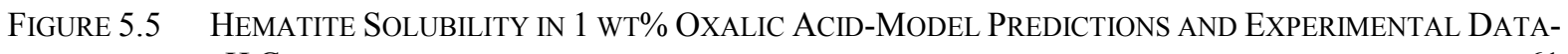

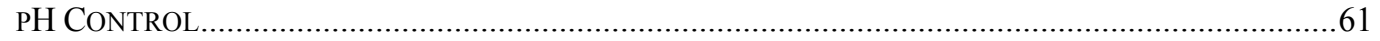




\section{LIST OF ACRONYMS}

$\begin{array}{ll}\text { AECC } & \text { Alternative Enhanced Chemical Cleaning } \\ \text { DOE } & \text { Department of Energy } \\ \text { ESP } & \text { Environmental Simulation Program } \\ \text { ICP-ES } & \text { Inductively Coupled Plasma-Emission Spectroscopy } \\ \text { PUREX } & \text { Plutonium Uranium Reduction Extraction } \\ \text { SRNL } & \text { Savannah River National Laboratory } \\ \text { SRS } & \text { Savannah River Site } \\ \text { XRD } & \text { X-ray Diffraction }\end{array}$




\subsection{SUMMARY}

Due to the need to close waste storage tanks, chemical cleaning methods are needed for the effective removal of the heels. Oxalic acid is the preferred cleaning reagent for sludge heel dissolution, particularly for iron-based sludge, due to the strong complexing strength of the oxalate. However, the large quantity of oxalate added to the tank farm from oxalic acid based chemical cleaning has significant downstream impacts. Optimization of the oxalic acid cleaning process can potentially reduce the downstream impacts from chemical cleaning. To optimize oxalic acid usage, a detailed understanding of the chemistry of oxalic acid based sludge dissolution is required. Additionally, other acid systems may be required for specific waste components with low solubility in oxalic acid and as a means to reduce oxalic acid usage in general.

Solubility tests were conducted using non-radioactive, pure metal phases known to be the primary phases present in High Level Waste sludge. The metal phases studied included the aluminum phases gibbsite and boehmite and the iron phases magnetite and hematite. Hematite and boehmite are expected to be the most difficult iron and aluminum phases to dissolve. These mineral phases have been identified in both SRS and Hanford High Level Waste sludge. Acids evaluated for dissolution included oxalic, nitric, and sulfuric acids. The results of the solubility tests indicate that oxalic and sulfuric acids are more effective for the dissolution of the primary sludge phases. For boehmite, elevated temperature will be required to promote effective phase dissolution in the acids studied.

Literature reviews, thermodynamic modeling, and experimental results have all confirmed that $\mathrm{pH}$ control using a supplemental proton source (additional acid) is critical for minimization of oxalic acid usage during the dissolution of hematite. These results emphasize the importance of $\mathrm{pH}$ control in optimizing hematite dissolution in oxalic acid and may explain the somewhat limited success observed during recent attempts to remove sludge heels from SRS Tanks 5F and 6F using oxalic acid.

Additionally, based on the results of the solubility tests conducted, the following conclusions can be drawn.

- Hematite dissolution in oxalic acid is a stoichiometric process dependant upon the provision of sufficient oxalate molar equivalents to complex the iron and sufficient $\mathrm{H}^{+}$to promote the dissolution reaction.

- The optimal utilization of oxalic acid for hematite dissolution requires an additional proton source, such as nitric acid, and a $\mathrm{pH}$ of $\leq 1$. In the absence of a supplemental proton source, greater than stoichiometric amounts of oxalate are required.

- Magnetite is generally more soluble than hematite in all acids tested.

- Gibbsite is generally more soluble than the boehmite form of aluminum in all acids tested.

- The OLI Thermodynamic Model is a useful tool for the prediction of equilibrium iron concentrations, but predictions must be experimentally verified. The OLI model appears to over-predict the solubility of the iron and aluminum phases studied in mineral acids 


\subsection{INTRODUCTION}

As the Department of Energy (DOE) continues to fund efforts to treat and dispose of millions of gallons of legacy radioactive materials from the production of nuclear weapons, noncompliant waste storage tanks will gradually be emptied of the bulk waste volume leaving heel materials requiring removal prior to tank closure. The waste heel slurries are distributed on the floor of large tanks which frequently contain numerous obstructions that limit the effectiveness of mechanical removal methods. As a result, chemical cleaning methods are needed for the effective removal of the heels. Oxalic acid is the preferred cleaning reagent for heel dissolution, particularly for iron-based sludge, due to the strong complexing strength of oxalate. Several recent literature reviews ${ }^{1-3}$ and a Systems Engineering Evaluation ${ }^{4}$ have considered the various known methods for sludge dissolution, and oxalic acid remains the chemical dissolution reagent of choice. Oxalic acid is an industry standard used for the cleaning and maintenance of nuclear power plants, although these operations often involve the removal of chemical scales with dilute acid and regeneration of the acid for reuse. ${ }^{5}$

Waste tanks at two DOE sites in Hanford, WA and Aiken, SC (Savannah River Site - SRS) contain large sludge and salt heel volumes (approaching 5,000 gallons at SRS) at the conclusion of bulk waste removal and heel washing campaigns. The current baseline chemical cleaning process for heel removal at SRS involves the addition of $8 \mathrm{wt}$. \% oxalic acid to the waste tanks in several treatment cycles. More concentrated oxalic acid is preferred in this case because available tank farm volume is limited and evaporation to remove excess liquid is expensive. The large mass of waste requiring treatment makes the utilization of traditional techniques such as ion exchange for acid regeneration impractical. As a result, sludge dissolution with oxalic acid involves the addition of large amounts of oxalate to the tank farm inventory after caustic adjustment of the spent cleaning solutions. The addition of oxalic acid and the subsequent addition of sodium hydroxide (required after heel removal to make the waste stream compatible with interim storage vessels) have significant impacts on downstream processes.

The baseline chemical cleaning method has recently been used for heel removal in two SRS waste tanks with limited success. ${ }^{6,7}$ Lower than expected amounts of solids were removed from the tanks in each case. The baseline method has not been optimized to minimize the use of oxalic acid and the results indicate that better understanding of sludge dissolution chemistry in oxalic acid is needed in order to achieve more consistent and effective results. Given that numerous waste tanks are targeted for closure within the next decade, there is an urgent need to understand and optimize the chemical cleaning process for heel removal. SRS operations is currently developing a chemical cleaning process for heel removal involving an oxalate destruction technology. In a separate effort as part of the Alternative Enhanced Chemical Cleaning (AECC) program, the Savannah River National Laboratory (SRNL) is working to refine the baseline chemical cleaning process to optimize sludge dissolution. This effort involves evaluations of various acids (including oxalic) and combinations of acids for sludge dissolution. The latest results from this testing are the subject of this report. 
Iron and aluminum are the most abundant chemical constituents of SRS waste tank heels, with variable amounts of sodium, uranium, manganese, nickel, and silicon present. Numerous other insoluble or moderately soluble metal salts (such as carbonate) and oxides are also present in the waste slurries to varying degrees depending on the tank history. The residual liquid portion of the sludge is dilute alkaline solution remaining after the waste removal campaigns and washing with water to remove soluble waste components. Except for certain tanks containing high levels of residual and moderately soluble salts, most of the metals present in the heels exist as oxides, hydroxides, and oxy-hydroxides. In many cases these materials have been stored and aged for many years in an alkaline environment in the presence of concentrated sodium salt solutions. Common crystalline aluminum phases include gibbsite $\left(\mathrm{AlOH}_{3}\right)$ and boehmite $(\mathrm{AlOOH})$. Common crystalline iron phases include hematite $\left(\mathrm{Fe}_{2} \mathrm{O}_{3}\right)$, magnetite $\left(\mathrm{Fe}_{3} \mathrm{O}_{4}\right)$, and lepidocrocite $(\mathrm{Fe}(\mathrm{O}) \mathrm{OH})$. It is believed that iron exists primarily as $\mathrm{Fe}(\mathrm{III})$, with $\mathrm{Fe}(\mathrm{II})$ contributing to a minor degree and being present in phases such as magnetite. The body of X-ray Diffraction (XRD) data for waste tank sludge is limited and one goal of this work is to summarize the available sludge characterization data and obtain additional data. The metal phase present in the waste tank sludge heels may significantly impact the effectiveness of dissolution methods. For aluminum, a dissolution method has already been developed involving contact with highly alkaline solutions. ${ }^{8}$ Acid dissolution of aluminum is limited in effectiveness at low acid concentrations and tank corrosion concerns prohibit the used of more concentrated acids. For feeds involving more refractory aluminum (boehmite or alumina) or aluminosilicate phases, it may be necessary to use combined and sequential caustic and acid treatment steps, although neutralization requirements with this approach result in significant salt and liquid additions to the waste stream.

In the early phase of this basic studies program, the focus has been on determining the solubility of the primary iron and aluminum phases in various acid systems. Oxalic acid has received the greatest attention, but mineral acids have also been evaluated with regard to dissolution strength and ability to assist with oxalic acid based dissolution. Under conditions where there is a need to minimize oxalate additions, it is important to ensure that oxalic acid is being utilized only for metal complexation and not as a proton source. Mineral acids that have minimal downstream impacts could be used for sludge neutralization and to provide protons needed for dissolution. The hematite dissolution reaction in Equation 2-1 reveals the importance of providing sufficient protons to promote dissolution and oxalate complex formation. The monobioxalate iron dication complex, $\mathrm{FeHC}_{2} \mathrm{O}_{4}{ }^{2+}$, is believed to be a primary species present in $\mathrm{Fe}(\mathrm{III})$-oxalate solutions at low $\mathrm{pH}$, as indicated by Lee. ${ }^{9}$ Two equivalents of protons are needed for every oxalic acid molecule and every iron atom to promote complex formation and iron dissolution. Note that these protons are needed in addition to those provided by oxalic acid. For the formation of this complex, these protons must be provided by excess oxalic acid, or by an alternative acid source. For the dissolution of sludge heels, where there is a need to minimize oxalic acid, utilization of a supplemental proton source may be critical.

$\mathrm{Fe}_{2} \mathrm{O}_{3(\mathrm{~s})}+2 \mathrm{H}_{2} \mathrm{C}_{2} \mathrm{O}_{4}(\mathrm{aq})+4 \mathrm{H}^{+}(\mathrm{aq}) \rightarrow 2 \mathrm{FeHC}_{2} \mathrm{O}_{4}{ }^{2+}{ }_{(\mathrm{aq})}+3 \mathrm{H}_{2} \mathrm{O}$ 
Based on the dissertation of Lee, iron speciation in solution may also be manipulated by controlling the $\mathrm{pH}$. For the Fe(III)-oxalate system with $1 \mathrm{wt} \%$ oxalic acid, Lee indicates that the iron exists almost entirely as the monobioxalate complex, $\mathrm{FeHC}_{2} \mathrm{O}_{4}{ }^{2+}$, at a $\mathrm{pH}$ below 1. Above $\mathrm{pH} \mathrm{2,} \mathrm{the} \mathrm{iron} \mathrm{exists} \mathrm{almost} \mathrm{exclusively} \mathrm{as} \mathrm{the} \mathrm{trioxalate,} \mathrm{trianion} \mathrm{complex,}$ $\mathrm{Fe}\left(\mathrm{C}_{2} \mathrm{O}_{4}\right)_{3}{ }^{3-}$. At intermediate $\mathrm{pH}$ values between 1 and 2 , the iron exists as a mixture of the monobioxalate, the trioxalate, and the dioxalate complex, $\mathrm{Fe}\left(\mathrm{C}_{2} \mathrm{O}_{4}\right)_{2}{ }^{-}$. Therefore it is expected that the mole ratio of oxalate:iron in solution changes from $3: 1$ to $1: 1$ as the $\mathrm{pH}$ is decreased from above 2 to below 1 . Obviously the 1:1 complex is preferred in the case where the goal is to minimize oxalate usage. The formation of the dioxalate and trioxalate complexes from hematite do not require the addition of excess acid, since more than enough protons are provided by the oxalic acid needed for complexation, as shown below (Eqns. 2-2 and 2-3). Since magnetite $\left(\mathrm{Fe}_{3} \mathrm{O}_{4}\right)$ can be formally viewed as a mixture of hematite $\left(\mathrm{Fe}_{2} \mathrm{O}_{3}\right)$ and Wustite (FeO), Equations 1-1 through 1-3 are also likely important in the dissolution of magnetite. The dissolution of $\mathrm{Fe}(\mathrm{II})$ with oxalic acid also does not require excess acid from a stoichiometric perspective, and a $\mathrm{pH}<1.5$ tends to favor the formation of uncomplexed $\mathrm{Fe}$ (II) cation in solution ${ }^{9}$ which involves no oxalate consumption. These observations indicate that lower $\mathrm{pH}$ is preferred for iron dissolution with oxalic acid and $\mathrm{pH}$ monitoring and control may be important for process optimization.

$$
\begin{aligned}
& \mathrm{Fe}_{2} \mathrm{O}_{3(\mathrm{~s})}+4 \mathrm{H}_{2} \mathrm{C}_{2} \mathrm{O}_{4(\mathrm{aq})} \rightarrow 2 \mathrm{Fe}\left(\mathrm{C}_{2} \mathrm{O}_{4}\right)_{2}^{-}{ }_{(\mathrm{aq})}+3 \mathrm{H}_{2} \mathrm{O}+2 \mathrm{H}^{+}{ }_{(\mathrm{aq})} \\
& \mathrm{Fe}_{2} \mathrm{O}_{3}(\mathrm{~s})+6 \mathrm{H}_{2} \mathrm{C}_{2} \mathrm{O}_{4}(\mathrm{aq}) \rightarrow 2 \mathrm{Fe}\left(\mathrm{C}_{2} \mathrm{O}_{4}\right)_{3}{ }^{3-}{ }_{(\mathrm{aq})}+3 \mathrm{H}_{2} \mathrm{O}+6 \mathrm{H}^{+}{ }_{(\mathrm{aq})}
\end{aligned}
$$

Nitric and sulfuric acids were evaluated in this testing for sludge neutralization and $\mathrm{pH}$ control. Minimal downstream impacts are expected from the addition of nitrate, since SRS waste streams already contain significant sodium nitrate salts. Sulfate could potentially have negative downstream impacts associated with the formation of separate phases during waste vitrification. However, based on the solubility of sodium sulfate, it is expected that the sulfate salts would be washed away from the re-precipitated sludge from chemical cleaning with disposal in the low activity grout (saltstone) waste stream. Sulfate is known to be a better metal complexing anion than nitrate. Hydrochloric and hydrofluoric acids are also expected to be somewhat effective at dissolving sludge solids. However, these acids have not been considered at this point since they are currently present only at low levels in SRS waste. Also, since any enhanced chemical cleaning process will almost certainly involve a complexing acid (such as oxalic acid), and a mineral acid is primarily needed to provide supplemental protons, $\mathrm{HCl}$ and $\mathrm{HF}$ were not evaluated.

Besides $\mathrm{pH}$ effects, the impacts of the volume phase ratio and oxalic acid concentration on sludge dissolution and iron solubility are unclear based on previous reports. Early in this testing, it became apparent that existing sludge simulants were inadequate with regard to their solubility properties. As discussed in the a literature review on chemical cleaning ${ }^{3}$, inconsistent results were frequently observed in previous testing which may have arisen from non-representative simulants and lack of $\mathrm{pH}$ control. As a result, testing in the current work has focused on the use of pure metal phases known to be present in SRS waste, $\mathrm{pH}$ control using mineral acids, and a focus on solutions with a $\mathrm{pH}$ near 1 . Improved simulants containing multiple representative phases and typical waste compositions are currently under 
development and will be used in future testing. Future testing will also need to consider the impacts of using mineral acids for neutralization and $\mathrm{pH}$ control on tank corrosion. Section 5 of this report outlines plans for future testing in this program. 


\subsection{EXPERIMENTAL DETAILS}

Solid reagents used for testing were purchased commercially and included ferric oxalate hexahydrate $\left(\mathrm{Fe}_{2}\left(\mathrm{C}_{2} \mathrm{O}_{4}\right)_{3} \cdot 6 \mathrm{H}_{2} \mathrm{O}\right)$, ferrous oxalate dihydrate $\left(\mathrm{FeC}_{2} \mathrm{O}_{4} \cdot 2 \mathrm{H}_{2} \mathrm{O}\right)$, hematite $\left(\mathrm{Fe}_{2} \mathrm{O}_{3}\right)$, magnetite $\left(\mathrm{Fe}_{3} \mathrm{O}_{4}\right)$, gibbsite $\left(\mathrm{Al}(\mathrm{OH})_{3}\right)$, boehmite $(\mathrm{AlOOH})$, and oxalic acid dihydrate $\left(\mathrm{H}_{2} \mathrm{C}_{2} \mathrm{O}_{4} \cdot 2 \mathrm{H}_{2} \mathrm{O}\right)$. All reagent and sample masses were corrected for any reported waters of hydration or measured sorbed water (as determined by sample drying at $50-70{ }^{\circ} \mathrm{C}$ under vacuum). Nitric and sulfuric acid solutions were prepared from concentrated, commercial reagents. Chemical reagents were purchased from several suppliers including Aldrich, Strem Chemicals, Inc. (Newburyport, MA), Almatis, Inc. (Bauxite, AK), and BASF Catalysts LLC (Port Allen, LA). Solid reagents were characterized by X-ray Diffraction. XRD results were provided in an earlier report for the phase-pure gibbsite and boehmite reagents. ${ }^{10} \mathrm{XRD}$ results for the magnetite and hematite reagents (also phase pure) are provided in Figures 3.1 and 3.2, respectively. Sample digestion and elemental analysis were also conducted on a sample of the hematite reagent. Trace amounts $(<0.5 \mathrm{wt} . \%$ for each element) of Si, S, Ca, and $\mathrm{Cr}$ were observed along with 65.4 wt. \% Fe (theoretical: 69.9 wt. \%). XRD analysis results for ferric and ferrous oxalate reagents used for testing are provided in Figures 3.3 and 3.4, respectively. Crystalline impurities were observed in the ferric oxalate reagent. Subsequent digestion and Inductively Coupled Plasma-Emission Spectroscopy (ICP-ES) analysis of a sub-sample of the ferrous oxalate did not identify significant metallic impurities ( $\mathrm{Ca}, \mathrm{Mg}$, and $\mathrm{Mn}$ were all present at $<0.5 \mathrm{wt}$. \%) and iron was present at $20.3 \mathrm{wt}$. \% (theoretical: $23.1 \mathrm{wt}$ \% for the hexahydrate). Limited initial testing was conducted with Tank $8 \mathrm{~F}$ sludge simulant prepared according to the recipe published by Poirier $^{11}$ and exposed to a brief elevated temperature aging treatment in which the slurry was maintained at near 90 ${ }^{\circ} \mathrm{C}$ overnight. XRD analysis results for the Tank $8 \mathrm{~F}$ simulant are provided in Figure 3.5. Gibbsite $\left(\mathrm{AlOH}_{3}\right)$, calcite $\left(\mathrm{CaCO}_{3}\right)$, and quartz $\left(\mathrm{SiO}_{2}\right)$ were the only crystalline phases identified, although broad amorphous peaks were observed near $35^{\circ}$ and $63^{\circ}$ in two-theta which may be associated with amorphous iron. Based on the simulant recipe and analytical results (ICP-ES of digested material), the sludge composition was believed to be approximately 10 wt. \% Al, 30 wt. \% Fe, and 2-4 wt. \% (per element) in $\mathrm{Na}, \mathrm{Ca}, \mathrm{Mn}$, and Ni.

Solubility testing involved simple batch contacts with known amounts of liquid and solid. Nearly all tests were conducted in duplicate. All sample and bottle weights were obtained using analytical balances that were calibrated annually in the SRNL Standards Laboratory and checked on a daily basis with a calibrated weight set. Teflon bottles were used for most tests which were confirmed to be leak tight by the periodic monitoring of liquid levels and sample masses during elevated temperature tests. Samples were maintained in temperaturecontrolled incubator shaker ovens (Innova Models 4230 and 42 from New Brunswick Scientific) at the target temperature $\left(25-70{ }^{\circ} \mathrm{C}\right)$ and agitated at $250 \mathrm{RPM}$. Prior to sample manipulations (sampling or $\mathrm{pH}$ adjustment), the agitation was stopped so that the solids could settle. Sampling and $\mathrm{pH}$ monitoring/adjustment were conducted out of the oven in a chemical hood. All sample manipulations were conducted quickly (within 2-3 minutes) to minimize sample cooling. Sample $\mathrm{pH}$ adjustments were conducted using 1 or $3 \mathrm{M}$ nitric or sulfuric acid solutions that were added either drop-wise or in 0.5 to $2.0 \mathrm{~mL}$ aliquots using a digital pipette. Acid volumes added were recorded and data calculations corrected for the 
added volume, as appropriate. Tests were typically continued for several weeks (2-6 weeks) while the $\mathrm{pH}$ was monitored and adjusted (as needed). Durations for individual tests are provided in the data tables in Section 3. If it was observed that most of the solids had dissolved for a given sample, a known mass of additional solids was added. For selected samples, at the conclusion of the test and after sampling, most of the liquid was removed and the residual solids were dried in a vacuum oven at $70{ }^{\circ} \mathrm{C}$ until a constant weight was obtained. The final mass data was used to calculate the mass-based weight percent dissolution for individual samples for comparison to the ICP-ES based dissolution data. Results from both calculations are provided in the data tables in Section 3.

For some of the reagents, the dissolution kinetics were quite slow. No tests were stopped or analytical sub-samples collected until the test samples were observed during inspection and $\mathrm{pH}$ measurement to have remained stable for at least a week. Characteristics of stable samples included no visual changes in the amount of solids present or solution color, and minimal changes in the measured $\mathrm{pH}$. For selected test samples, repeated analytical subsamples were collected approximately one week apart to confirm that stable solution concentrations had been obtained, but this was not possible for every sample. In most cases (and for all elevated temperature tests), analysis sample bottles were prepared by the addition of known a mass (typically $6 \mathrm{~g}$ ) of $3 \mathrm{M}$ nitric acid. Sub-samples of solutions from each test sample were then collected and filtered through a $0.45 \mu \mathrm{m}$ nylon syringe filter (at temperature) directly into the analysis bottles containing nitric acid. The mass of each filtered sub-sample added to the bottles (typically $2 \mathrm{~g}$ ) was determined by difference and recorded for the calculation of dilution factors. Dilution in oxidizing $3 \mathrm{M}$ nitric acid serves to avoid the precipitation of insoluble phases. Visual inspection of each acidified sample confirmed that no precipitates had formed upon dilution. As a result of the possibility of light-promoted reduction of $\mathrm{Fe}(\mathrm{III})$ to $\mathrm{Fe}(\mathrm{II})$, and the subsequent precipitation of ferrous oxalate, samples were typically kept in closed buckets to reduce light exposure. In addition the shaker oven windows were covered to exclude light from the test solutions. Although there was no evidence that precipitation had occurred in any of the analytical samples, these procedures were adopted as precautionary measures.

Solution $\mathrm{pH}$ values were measured using Oakton $\mathrm{pH} 110$ Series probes after allowing the solids to settle to the bottom of the bottle. Each time that the $\mathrm{pH}$ probes were used, the instruments were calibrated using four standard buffer solutions. During the testing, problems were experienced on occasion in obtaining stable and consistent $\mathrm{pH}$ measurements. As a result, a modified calibration sequence was developed for this specific application based on discussions with the probe manufacturer. This calibration sequence $(\mathrm{pH} 7.0, \mathrm{pH} 1.68, \mathrm{pH}$ 4.0, and $\mathrm{pH} 10.0$ ) was found to result in greater measurement consistency. As a result, $\mathrm{pH}$ measurements from later experiments are believed to be more accurate. Each $\mathrm{pH}$ measurement was conducted with two separate probes. The probes were rinsed, lightly wiped, and briefly stored in de-ionized water between measurements. Prior to and after the measurement of the $\mathrm{pH}$ for a given sample set, the $\mathrm{pH}$ was measured and recorded for the four buffer solutions. Reported $\mathrm{pH}$ values are the averaged data recorded for the two probes. Generally, good agreement was observed between the two probes, although periodically the repeated utilization of the probes in low $\mathrm{pH}$ solutions with moderate dissolved metal concentrations resulted in a slight drifting $(\leq 0.5 \mathrm{pH}$ units) of the measured $\mathrm{pH}$ to higher 
values. When a probe was observed to drift to higher $\mathrm{pH}$ values, the probe was discarded and replaced with a new probe. 
SRNL-STI-2009-00791, REV. 0

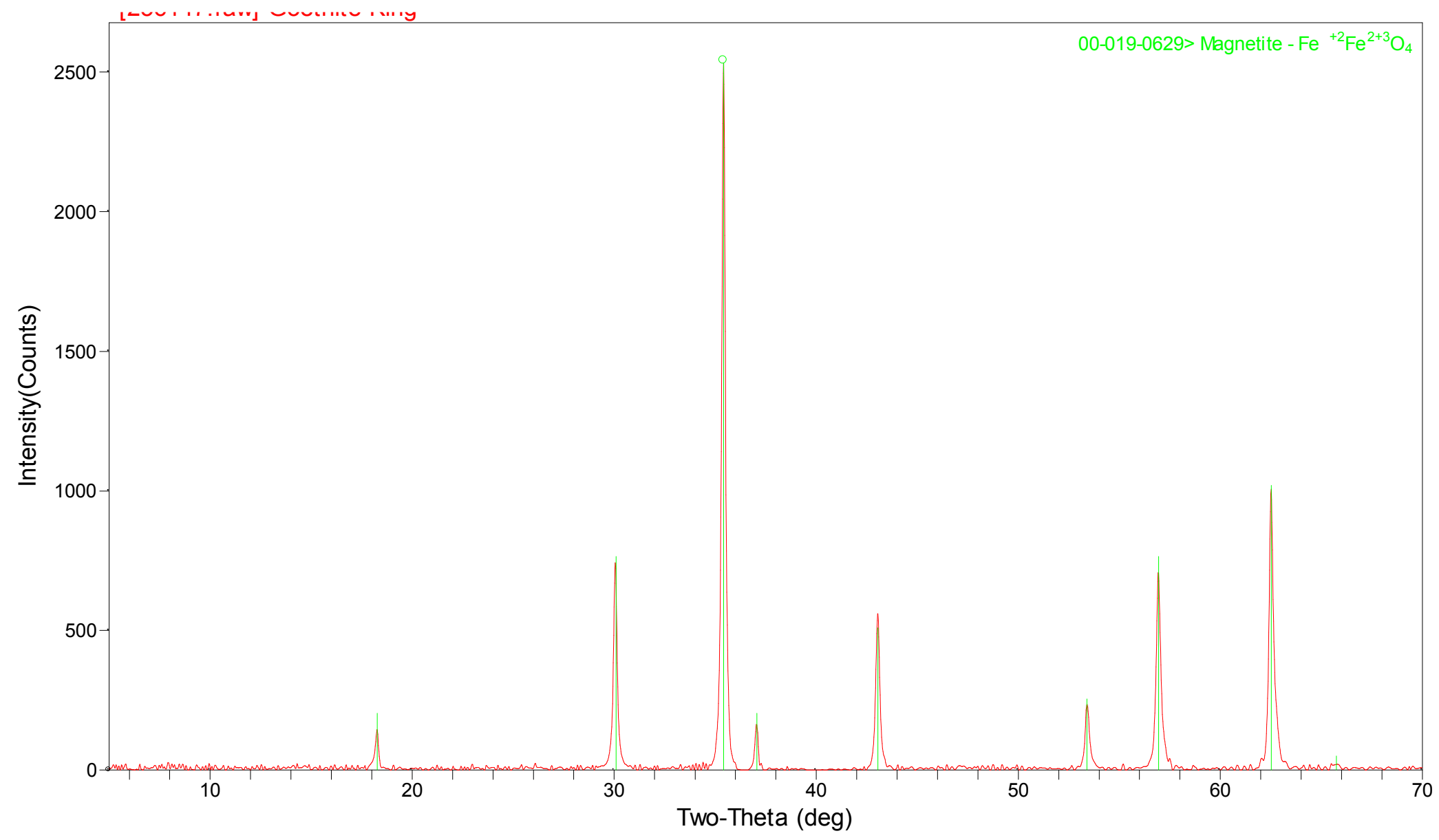

Figure 3.1 XRD Analysis of Magnetite Reagent 
SRNL-STI-2009-00791, REV. 0

[261399.raw] Strem June 22 Hematite King

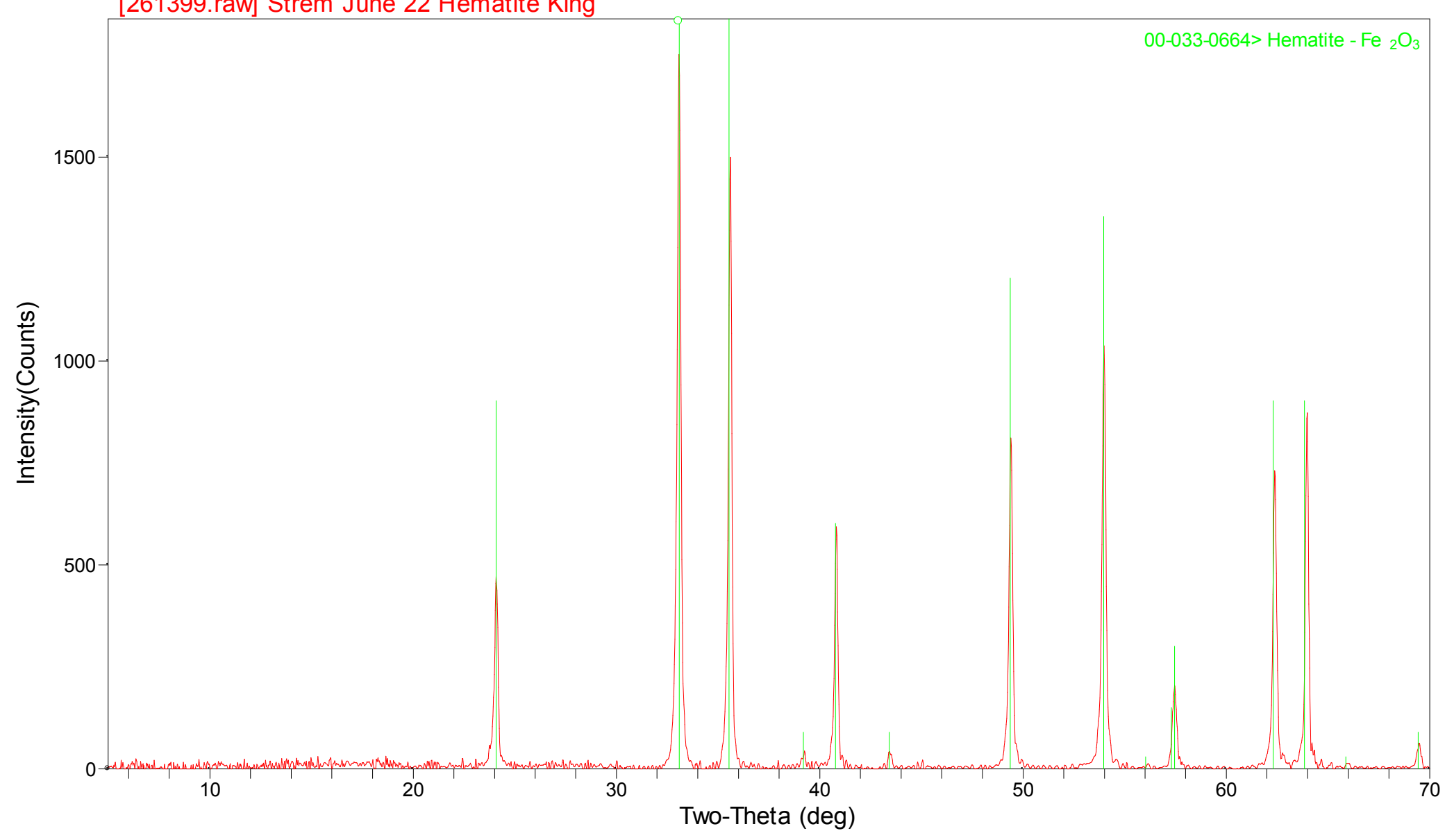

Figure 3.2 XRD Analysis of Hematite Reagent

$-15-$ 


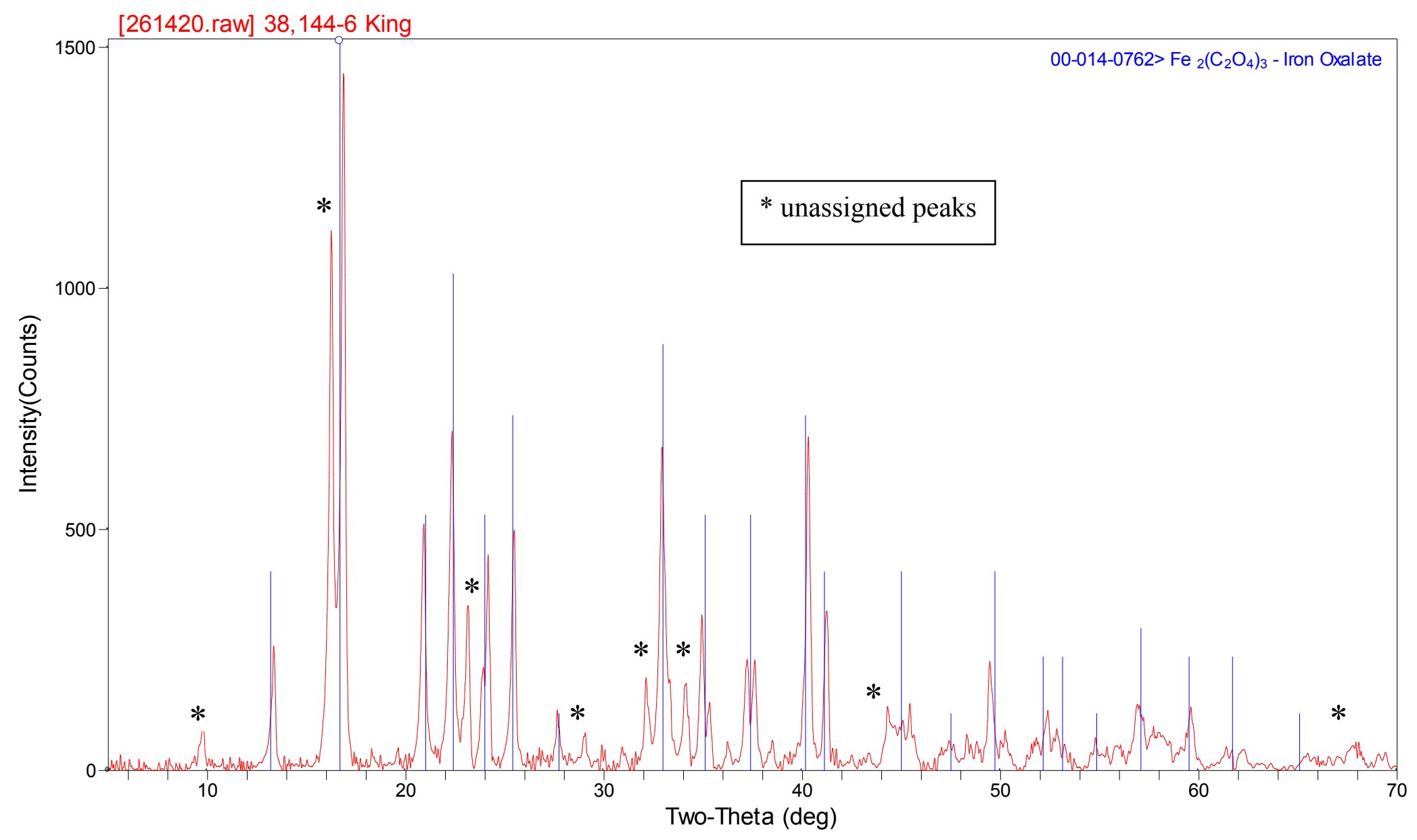

Figure 3.3 XRD Analysis of Ferric Oxalate Reagent 
SRNL-STI-2009-00791, REV. 0

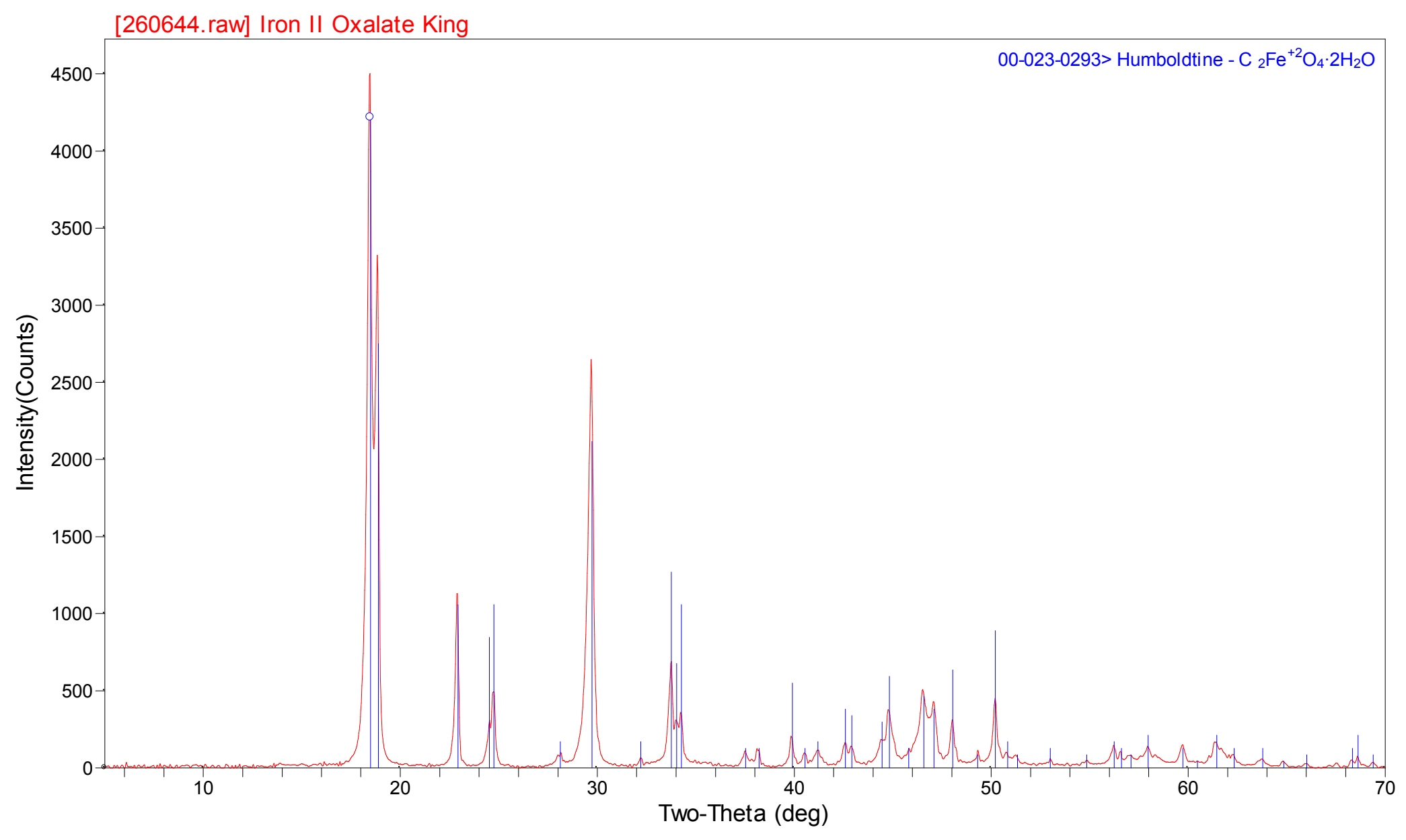

Figure 3.4 XRD Analysis of Ferrous Oxalate Reagent

$-17-$ 
SRNL-STI-2009-00791, REV. 0

[256150.raw] 8F Sludge Sim. Washed King

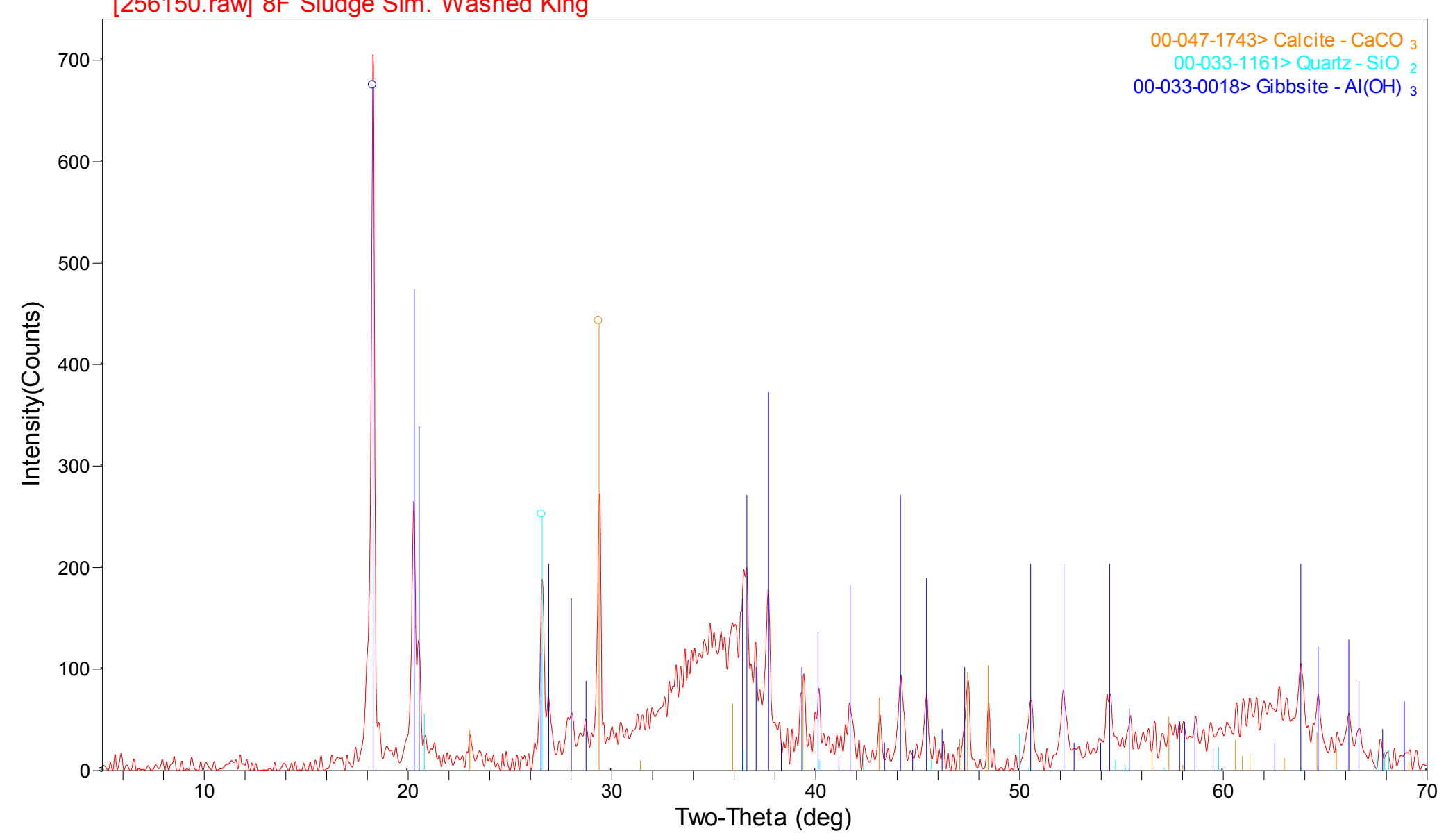

Figure 3.5 XRD Analysis of Tank 8F Sludge Simulant 
SRNL-STI-2009-00791, REV. 0

\subsection{EXPERIMENTAL RESULTS}

\subsection{SLUDGE CHARACTERIZATION}

The solubility characteristics of tank sludge heels and the optimization of dissolution methods is dependant upon the identity and concentration of the various metal phases present in the heels. As a result, it is useful to review the somewhat limited information available regarding the metal phases present in actual sludge material. A summary of phases identified in SRS sludge materials is provided in Table 4.1 along with tank and sample histories and references for the characterization data. The Tank 4F characterization data has not been previously published and the XRD scan is provided in Figure 4.1. Due to the cost and difficulty of retrieving and analyzing tank sludge materials, and the high dose rates associated with these materials, only six samples have been characterized by XRD. Two of these samples (7F and 19F) have non-typical process histories and compositions. Tank 7F contains the solids formed from the neutralization of spent oxalic acid solutions transferred from Tanks 5F and 6F after bulk chemical cleaning operations for sludge heel removal. The sludge solids in Tank 7F represent "fresh" sludge that has not been aged or exposed to the elevated temperatures typically experienced by SRS sludge waste. Sodium oxalate formed from the neutralization of spent oxalic acid with sodium hydroxide is a primary phase in the Tank 7F sample. The Tank 19F sample was a core sample collected from a mound observed after bulk mechanical cleaning operations. The mound was believed to have formed from the degradation of zeolite ion exchange media used for cesium removal that was dumped into the tank. The primary phase observed in the Tank 19F sample was an aluminosilicate (presumably from degraded zeolite materials). The Al and Fe phases observed for this sample did not include boehmite and hematite, the more common phases observed in SRS waste. $\mathrm{H}$-area sludge were typically exposed to higher temperatures during storage $\left(>100{ }^{\circ} \mathrm{C}\right.$ for many years) than $\mathrm{F}$ area sludge. As a result, $\mathrm{H}$ area sludge $(11 \mathrm{H}, 12 \mathrm{H}$, and $15 \mathrm{H})$ typically have higher Al content and include refractory phases such as boehmite and hematite. The Tank $51 \mathrm{H}$ sample, with sludge from primarily Tank $11 \mathrm{H}$, also included sodium carbonate, a low solubility salt at the high $\mathrm{pH}$ found in SRS waste tanks. Of the seven samples characterized by XRD, hematite was observed in four cases and boehmite was observed in three cases. Gibbsite was the only other pure aluminum phase observed. Magnetite, observed in two cases, is the only phase observed containing Fe(II). All other iron phases observed in XRD scans contain only Fe(III). This XRD data served as the basis for the target mineral phases included in the solubility evaluation testing. Hematite and magnetite were the primary iron phases studied, while boehmite and gibbsite were the primary aluminum phases studied. A greater emphasis was placed on the study of boehmite and hematite, since these phases were most commonly observed in sludge and are known to be refractory.

\subsection{TANK 8F SLUDGE SIMULANT SOLUBILITY EVALUATIONS}

Initial testing conducted in this program involved the use of Tank $8 \mathrm{~F}$ sludge simulant slurry that was prepared as described by Poirier. ${ }^{11}$ Prior to use, the simulant was subjected to a heat treatment with the goal of producing a material with crystalline phases that were more representative of SRS sludge waste. However, gibbsite was the only crystalline aluminum 
phase observed in the XRD. No crystalline iron phases were identified in the XRD, although broad peaks were present in the diffraction pattern possibly associated with amorphous iron phases (Figure 3.5). As is typical of much of the F tank farm sludge, the primary chemical component was iron $(\sim 30$ wt. $\%)$ with aluminum being the second most abundant metal $(\sim 10$ wt. \%). Initial tests were conducted using $11 \mathrm{~g}$ (mass corrected for water content) of damp sludge solids and $265 \mathrm{~mL}$ of $0.25 \mathrm{M}$ nitric acid. The purpose of this test was to perform a rough titration of the sludge and evaluate simulant solubility in nitric acid. $10 \mathrm{~mL}$ of $4 \mathrm{M}$ nitric acid were also added to the slurry to lower the $\mathrm{pH}$ to a value near 1 . This resulted in a mass phase ratio (liquid:solid) of 25 , which corresponds to a volume phase ratio in the range of 5 to 10. Minimal off-gassing was observed after acid contact with the simulant and the solution color quickly changed to dark brown. Based on the total acid added and the final measured $\mathrm{pH}$, the simulant contained $\sim 2 \mathrm{mmol}$ base per gram of dry sludge. Upon standing, only $5 \mathrm{~mL}$ of tan colored solids were observed to settle to the bottom of the vessel. Subsequent isolation and drying of the solids revealed that $66 \mathrm{wt}$. \% of the solids had dissolved. Depending on the density of the solid phase, this amount of dissolution corresponds to 1-2.5 L sludge dissolved per mole of nitric acid. The unwashed residual solids contained 28 wt. \% Al and only 4 wt. \% Fe. The spent nitric acid contained $0.15 \mathrm{M} \mathrm{Fe}$ and $0.01 \mathrm{M} \mathrm{Al}$, which corresponds to $86 \%$ iron dissolution and $8 \%$ aluminum dissolution.

The solubility observed for the Tank $8 \mathrm{~F}$ sludge simulant was much higher than typically observed for tank waste sludge even when using complexing acids (e.g., oxalic acid). Based on these results, the Tank $8 \mathrm{~F}$ sludge simulant likely contains non-representative iron phases and therefore, was considered unacceptable for solubility evaluations. Recent difficulties with oxalic acid cleaning in Tanks $5 \mathrm{~F}$ and $6 \mathrm{~F}$, along with some inconsistencies in data from previous sludge solubility testing with oxalic acid indicate the need for better sludge simulants and illustrate the complexity of the chemistry of sludge dissolution. As a result of these observations, this program has focused on the use of pure metal phases identified in the sludge samples for solubility testing. These materials can be obtained commercially and quickly analyzed for purity. The use of pure metal phases reduces the complexity of the chemical reactions involved which should facilitate elucidating the variables involved in sludge dissolution.

\subsection{SOLUBILITY TESTING WITH PURE ALUMINUM PHASES}

Aluminum solubility testing was conducted using phase pure gibbsite $\left(\mathrm{Al}(\mathrm{OH})_{3}\right)$ and boehmite $(\mathrm{Al}(\mathrm{O}) \mathrm{OH})$ reagents. Acids used for testing included oxalic, nitric, and sulfuric acid at concentrations ranging from 0.1 to $1 \mathrm{M}$. Initial mass phase ratios were near 100 (liquid:dry solid) for all samples. However, for some samples, all solids were observed to dissolve and the subsequent addition of more solids lowered the phase ratio. In addition, acid was added to selected samples during testing as needed to maintain the $\mathrm{pH}$ near 1 . Nitric acid was used for $\mathrm{pH}$ control with the samples involving initial contact with nitric and oxalic acids. Sulfuric acid was used for $\mathrm{pH}$ control with samples containing sulfuric acid. The amounts and concentrations ( 1 or $3 \mathrm{M}$ ) of acid added were recorded for each sample. The addition of small volumes of acid also changed the phase ratio. 
Solubility results obtained for gibbsite using $0.125 \mathrm{M}$ oxalic, nitric, and sulfuric acids at 25 and $70{ }^{\circ} \mathrm{C}$ are provided in Table 4.2 and Figure 4.2. For each acid, higher temperature resulted in greater dissolution. Good agreement was observed for the percent gibbsite dissolution calculated by two different methods (ICP-ES and mass-based). Soluble aluminum concentrations as high as $0.2 \mathrm{M}$ were observed for the dissolution of gibbsite with sulfuric acid at $70{ }^{\circ} \mathrm{C}$. ICP-ES analysis results and mass loss data indicate that this sample had completely dissolved, although a small amount of solids were still visually observed in solution. Soluble aluminum concentrations as high as $0.1 \mathrm{M}$ were observed for the dissolution of gibbsite with both oxalic acid and nitric acid at $70{ }^{\circ} \mathrm{C}$. For nitric acid at $70{ }^{\circ} \mathrm{C}$, the molar ratio of $\mathrm{H}^{+}$consumed to dissolved aluminum in solution was $\sim 2.6$. This molar ratio is consistent with a simple acid-base reaction whereby the acid protons reacted with (and neutralized) the three hydroxyl anions of the gibbsite reagent. The calculation of similar molar ratios for oxalic and sulfuric acids is more complex, since these acids are not fully dissociated under these conditions. It does appear that the molar ratios of $\mathrm{H}^{+}$consumed to dissolved aluminum for these acids are less than 3:1, indicating that some level of metal complexation may be involved. Significantly lower aluminum concentrations $(50-80 \%)$ were observed with all three acids at $25^{\circ} \mathrm{C}$, with the lowest solubility observed for nitric acid $(0.02$ $\mathrm{M} \mathrm{Al}$ ). Based on these results, acid dissolution of gibbsite is a viable concept although caustic aluminum dissolution appears to be more effective, ${ }^{8,10}$ partly due to the fact that concentrated caustic can be used to promote dissolution.

Solubility results for boehmite in $0.125 \mathrm{M}$ oxalic, nitric, and sulfuric acids at 25, 50, and 70 ${ }^{\circ} \mathrm{C}$ are provided in Table 4.3 and Figure $4.3\left(50{ }^{\circ} \mathrm{C}\right.$ data from Table 4.4). Not surprisingly, gibbsite is more soluble than boehmite in all acids tested. As was observed with gibbsite, boehmite solubility increases significantly at elevated temperature. The highest aluminum concentration $(0.09 \mathrm{M})$ observed in tests with boehmite was with oxalic acid at $70{ }^{\circ} \mathrm{C}$. Nitric acid was ineffective at dissolving boehmite even at $70{ }^{\circ} \mathrm{C}$, where the equilibrium aluminum concentration observed was only $0.009 \mathrm{M}$ and the molar ratio of $\mathrm{H}^{+}$consumed to dissolved aluminum was 7.4. At $25^{\circ} \mathrm{C}$, the dissolved aluminum concentration in oxalic acid decreased by $98 \%$ to $0.02 \mathrm{M}$. Similarly with sulfuric acid, the soluble aluminum concentration decreased by $97 \%$ when the temperature was decreased from 70 to $25^{\circ} \mathrm{C}$.

Additional solubility tests were conducted with boehmite at $50{ }^{\circ} \mathrm{C}$ using oxalic acid concentrations of 1,4 , and $8 \mathrm{wt} . \%(0.11,0.45$, and $0.92 \mathrm{M}$ oxalic acid, respectively). These tests were only continued for 19 days, since very little change in the samples was observed over the second half of the time period. Results are provided in Table 4.4 and Figure 4.3. Replicate tests were conducted with and without $\mathrm{pH}$ control using nitric acid. Based on the measured Al solubilities, $\mathrm{pH}$ control under these conditions does not greatly impact boehmite solubility. Furthermore, increasing the oxalic acid concentration from $0.11 \mathrm{M}$ to $0.92 \mathrm{M}$ only resulted in a small increase $(\sim 20 \%)$ in the boehmite solubility. As was observed in the mass loss data at $25^{\circ} \mathrm{C}$, significant mass gains were observed for all of the samples in these tests, and the mass gains increased with increasing oxalic acid concentration. In order to identify any new solid phases that might have formed as precipitates during boehmite solubility testing, XRD analysis was performed on the residue isolated after contact with $8 \mathrm{wt}$. \% oxalic acid. As shown in Figure 4.4, the only phases observed were boehmite and oxalic acid. This observation leads us to conclude that the mass increases are associated with incomplete 
removal of the oxalic acid solution from these samples. The boehmite reagent used for this testing contained very fine particles which settled slowly. As a result, it was more difficult to remove the acid from the sample at the conclusion of the testing. Upon drying in the oven, the residual oxalic acid presumably precipitated and crystallized resulting in the observed sample mass gains. The $50{ }^{\circ} \mathrm{C}$ solubility data obtained with $1 \mathrm{wt} . \%$ oxalic acid is plotted in Figure 4.3 along with the data at 25 and $70{ }^{\circ} \mathrm{C}$. The results indicate that increasing the temperature from 25 to $50{ }^{\circ} \mathrm{C}$ in oxalic acid does not lead to large increases in boehmite solubility, while further increasing the temperature to $70^{\circ} \mathrm{C}$ leads to a significant solubility increase.

\subsection{METHOD DEVELOPMENT AND SUPPORTIVE DATA FOR IRON PHASE SOLUBILITY TESTING}

To validate sample handling methods and analytical abilities to measure iron and oxalate, a number of control samples were prepared for analysis. A primary concern with regard to sample handling was the possibility that sample exposure to light might promote reduction of $\mathrm{Fe}(\mathrm{III})$ to $\mathrm{Fe}(\mathrm{II})$ with subsequent precipitation of ferrous oxalate solids from oxalic acid solution. Personnel in the SRNL Analytical Development Department had reported such observations on similar solutions after storing samples on a bench top in the presence of UV light. Furthermore, there were concerns that ion chromatography analytical methods might only measure uncomplexed rather than total oxalate (complexed and uncomplexed). Tests were conducted with ferric and ferrous oxalate reagents $\left(\mathrm{Fe}_{2}\left(\mathrm{C}_{2} \mathrm{O}_{4}\right)_{3} \cdot 6 \mathrm{H}_{2} \mathrm{O}\right.$ and $\mathrm{Fe}\left(\mathrm{C}_{2} \mathrm{O}_{4}\right) \cdot 2 \mathrm{H}_{2} \mathrm{O}$, respectively). Additional tests were conducted with hematite to determine if light-promoted iron reduction and precipitation occurred with this reagent. Samples were prepared with the intent of completely dissolving a known amount of material in either water or 8 wt. $\%$ oxalic acid. Some samples were maintained in the dark even after submission for analysis while others were directly exposed to the incubator shaker oven UV light in transparent containers for several weeks.

Experimental conditions and results are summarized in Table 4.5. For the samples that were maintained in the dark, oxalate analysis results were generally acceptable and within $25 \%$ of the calculated value. Iron analysis results for the ferrous oxalate sample in water that was maintained in the dark was low by $40 \%$, despite the fact that the oxalate analysis result was very near the expected value. This may indicate that $\mathrm{Fe}(\mathrm{II})$ is not stable in water at this $\mathrm{pH}$ and that some precipitation of iron containing solids may have occurred prior to analysis. For the ferric oxalate (Fe III) sample in water that was maintained in the dark, the measured oxalate iron concentrations were slightly low but within $\sim 15 \%$ of the target value. Three separate samples containing dissolved Fe(III) were directly exposed to light for several weeks and solid formation was observed within 11 days for each sample (see Figure 4.5). Solids formed from the ferric oxalate in water were brown-orange in color. Solids formed from solutions of ferric oxalate and hematite in $8 \mathrm{wt}$ \% oxalic acid were both yellow in color and similar in appearance to ferrous oxalate. For each sample that was exposed to light there was a dramatic decrease in the measured iron concentration as well. For the ferric oxalate sample in water, the oxalate concentration was also observed to decrease to only $2 \%$ of initial calculated value. The complete conversion of the dissolved ferric oxalate to ferrous oxalate

solids should have resulted in the loss of only $66 \%$ of the oxalate from solution. Loss of 
oxalate could not be detected for the samples dissolved in oxalic acid since the background oxalate concentration was high. These results from these control samples are consistent with light-promoted reduction of Fe(III) to form insoluble Fe(II) phases. Based on these results, it was concluded that analytical methods were satisfactory, but testing and analytical sample handling should be conducted in such a way as to exclude light exposure. All subsequent testing was conducted with the oven light off and the oven window covered, and analytical samples were submitted in sealed buckets and maintained in the dark.

There was also a need to determine the solubility limits of both ferric and ferrous oxalate in various acids. Solubility tests were conducted over a 1-2 week period with each reagent in water, oxalic acid, nitric acid, and sulfuric acid at $50{ }^{\circ} \mathrm{C}$. Acid concentrations ranged from 0.1 to $1.0 \mathrm{M}$. Results are provided in Table 4.6. As expected, based on the reported solubilities of these materials, ferrous oxalate was considerably less soluble than ferric oxalate in water. However, the observed ferrous oxalate solubility in water $(0.011 \mathrm{M})$ was an order of magnitude higher than reported in the literature $(0.0012$ and $0.0014 \mathrm{M}$ in cold and hot water, respectively ${ }^{16}$ ). The measured $\mathrm{pH}$ for the ferrous oxalate sample in water was 3.2 , presumably due to the acidity of the Fe(II) cation. The solubility limit for ferric oxalate in water was never reached due to limited reagent amounts, but was greater than $0.8 \mathrm{M}$. The CRC Handbook lists the solubility of ferric oxalate as "very soluble", but provides no solubility limit. ${ }^{16}$ Increasing the oxalic acid concentration from 0.11 to $0.92 \mathrm{M}$ only resulted in a $75 \%$ increase in the ferrous oxalate solubility. The measured iron concentrations for ferrous oxalate varied from 0.02 to $0.04 \mathrm{M}$, which is in the range of concentrations reported in subsequent sections of this report for tests with target iron phases. This observation further emphasizes the importance of minimizing light exposure during testing which could promote iron reduction and precipitation of $\mathrm{Fe}$ (II) phases and lead to artificially low solubility results. Exclusion of light during testing is also expected to be prototypical of conditions inside a waste tank since little light enters through the SRS tank tops. Equilibrium iron concentrations observed with nitric and sulfuric acids and ferrous oxalate were significantly higher than was observed with similar oxalic acid concentrations. With $1 \mathrm{M}$ nitric acid the solubility limit for ferrous oxalate approached $1 \mathrm{M} \mathrm{Fe}$. Mild off-gassing was observed with this sample, presumably due to the oxidation of some oxalate by nitric acid. Ion chromatography analysis of the solution indicated that the oxalate ion concentration was $0.85 \mathrm{M}$, which is $95 \%$ of the expected concentration based on the measured iron concentration. Solubility limits were not determined for ferric oxalate in dilute or concentrated mineral acids due to limited quantities of reagent, but were determined to exceed $0.4 \mathrm{M}$. Ferric oxalate solubility in 1 to $8 \mathrm{wt}$ \% oxalic acid was near $1 \mathrm{M}$. Based on these results, as long as light promoted reduction of $\mathrm{Fe}(\mathrm{III})$ is avoided, the iron oxalates will not be the solubility limiting species for hematite dissolution. These limits should be considered when determining magnetite solubility, since this phase contains $33 \% \mathrm{Fe}(\mathrm{II})$.

\subsection{SOLUBILITY TESTING WITH PURE IRON PHASES}

Iron solubility testing was conducted using phase pure magnetite $\left(\mathrm{Fe}_{3} \mathrm{O}_{4}\right)$ and hematite $\left(\mathrm{Fe}_{2} \mathrm{O}_{3}\right)$ reagents at temperatures ranging from 25 to $70{ }^{\circ} \mathrm{C}$. Acids used for testing included oxalic, nitric, and sulfuric at concentrations ranging from 0.1 to $1 \mathrm{M}$. Samples were 
monitored during testing to ensure that sufficient solids remained in each bottle. Additional solids were added when necessary. Additional acid was added to individual samples requiring $\mathrm{pH}$ control. Nitric acid was used for $\mathrm{pH}$ control with the samples involving initial contact with nitric and oxalic acids. Sulfuric acid was used for $\mathrm{pH}$ control with samples containing sulfuric acid (unless otherwise indicated). The amounts and concentrations (1 or $3 \mathrm{M}$ ) of acid added were recorded for each sample. The oven light was left off for all testing to avoid light-promoted reduction of iron. For later tests, the oven window was also covered to exclude indirect light exposure from the room lights and analysis samples were maintained in the dark during transport and storage. Sub-samples were periodically collected for analysis and passed through a syringe filter directly into $3 \mathrm{M}$ nitric acid diluent. The $3 \mathrm{M}$ nitric acid diluent appears to reduce or eliminate the light-induced reduction of $\mathrm{Fe}(\mathrm{III})$ in solution and avoid the precipitation of insoluble phases. For elevated temperature tests, dilution also helps to avoid precipitation associated with the temperature reduction that occurs after sample collection.

Solubility results obtained for magnetite using $0.125 \mathrm{M}$ oxalic, nitric, and sulfuric acids at 25 and $70{ }^{\circ} \mathrm{C}$ are provided in Table 4.7 and Figure 4.6. Low solubility $(<0.01 \mathrm{M} \mathrm{Fe})$ was observed in nitric acid at 25 and $70{ }^{\circ} \mathrm{C}$. Modest solubility, approaching $0.1 \mathrm{M} \mathrm{Fe}$, was observed in both sulfuric and oxalic acids at $25^{\circ} \mathrm{C}$. Little change in the magnetite solubility was observed at $70^{\circ} \mathrm{C}$ with sulfuric acid, while a solubility decrease was observed at elevated temperature with oxalic acid. Generally good agreement was observed for the percent magnetite dissolution calculated by two different methods (ICP-ES and mass-based), except for the elevated temperature tests with oxalic and nitric acids where small mass gains were observed after contact (as indicated by negative \% dissolution values). For oxalic and sulfuric acids, the molar ratio of anion to soluble iron was in the range of 1 to 3 for all samples. For all tests but one, the measured iron concentrations are below the expected solubility limits for ferrous oxalate (assuming 33\% Fe(II)). For the test with oxalic acid at 25 ${ }^{\circ} \mathrm{C}$, the measured iron concentration of $0.1 \mathrm{M}$ would include $33 \%$ (or $0.033 \mathrm{M}$ ) $\mathrm{Fe}$ (II) if the molar ratio of $\mathrm{Fe}(\mathrm{III}): \mathrm{Fe}(\mathrm{II})$ in solution was the same as the solid phase. Since 85 to $90 \%$ of the magnetite dissolved during this test, a significant amount of $\mathrm{Fe}(\mathrm{II})$ must have dissolved. The measured solubility limit for ferrous oxalate in $0.11 \mathrm{M}$ oxalic acid at $50{ }^{\circ} \mathrm{C}$ was only $0.024 \mathrm{M} \mathrm{Fe}$. This apparent discrepancy can be explained based on the nitric acid added for $\mathrm{pH}$ control in this test which resulted in a final nitric acid concentration of $0.2 \mathrm{M}$. The ferrous oxalate solubility limit in $0.1 \mathrm{M}$ nitric acid at $50{ }^{\circ} \mathrm{C}$ was $0.2 \mathrm{M} \mathrm{Fe}$. Based on these results, dissolution of magnetite is effective using either oxalic or sulfuric acids and increasing the temperature does not have a positive effect on the dissolution. Furthermore, the addition of nitric acid for $\mathrm{pH}$ control can be used to avoid the precipitation of solubility limiting phases such as ferrous oxalate.

Solubility results for hematite under conditions identical to those used for magnetite $(0.125$ $\mathrm{M}$ oxalic, nitric, and sulfuric acids at 25 and $70^{\circ} \mathrm{C}$ ) are provided in Table 4.8. Lower solubility was observed for hematite in all acids tested, compared to magnetite. The highest solubility for hematite $(0.07 \mathrm{M} \mathrm{Fe})$ was observed in oxalic acid at $25^{\circ} \mathrm{C}$. Very low iron concentrations $(0.003 \mathrm{M})$ were observed with nitric acid at $25^{\circ} \mathrm{C}$, while intermediate results were observed with sulfuric acid. Mass loss data is not available for these samples. Based on these results, oxalic acid is clearly the dissolution agent of choice for hematite. 
Additional tests were conducted to determine whether hematite dissolution could be accomplished with more concentrated mineral acids. Solubility tests were conducted at 50 ${ }^{\circ} \mathrm{C}$ using $0.1,0.5$ and $1.0 \mathrm{M}$ nitric and sulfuric acids without $\mathrm{pH}$ control. Results are provided in Table 4.9. Increasing the concentrations of the mineral acids to $1.0 \mathrm{M}$ results in significant increases in dissolved iron (0.09 $\mathrm{M} \mathrm{Fe}$ for nitric and $0.2 \mathrm{M} \mathrm{Fe}$ for sulfuric) to concentrations comparable to or greater than that observed with dilute oxalic acid. However, it not known at this time whether mineral acid concentrations as high as $1 \mathrm{M}$ are acceptable for sludge heel removal, due to the higher tank corrosion rates associated with these acids.

Solubility tests were also conducted with hematite using oxalic acid concentrations of 0.1 , 0.5 , and $0.9 \mathrm{M}(1,4$, and 8 wt. $\%)$ at $50{ }^{\circ} \mathrm{C}$. Note that the test duration for these samples was only 15 days, which is significantly shorter than was used for most other tests. At each acid concentration, the phase ratio was adjusted to promote nearly complete hematite dissolution (70-90\%). Additional tests were conducted with $1 \mathrm{wt} . \%$ acid at lower phase ratios to evaluate the effect on dissolution. Results are provided in Table 4.10. The $\mathrm{pH}$ was controlled for selected tests in this dataset as indicated. The iron concentration of $0.45 \mathrm{M}$ observed with $8 \mathrm{wt} \%$ acid was the highest concentration observed in any test conducted. The results indicate that at a $\mathrm{pH}$ near 1 , oxalic acid dissolution of hematite is essentially a stoichiometric process whereby the level of iron dissolution is directly related to the moles of oxalate available for complexation. As shown in Figure 4.7, a linear response is observed in the soluble iron versus the oxalic acid concentration. Also apparent from the figure is the superior dissolution strength of oxalic acid versus the mineral acids and the somewhat linear temperature dependence of the iron concentration with the mineral acids. For nearly every sample and at each acid concentration, the molar ratio of soluble iron to oxalate was near 2, which is consistent with the formation of an iron di-oxalate complex. Based on the dissertation of $\mathrm{Lee}^{9}$ (discussed in the Introduction) at a $\mathrm{pH}$ of 1 , the iron speciation should involve a mixture of the monobioxalate complex, $\mathrm{FeHC}_{2} \mathrm{O}_{4}{ }^{2+}$, and the dioxalate complex, $\mathrm{Fe}\left(\mathrm{C}_{2} \mathrm{O}_{4}\right)_{3}{ }^{3-}$, with the monobioxalate being dominant. If the monobioxalate complex is dominant, the molar ratio should be closer to 1 . For $1 \mathrm{wt} . \%$ acid, there was little impact from the presence of excess solid (lower phase ratios). The iron concentration in every case but one was in the range 0.05 to $0.06 \mathrm{M}$. For the test conducted at a phase ratio of 45 with $\mathrm{pH}$ control, the observed iron concentration was $0.1 \mathrm{M}$, which corresponds to an oxalate:iron molar ratio near 1 . This is the only case in this dataset where it appeared that $\mathrm{pH}$ control resulted in the formation of the preferred monobioxalate complex. Perhaps this was the only test in which sufficient excess iron was available for complexation to utilize all of the oxalate in solution. These results indicate that sludge dissolution in oxalic acid should be viewed and approached as a stoichiometric process and that $\mathrm{pH}$ control is critical to fully utilizing the available oxalate anion for dissolution.

In order to evaluate the effects of $\mathrm{pH}$ on hematite dissolution with oxalic acid, solutions were prepared with varying initial $\mathrm{pH}$ values. All samples contained $0.11 \mathrm{M}$ oxalic acid. For most samples the ionic strength was held constant by the addition of either sodium chloride or sodium nitrate background salt. Both nitrate and chloride salts were tested due to concerns that the chloride salt used for initial tests could promote iron dissolution via halide complexation and impact the results. Also, background nitrate is more representative of SRS waste tank conditions. The total sodium concentration for all samples was $\sim 0.22 \mathrm{M}$. Sodium 
hydroxide or nitric acid was used to adjust the $\mathrm{pH}$ of the solutions to the targeted values. Only the lowest $\mathrm{pH}$ solution used nitric acid and therefore this solution had a different ionic strength than the other solutions. The initial concentrations of various reagents in the test solutions are provided in Tables $4.11\left(\mathrm{NaNO}_{3}\right.$ background salt) and $4.12(\mathrm{NaCl}$ background salt) along with the solubility data. The data indicates that $\mathrm{pH}$ significantly impacts hematite dissolution in a manner that is consistent with the iron speciation proposed by Lee ${ }^{9}$ and confirms that hematite dissolution in oxalic acid should be viewed as a stoichiometric process. Final iron concentrations versus $\mathrm{pH}$ are provided in Figure 4.8 for solutions containing both background salts. It does not appear that the identity of the background salt greatly impacts the results, since all of the data follows the same trend. At a constant oxalate concentration of $0.11 \mathrm{M}$, greater iron dissolution is observed at a $\mathrm{pH}$ near 0.5 while at $\mathrm{pH}$ values greater than 5, the effectiveness of oxalic acid for hematite dissolution is quite low. These results emphasize the importance of $\mathrm{pH}$ control for the dissolution of iron-based sludge. When the final $\mathrm{pH}$ is decreased from 5.0 to 0.5 the soluble iron concentration increases by nearly $3 \mathrm{X}$. This is consistent with the formation of the trioxalate complex at $\mathrm{pH}$ 5 and the monobioxalate complex at $\mathrm{pH}$ 0.5. As shown in Figure 4.9, the molar ratio of oxalate to soluble iron is also consistent with the formation of these complexes. It appears there is a small offset of $\sim 0.5 \mathrm{pH}$ units in the $\mathrm{pH}$ dependence relative to the predictions of Lee, since it was expected that at a $\mathrm{pH}$ of 1 the monobioxalate complex would dominate. Based on the results, it is expected that similar $\mathrm{pH}$ dependence would be observed in $8 \mathrm{wt} . \%$ oxalic acid and that iron concentrations $\geq 0.7 \mathrm{M}$ could be achieved at $\mathrm{pH}$ values $\leq 0.5$. Also, based on the solubility tests conducted with ferric oxalate in $8 \mathrm{wt} . \%$ acid (Table 4.6), as long as the solution does not contain significant Fe(II), iron oxalate precipitates should not form under these conditions, particularly if nitric acid is used for $\mathrm{pH}$ control. 
Table 4.1 Summary of XRD Analysis Results for SRS Tank Sludge Samples.

\begin{tabular}{|c|c|c|c|}
\hline Tank & Reference & Tank/Sample History and Comments & Phases Identified \\
\hline $4 \mathrm{~F}$ & $\begin{array}{l}\text { previously } \\
\text { unpublished }\end{array}$ & sample retrieved during sludge mechanical removal operations & $\begin{array}{c}\text { Clarkeite, } \mathrm{Na}\left(\mathrm{UO}_{2}\right) \mathrm{O}(\mathrm{OH}) \cdot \mathrm{H}_{2} \mathrm{O} \\
\text { magnetite, } \mathrm{Fe}_{3} \mathrm{O}_{4} \\
\text { hematite, } \mathrm{Fe}_{2} \mathrm{O}_{3}\end{array}$ \\
\hline $7 \mathrm{~F}$ & 12 & neutralized product from Tank $5 \mathrm{~F}$ and $6 \mathrm{~F}$ chemical cleaning operations & $\begin{array}{c}\text { Natroxalate, } \mathrm{Na}_{2} \mathrm{C}_{2} \mathrm{O}_{4} \\
\text { Clarkeite, } \mathrm{Na}\left(\mathrm{UO}_{2}\right) \mathrm{O}(\mathrm{OH}) \cdot \mathrm{H}_{2} \mathrm{O} \\
\text { magnetite, } \mathrm{Fe}_{3} \mathrm{O}_{4} \\
\mathrm{Na}_{8}\left(\mathrm{Al}_{6} \mathrm{Si}_{2} \mathrm{O}_{24}\right)\left(\mathrm{NO}_{3}\right)_{2} \cdot 4 \mathrm{H}_{2} \mathrm{O} \\
\mathrm{Na}_{2} \mathrm{U}_{2} \mathrm{O}_{7} \cdot 6 \mathrm{H}_{2} \mathrm{O}\end{array}$ \\
\hline $12 \mathrm{H}$ & 8 & sample retrieved during sludge mechanical removal operations & $\begin{array}{l}\text { boehmite, } \mathrm{Al}(\mathrm{O}) \mathrm{OH} \\
\text { hematite, } \mathrm{Fe}_{2} \mathrm{O}_{3}\end{array}$ \\
\hline $19 \mathrm{~F}$ & 13 & $\begin{array}{l}\text { zeolite (Cs ion exchange media) mound core sample remaining after bulk } \\
\text { sludge mechanical removal operations (aluminosilicate phase dominant) }\end{array}$ & $\begin{array}{c}\mathrm{Na}_{8}\left(\mathrm{Al}_{6} \mathrm{Si}_{2} \mathrm{O}_{24}\right)\left(\mathrm{NO}_{3}\right)_{2} \cdot 4 \mathrm{H}_{2} \mathrm{O} \\
\text { gibbsite, } \mathrm{Al}(\mathrm{OH})_{3} \\
\text { Maghemite, } \mathrm{Fe}_{2} \mathrm{O}_{3} \\
\text { Goethite, } \mathrm{Fe}(\mathrm{O}) \mathrm{OH} \\
\text { Lepidocrocite, } \mathrm{Fe}(\mathrm{O}) \mathrm{OH} \\
\end{array}$ \\
\hline $42 \mathrm{H}$ & 14 & $\begin{array}{l}\text { Tank } 15 \mathrm{H} \text { sludge transferred to } 42 \mathrm{H} \text { sludge processing tank for DWPF } \\
\text { Sludge Batch } 1-\mathrm{B}\end{array}$ & $\begin{array}{l}\text { boehmite, } \mathrm{Al}(\mathrm{O}) \mathrm{OH} \\
\text { hematite, } \mathrm{Fe}_{2} \mathrm{O}_{3}\end{array}$ \\
\hline $51 \mathrm{H}$ & 15 & $\begin{array}{l}\text { primarily Tank } 11 \mathrm{H} \text { sludge transferred to } 51 \mathrm{H} \text { sludge processing tank for } \\
\text { DWPF Sludge Batch } 4 \text { (also includes Sludge Batch } 3 \text { heel) }\end{array}$ & $\begin{array}{c}\text { boehmite, } \mathrm{Al}(\mathrm{O}) \mathrm{OH} \\
\text { hematite, } \mathrm{Fe}_{2} \mathrm{O}_{3} \\
\text { Lepidocrocite, } \mathrm{Fe}(\mathrm{O}) \mathrm{OH} \\
\text { Natron, } \mathrm{Na}_{2} \mathrm{CO}_{3} \cdot 10 \mathrm{H}_{2} \mathrm{O}\end{array}$ \\
\hline
\end{tabular}


Table 4.2 Experimental Results - Gibbsite Solubility in 0.125 M Acids at 25 and $70{ }^{\circ} \mathrm{C}$.

\begin{tabular}{|c|c|c|c|c|c|c|c|}
\hline $\begin{array}{l}\text { Initial } \\
\text { Acid }^{\mathrm{a}}\end{array}$ & $\begin{array}{c}\text { Temp. } \\
\left({ }^{\circ} \mathrm{C}\right)^{b}\end{array}$ & $\begin{array}{c}\text { pH } \\
\text { Control } \\
\text { Acid }^{c} \\
\end{array}$ & $\begin{array}{c}\text { Final } \\
\text { Mass Ratio } \\
\text { (liq./solid) }^{d}\end{array}$ & $\begin{array}{c}\text { Measured Al } \\
\text { Solubility } \\
(\mathrm{M})^{\mathrm{e}}\end{array}$ & $\begin{array}{c}\text { \% Al }(\mathrm{OH})_{3} \\
\text { Dissolved } \\
(\text { ICP-ES })\end{array}$ & $\begin{array}{c}\% \mathrm{Al}(\mathrm{OH})_{3} \\
\text { Dissolved } \\
\text { (mass-based) }\end{array}$ & $\begin{array}{c}\text { Final } \\
\text { Solution } \\
\text { pH } \\
\end{array}$ \\
\hline Oxalic & 25 & Nitric & 106.8 & 0.059 & 48.6 & 51.7 & 0.80 \\
\hline Oxalic & 70 & Nitric & 100.0 & 0.118 & 91.6 & 96.2 & 1.27 \\
\hline Nitric & 25 & Nitric & 106.8 & 0.017 & 13.5 & 21.3 & 0.92 \\
\hline Nitric & 70 & Nitric & 121.2 & 0.087 & 81.8 & 84.7 & 1.20 \\
\hline Sulfuric & 25 & Sulfuric & 105.6 & 0.061 & 50.0 & 50.0 & 0.88 \\
\hline Sulfuric & 70 & Sulfuric & $75.4^{\mathrm{f}}$ & 0.191 & 111.4 & 102.3 & 1.44 \\
\hline
\end{tabular}

all initial acid concentrations $0.125 \mathrm{M}$

${ }^{b}$ test durations: 37 days at $25{ }^{\circ} \mathrm{C}, 34$ days at $70{ }^{\circ} \mathrm{C}$

${ }^{\mathrm{c}} 3 \mathrm{M}$ acids typically used for $\mathrm{pH}$ control, although $1 \mathrm{M}$ nitric used sometimes

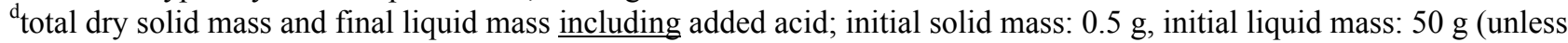
otherwise indicated)

e determined by ICP-ES

findicates cases where additional gibbsite was added due to complete solids dissolution 
Table 4.3 Experimental Results - Boehmite Solubility in $0.125 \mathrm{M}$ Acids at 25 and $70{ }^{\circ} \mathrm{C}$.

\begin{tabular}{|c|c|c|c|c|c|c|c|}
\hline $\begin{array}{l}\text { Initial } \\
\text { Acid }^{\mathrm{a}}\end{array}$ & $\begin{array}{c}\text { Temp. } \\
\left({ }^{\circ} \mathrm{C}\right)^{b}\end{array}$ & $\begin{array}{c}\text { pH } \\
\text { Control } \\
\text { Acid }^{c} \\
\end{array}$ & $\begin{array}{c}\text { Final } \\
\text { Mass Ratio } \\
\text { (liq./solid) }^{d}\end{array}$ & $\begin{array}{c}\text { Measured Al } \\
\text { Solubility } \\
(\mathrm{M})^{\mathrm{e}}\end{array}$ & $\begin{array}{c}\text { \% } \mathrm{Al}(\mathrm{OH})_{3} \\
\text { Dissolved } \\
(\mathrm{ICP}-\mathrm{ES})\end{array}$ & $\begin{array}{c}\text { \% Al(OH) } \\
\text { Dissolved } \\
\text { (mass-based) }\end{array}$ & $\begin{array}{c}\text { Final } \\
\text { Solution } \\
\text { pH } \\
\end{array}$ \\
\hline Oxalic & 25 & Nitric & 104.2 & 0.0017 & 1.0 & -9.1 & 1.25 \\
\hline Oxalic & 70 & Nitric & 106.8 & 0.0910 & 58.0 & 55.2 & 1.34 \\
\hline Nitric & 25 & --- & 100.1 & 0.0003 & 0.2 & 3.3 & 1.27 \\
\hline Nitric & 70 & --- & 105.2 & 0.0091 & 5.7 & 2.4 & 1.23 \\
\hline Sulfuric & 25 & Sulfuric & 100.3 & 0.0014 & 0.5 & -32.6 & 1.28 \\
\hline Sulfuric & 70 & --- & 105.9 & 0.0541 & 34.1 & 17.7 & 1.33 \\
\hline
\end{tabular}

all initial acid concentrations $0.125 \mathrm{M}$

best durations: 37 days at $25^{\circ} \mathrm{C}, 22$ days at $70{ }^{\circ} \mathrm{C}$

${ }^{\mathrm{c}} 3 \mathrm{M}$ acids typically used for $\mathrm{pH}$ control, although $1 \mathrm{M}$ nitric used sometimes

dotal dry solid mass and final liquid mass including added acid; initial solid mass: $0.5 \mathrm{~g}$, initial liquid mass: $50 \mathrm{~g}$

e determined by ICP-ES 
Table 4.4 Experimental Results - Boehmite Solubility in 1, 4, and 8 wt. \% Oxalic Acid at 50 'C (Test Duration: 19 Days).

\begin{tabular}{|c|c|c|c|c|c|}
\hline $\begin{array}{c}\text { Oxalic } \\
\text { Acid } \\
\text { (M) }^{\mathbf{a}}\end{array}$ & $\begin{array}{c}\text { Final } \\
\text { Mass Ratio } \\
\text { (liq./solid) }^{\mathbf{b}}\end{array}$ & $\begin{array}{c}\text { Measured Al } \\
\text { Solubility } \\
\text { (M) }^{\mathbf{c}}\end{array}$ & $\begin{array}{c}\text { \% AlO(OH) } \\
\text { Dissolved } \\
\text { (ICP-ES) }\end{array}$ & $\begin{array}{c}\text { \% AlO(OH) } \\
\text { Dissolved } \\
\text { (mass-based) }\end{array}$ & $\begin{array}{c}\text { Final } \\
\text { Solution } \\
\mathbf{p H}\end{array}$ \\
\hline $0.11^{*}$ & 118.7 & 0.0065 & 4.5 & -20.1 & 0.94 \\
\hline 0.11 & 105.6 & 0.0075 & 4.8 & -20.1 & 1.59 \\
\hline $0.45^{*}$ & 119.7 & 0.0073 & 5.12 & -53.8 & 0.80 \\
\hline 0.45 & 104.8 & 0.0080 & 4.94 & -53.8 & 1.04 \\
\hline $0.92^{*}$ & 114.5 & 0.0082 & 5.42 & -121.4 & 0.83 \\
\hline 0.92 & 105.4 & 0.0087 & 5.29 & -121.4 & 0.96 \\
\hline
\end{tabular}

${ }^{\mathrm{a}} \mathrm{An}$ asterisk indicates $\mathrm{pH}$ was controlled using nitric acid; $3 \mathrm{M}$ nitric acid typically used for $\mathrm{pH}$ control, although $1 \mathrm{M}$ nitric acid used sometimes

${ }^{\mathrm{b}}$ total dry solid mass and final liquid mass including added acid

${ }^{c}$ determined by ICP-ES 
Table 4.5 Experimental Results - Method Verification Testing with Ferrous Oxalate, Ferric Oxalate, and hematite at $25{ }^{\circ} \mathrm{C}$.

\begin{tabular}{|c|c|c|c|c|c|c|c|c|}
\hline Solid & Solution & $\begin{array}{c}\text { Light } \\
\text { Exposure }^{a}\end{array}$ & $\begin{array}{l}\text { Calculated } \\
\text { Oxalate } \\
(\mathbf{M})^{\mathbf{b}}\end{array}$ & $\begin{array}{l}\text { Measured } \\
\text { Oxalate } \\
(\mathrm{M})\end{array}$ & $\begin{array}{c}\text { Oxalate } \\
\text { Ratio } \\
\text { (Meas./Calc.) }\end{array}$ & $\begin{array}{c}\text { Calculated } \\
\text { Fe } \\
(\mathbf{M})^{\mathbf{b}} \\
\end{array}$ & $\begin{array}{c}\text { Measured } \\
\text { Fe } \\
(\mathrm{M})\end{array}$ & $\begin{array}{c}\text { Fe Ratio } \\
\text { (Meas./Calc.) }\end{array}$ \\
\hline $\mathrm{Fe}\left(\mathrm{C}_{2} \mathrm{O}_{4}\right) \cdot 2 \mathrm{H}_{2} \mathrm{O}$ & water & dark & $1.00 \mathrm{E}-04$ & $1.25 \mathrm{E}-04$ & 1.25 & $1.00 \mathrm{E}-04$ & $6.03 \mathrm{E}-05$ & 0.60 \\
\hline $\mathrm{Fe}_{2}\left(\mathrm{C}_{2} \mathrm{O}_{4}\right)_{3} \cdot 6 \mathrm{H}_{2} \mathrm{O}$ & water & dark & $1.50 \mathrm{E}-02$ & $1.31 \mathrm{E}-02$ & 0.87 & $1.00 \mathrm{E}-02$ & $8.25 \mathrm{E}-03$ & 0.83 \\
\hline $\mathrm{Fe}_{2}\left(\mathrm{C}_{2} \mathrm{O}_{4}\right)_{3} \cdot 6 \mathrm{H}_{2} \mathrm{O}$ & water & light & $1.50 \mathrm{E}-02$ & $3.64 \mathrm{E}-04$ & 0.02 & $1.00 \mathrm{E}-02$ & $1.31 \mathrm{E}-03$ & 0.13 \\
\hline $\mathrm{Fe}_{2}\left(\mathrm{C}_{2} \mathrm{O}_{4}\right)_{3} \cdot 6 \mathrm{H}_{2} \mathrm{O}$ & 8 wt. $\%$ oxalic acid & dark & 0.935 & 0.957 & 1.02 & $1.00 \mathrm{E}-02$ & $8.68 \mathrm{E}-03$ & 0.87 \\
\hline $\mathrm{Fe}_{2}\left(\mathrm{C}_{2} \mathrm{O}_{4}\right)_{3} \cdot 6 \mathrm{H}_{2} \mathrm{O}$ & 8 wt. $\%$ oxalic acid & light & 0.935 & 0.864 & 0.94 & $1.00 \mathrm{E}-02$ & 1.69E-03 & 0.17 \\
\hline $\mathrm{Fe}_{2} \mathrm{O}_{3}$ (hematite) & 8 wt. $\%$ oxalic acid & dark & 0.920 & 0.940 & 1.02 & $1.00 \mathrm{E}-02$ & $5.21 \mathrm{E}-03$ & 0.80 \\
\hline $\mathrm{Fe}_{2} \mathrm{O}_{3}$ (hematite) & 8 wt. $\%$ oxalic acid & light & 0.920 & 0.874 & 0.95 & $1.00 \mathrm{E}-02$ & $1.40 \mathrm{E}-03$ & 0.21 \\
\hline none & 8 wt. $\%$ oxalic acid & -- & 0.920 & 0.911 & 0.99 & 0.00 & $<4.69 \mathrm{E}-02$ & --- \\
\hline
\end{tabular}

a light exposure not quantified, involved placing samples in transparent containers directly in front of oven UV light for 32 days; samples maintained in dark by turning off oven light, taping oven window shut, and submitting analysis samples in sealed drum

based on total solid added and assuming that all solid dissolved 
Table 4.6 Experimental Results - Ferric and Ferrous Oxalate Solubilities in Oxalic, Nitric, and Sulfuric acids at $50{ }^{\circ} \mathrm{C}$.

\begin{tabular}{|c|c|c|c|c|}
\hline Reagent & Solution & $\begin{array}{c}\text { Acid Conc. } \\
(\mathbf{M})\end{array}$ & $\begin{array}{c}\text { Measured Fe } \\
\text { Solubility (M) }\end{array}$ & $\begin{array}{c}\text { Final } \\
\text { pH }\end{array}$ \\
\hline Ferrous Oxalate & & & & \\
\hline $\mathrm{Fe}\left(\mathrm{C}_{2} \mathrm{O}_{4}\right) \cdot 2 \mathrm{H}_{2} \mathrm{O}$ & water & --- & 0.011 & 3.18 \\
\hline $\mathrm{Fe}\left(\mathrm{C}_{2} \mathrm{O}_{4}\right) \cdot 2 \mathrm{H}_{2} \mathrm{O}$ & oxalic acid & 0.11 & 0.024 & 1.46 \\
\hline $\mathrm{Fe}\left(\mathrm{C}_{2} \mathrm{O}_{4}\right) \cdot 2 \mathrm{H}_{2} \mathrm{O}$ & oxalic acid & 0.45 & 0.035 & 1.19 \\
\hline $\mathrm{Fe}\left(\mathrm{C}_{2} \mathrm{O}_{4}\right) \cdot 2 \mathrm{H}_{2} \mathrm{O}$ & oxalic acid & 0.92 & 0.042 & 1.01 \\
\hline $\mathrm{Fe}\left(\mathrm{C}_{2} \mathrm{O}_{4}\right) \cdot 2 \mathrm{H}_{2} \mathrm{O}$ & nitric & 0.1 & 0.189 & 2.07 \\
\hline $\mathrm{Fe}\left(\mathrm{C}_{2} \mathrm{O}_{4}\right) \cdot 2 \mathrm{H}_{2} \mathrm{O}$ & nitric & 1.0 & $0.893^{\mathrm{c}}$ & 1.07 \\
\hline $\mathrm{Fe}\left(\mathrm{C}_{2} \mathrm{O}_{4}\right) \cdot 2 \mathrm{H}_{2} \mathrm{O}$ & sulfuric & 0.1 & 0.067 & 1.54 \\
\hline $\mathrm{Fe}_{\left(\mathrm{C}_{2} \mathrm{O}_{4}\right) \cdot 2 \mathrm{H}_{2} \mathrm{O}}$ & sulfuric & 1.0 & 0.216 & 0.91 \\
\hline${\mathrm{Ferric} \mathrm{Oxalate}^{\mathrm{a}}}^{\mathrm{a}}$ & & & & $>0.83 *$ \\
\hline $\mathrm{Fe}_{2}\left(\mathrm{C}_{2} \mathrm{O}_{4}\right)_{3} \cdot 6 \mathrm{H}_{2} \mathrm{O}$ & water & --- & 1.008 & --- \\
\hline $\mathrm{Fe}_{2}\left(\mathrm{C}_{2} \mathrm{O}_{4}\right)_{3} \cdot 6 \mathrm{H}_{2} \mathrm{O}$ & oxalic acid & 0.11 & 0.958 & 1.44 \\
\hline $\mathrm{Fe}_{2}\left(\mathrm{C}_{2} \mathrm{O}_{4}\right)_{3} \cdot 6 \mathrm{H}_{2} \mathrm{O}$ & oxalic acid & 0.45 & 0.960 & 0.99 \\
\hline $\mathrm{Fe}_{2}\left(\mathrm{C}_{2} \mathrm{O}_{4}\right)_{3} \cdot 6 \mathrm{H}_{2} \mathrm{O}$ & oxalic acid & 0.92 & $>0.42^{*}$ & --- \\
\hline $\mathrm{Fe}_{2}\left(\mathrm{C}_{2} \mathrm{O}_{4}\right)_{3} \cdot 6 \mathrm{H}_{2} \mathrm{O}$ & nitric & 0.1 & $>0.42^{*}$ & --- \\
\hline $\mathrm{Fe}_{2}\left(\mathrm{C}_{2} \mathrm{O}_{4}\right)_{3} \cdot 6 \mathrm{H}_{2} \mathrm{O}$ & nitric & 1.0 & $>0.42^{*}$ & --- \\
\hline $\mathrm{Fe}_{2}\left(\mathrm{C}_{2} \mathrm{O}_{4}\right)_{3} \cdot 6 \mathrm{H}_{2} \mathrm{O}$ & sulfuric & 0.1 & $>0.42^{*}$ & --- \\
\hline $\mathrm{Fe}_{2}\left(\mathrm{C}_{2} \mathrm{O}_{4}\right)_{3} \cdot 6 \mathrm{H}_{2} \mathrm{O}$ & sulfuric & 1.0 & & \\
\hline
\end{tabular}

${ }^{\text {a }}$ test durations: 11 days for ferrous oxalate, 5 days for ferric oxalate

b based on ICP-ES analysis; asterick indicates experiments stopped due to perceived high solubilities and limited available reagent ${ }^{c}$ mild off-gassing observed for this sample as amount of solid was increased, oxalate analysis of final solution indicated $0.850 \mathrm{M}$ oxalate 
Table 4.7 Experimental Results - Magnetite Solubility in 0.125 M Acids at 25 and $70{ }^{\circ} \mathrm{C}$.

\begin{tabular}{|c|c|c|c|c|c|c|c|c|}
\hline $\begin{array}{c}\text { Initial } \\
\text { Acid }^{\mathrm{a}}\end{array}$ & $\begin{array}{c}\text { Temp. } \\
\left({ }^{\circ} \mathrm{C}\right)^{b}\end{array}$ & $\begin{array}{c}\text { pH } \\
\text { Control } \\
\text { Acid }^{\mathrm{c}} \\
\end{array}$ & $\begin{array}{c}\text { Final } \\
\text { Mass Ratio } \\
\text { (liq./solid) }^{d}\end{array}$ & $\begin{array}{c}\text { Measured Fe } \\
\text { Solubility } \\
(\mathrm{M})^{\mathrm{e}}\end{array}$ & $\begin{array}{c}\text { Molar Ratio } \\
\text { Anion:Fe } \\
\text { (Dissolved) }\end{array}$ & $\begin{array}{c}\% \mathrm{Fe}_{3} \mathrm{O}_{4} \\
\text { Dissolved } \\
\text { (ICP-ES) }\end{array}$ & $\begin{array}{c}\text { \% } \mathrm{Fe}_{3} \mathrm{O}_{4} \\
\text { Dissolved } \\
\text { (mass-based) }\end{array}$ & $\begin{array}{c}\text { Final } \\
\text { Solution } \\
\text { pH } \\
\end{array}$ \\
\hline Oxalic & 25 & Nitric & 108.3 & 0.1005 & 1.1 & 84.0 & 90.3 & 1.18 \\
\hline Oxalic & 70 & Nitric & 120.1 & 0.0427 & 2.8 & 39.4 & -8.8 & 1.34 \\
\hline Nitric & 25 & Nitric & 100.6 & 0.0045 & 34.5 & 3.5 & 7.8 & 1.17 \\
\hline Nitric & 70 & Nitric & 114.4 & 0.0070 & 17.9 & 6.2 & -4.7 & 1.22 \\
\hline Sulfuric & 25 & Sulfuric & 105.0 & 0.0972 & 2.4 & 78.8 & 79.5 & 1.25 \\
\hline Sulfuric & 70 & Sulfuric & 118.7 & 0.0993 & 1.9 & 90.7 & 70.2 & 1.27 \\
\hline
\end{tabular}

all initial acid concentrations $0.125 \mathrm{M}$

test durations: 36 days at $25^{\circ} \mathrm{C}, 22$ days at $70{ }^{\circ} \mathrm{C}$

${ }^{c} 3 \mathrm{M}$ acids typically used for $\mathrm{pH}$ control, although $1 \mathrm{M}$ nitric used sometimes

total dry solid mass and final liquid mass including added acid

edetermined by ICP-ES

fnitrate not included in total anion calculation for oxalic acid 
Table 4.8 Experimental Results - Hematite Solubility in 0.125 M Acids at 25 and $70{ }^{\circ} \mathrm{C}$.

\begin{tabular}{|c|c|c|c|c|c|c|c|}
\hline $\begin{array}{l}\text { Initial } \\
\text { Acid }^{\mathrm{a}}\end{array}$ & $\begin{array}{c}\text { Temp. } \\
\left({ }^{\circ} \mathrm{C}\right)^{b}\end{array}$ & $\begin{array}{c}\text { pH } \\
\text { Control } \\
\text { Acid }^{\mathrm{c}} \\
\end{array}$ & $\begin{array}{c}\text { Final } \\
\text { Mass Ratio } \\
\text { (liq./solid) }^{d}\end{array}$ & $\begin{array}{c}\text { Measured Fe } \\
\text { Solubility } \\
(\mathrm{M})^{\mathrm{e}}\end{array}$ & $\begin{array}{c}\text { Molar Ratio } \\
\text { Anion:Fe } \\
\text { (Dissolved) }^{\text {f }}\end{array}$ & $\begin{array}{c}\% \mathrm{Fe}_{3} \mathrm{O}_{4} \\
\text { Dissolved } \\
(\text { ICP-ES) }\end{array}$ & $\begin{array}{c}\text { Final } \\
\text { Solution } \\
\text { pH } \\
\end{array}$ \\
\hline Oxalic & 25 & Nitric & 106.3 & 0.0695 & 1.7 & 58.5 & 1.05 \\
\hline Oxalic & 70 & Nitric & 102.2 & 0.050 & 2.4 & 40.7 & 0.86 \\
\hline Nitric & 25 & Nitric & 102.3 & 0.0026 & 68.9 & 2.1 & 1.00 \\
\hline Nitric & 70 & Nitric & 99.9 & 0.0023 & 63.1 & 1.9 & 0.64 \\
\hline Sulfuric & 25 & Nitric & 102.0 & 0.0255 & 4.8 & 20.6 & 1.07 \\
\hline Sulfuric & 25 & Sulfuric & 102.3 & 0.0370 & 4.9 & 29.9 & 1.14 \\
\hline Sulfuric & 70 & Sulfuric & 99.0 & 0.194 & 6.8 & 15.2 & 0.75 \\
\hline
\end{tabular}

a all initial acid concentrations $0.125 \mathrm{M}$

${ }^{b}$ test durations: 41 days at $25^{\circ} \mathrm{C}, 35$ days at $70^{\circ} \mathrm{C}$

${ }^{\mathrm{c}} 3 \mathrm{M}$ acids used for $\mathrm{pH}$ control

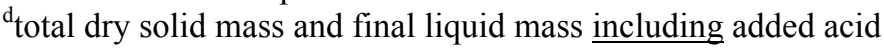

edetermined by ICP-ES

nitrate not included in total anion calculation for oxalic acid or sulfuric 
Table 4.9 Experimental Results - Hematite Solubility in Various Mineral Acid Concentrations at $50{ }^{\circ} \mathrm{C}$ (Test Duration: 39 Days).

\begin{tabular}{|c|c|c|c|c|c|}
\hline Acid & $\begin{array}{c}\text { Concentration } \\
\text { (M) }\end{array}$ & $\begin{array}{c}\text { Final } \\
\text { Mass Ratio } \\
\text { (liq./solid) }\end{array}$ & $\begin{array}{c}\text { Measured Fe } \\
\text { Solubility } \\
(\mathbf{M})^{\mathbf{b}}\end{array}$ & $\begin{array}{c}\text { \% Fe } \mathbf{F e}_{2} \text { Dissolved } \\
\text { (ICP-ES) }\end{array}$ & $\begin{array}{c}\text { Final } \\
\text { Solution } \mathbf{p H}^{\mathbf{c}}\end{array}$ \\
\hline $\mathrm{HNO}_{3}$ & 0.1 & 100.5 & 0.0017 & 1.4 & 0.98 \\
\hline $\mathrm{HNO}_{3}$ & 0.5 & 100.9 & 0.0394 & 31.3 & 0.48 \\
\hline $\mathrm{HNO}_{3}$ & 1.0 & 100.8 & 0.0858 & 66.8 & 0.21 \\
\hline & & & & & \\
\hline $\mathrm{H}_{2} \mathrm{SO}_{4}$ & 0.1 & 100.2 & 0.0170 & 13.5 & 1.18 \\
\hline $\mathrm{H}_{2} \mathrm{SO}_{4}$ & 0.5 & 80.2 & 0.1347 & 83.8 & 0.83 \\
\hline $\mathrm{H}_{2} \mathrm{SO}_{4}$ & 1.0 & 50.6 & 0.2180 & 83.1 & 0.60 \\
\hline
\end{tabular}

adry solid mass and final liquid mass

bdetermined by ICP-ES

${ }^{\mathrm{c}} \mathrm{pH}$ not controlled for any samples 
Table 4.10 Experimental Results - Phase Ratio Dependence of Hematite Solubility in 1, 4, and 8 wt. \% Oxalic Acid at $50{ }^{\circ} \mathrm{C}$ (Test Duration: 15 Days).

\begin{tabular}{|c|c|c|c|c|c|c|}
\hline $\begin{array}{c}\text { Oxalic } \\
\text { Acid } \\
(\mathrm{M})^{\mathrm{a}}\end{array}$ & $\begin{array}{c}\text { Final } \\
\text { Mass Ratio } \\
\text { (liq./solid) }^{b}\end{array}$ & $\begin{array}{c}\text { Measured Fe } \\
\text { Solubility } \\
(\mathrm{M})^{\mathrm{c}}\end{array}$ & $\begin{array}{c}\text { Molar Ratio } \\
\text { Oxalate:Fe } \\
\text { (Dissolved) }^{d} \\
\end{array}$ & $\begin{array}{c}\text { \% } \mathrm{Fe}_{2} \mathrm{O}_{3} \\
\text { Dissolved } \\
\text { (ICP-ES) }\end{array}$ & $\begin{array}{c}\text { \% } \mathrm{Fe}_{2} \mathrm{O}_{3} \\
\text { Dissolved } \\
\text { (mass-based) }\end{array}$ & $\begin{array}{c}\text { Final } \\
\text { Solution } \\
\text { pH } \\
\end{array}$ \\
\hline 0.11 & 37.5 & 0.0617 & 1.8 & 18.4 & 15.9 & 1.79 \\
\hline $0.11 *$ & 45.3 & 0.1033 & 0.9 & 36.6 & 20.1 & 0.92 \\
\hline 0.11 & 149.8 & 0.0590 & 1.9 & 70.2 & 50.3 & 1.53 \\
\hline $0.11^{*}$ & 165.0 & 0.0625 & 1.6 & 81.3 & 83.8 & 0.96 \\
\hline 0.11 & 209.5 & 0.0523 & 2.2 & 87.1 & 72.2 & 1.41 \\
\hline $0.11 *$ & 227.7 & 0.0499 & 2.1 & 89.9 & 92.2 & 0.92 \\
\hline 0.45 & 52.5 & 0.2216 & 2.0 & 91.1 & 88.8 & 0.98 \\
\hline $0.45^{*}$ & 53.5 & 0.2189 & 2.1 & 91.7 & 80.1 & 0.93 \\
\hline 0.92 & 26.4 & 0.4542 & 2.0 & 92.1 & 86.1 & 0.76 \\
\hline
\end{tabular}

${ }^{\mathrm{a}}$ samples for which $\mathrm{pH}$ was controlled using nitric acid are indicated with an asterisk; $3 \mathrm{M}$ nitric acid typically used for $\mathrm{pH}$ control, although $1 \mathrm{M}$ nitric acid used sometimes

${ }^{\mathrm{b}}$ dry solid mass and final liquid mass including added hematite and acid

cdetermined by ICP-ES

${ }^{d}$ nitrate not included in total anion calculation for oxalic acid 
Table 4.11 Experimental Results - pH Dependence of Hematite Solubility in 1 wt. \% Oxalic Acid with $\mathrm{NaNO}_{3} \mathrm{Salt}_{\text {Background at } 50}{ }^{\circ} \mathrm{C}$ without pH Control (Test Duration: 30 Days).

\begin{tabular}{|c|c|c|c|c|c|c|c|c|}
\hline $\begin{array}{c}\text { Total } \\
{[\mathrm{Na}]} \\
(\mathrm{M}) \\
\end{array}$ & $\begin{array}{c}\text { Initial } \\
{\left[\mathrm{OH}^{-}\right]} \\
(\mathrm{M})\end{array}$ & $\begin{array}{c}\text { Total } \\
{\left[\mathrm{NO}_{3}^{-}\right]} \\
(\mathrm{M})\end{array}$ & $\begin{array}{c}{\left[\mathrm{HNO}_{3}\right]} \\
(\mathrm{M})\end{array}$ & $\begin{array}{c}\text { Final } \\
\text { Mass Ratio } \\
\text { (liq./solid) }\end{array}$ & $\begin{array}{c}\text { Measured Fe } \\
\text { Solubility } \\
(\mathrm{M})^{\mathrm{a}}\end{array}$ & $\begin{array}{c}\text { Molar Ratio } \\
\text { Oxalate:Fe } \\
\text { (Dissolved) }\end{array}$ & $\begin{array}{c}\text { o/ } \mathrm{Fe}_{2} \mathrm{O}_{3} \\
\text { Dissolved } \\
\text { (ICP-ES) }\end{array}$ & $\begin{array}{c}\text { Final } \\
\text { pH }\end{array}$ \\
\hline 0.22 & 0.00 & 0.72 & 0.5 & 127.4 & 0.0855 & 1.3 & 84.5 & 0.47 \\
\hline 0.22 & 0.00 & 0.22 & 0.00 & 151.0 & 0.0581 & 1.9 & 69.2 & 1.00 \\
\hline 0.22 & 0.08 & 0.13 & 0.00 & 151.9 & 0.0447 & 2.5 & 53.7 & 2.04 \\
\hline 0.22 & 0.11 & 0.11 & 0.00 & 151.4 & 0.0376 & 3.0 & 44.9 & 3.41 \\
\hline 0.22 & 0.15 & 0.07 & 0.00 & 151.1 & 0.0226 & 4.9 & 27.0 & 5.66 \\
\hline 0.22 & 0.20 & 0.02 & 0.00 & 151.4 & 0.0081 & 13.8 & 9.7 & 6.20 \\
\hline 0.22 & 0.22 & 0.00 & 0.00 & 151.2 & 0.0013 & 83.9 & 1.6 & 6.62 \\
\hline
\end{tabular}

adetermined by ICP-ES 
Table 4.12 Experimental Results - pH Dependence of Hematite Solubility in 1 wt. \% Oxalic Acid with NaCl Salt Background at $50{ }^{\circ} \mathrm{C}$ with $\mathrm{pH}$ Control.

\begin{tabular}{|c|c|c|c|c|c|c|c|c|}
\hline $\begin{array}{l}\text { Total } \\
{[\mathbf{N a}]} \\
(\mathrm{M})\end{array}$ & $\begin{array}{l}\text { Initial } \\
{\left[\mathrm{OH}^{-}\right]} \\
(\mathrm{M})\end{array}$ & $\begin{array}{l}\text { Total } \\
{\left[\mathrm{Cl}^{-}\right]} \\
(\mathrm{M})\end{array}$ & $\begin{array}{c}\text { Initial } \\
{\left[\mathrm{HNO}_{3}\right]} \\
(\mathrm{M})\end{array}$ & $\begin{array}{c}\text { Final } \\
\text { Mass Ratio } \\
\text { (liq./solid) }\end{array}$ & $\begin{array}{c}\text { Measured Fe } \\
\text { Solubility }^{\mathrm{a}} \\
\text { (M) }\end{array}$ & $\begin{array}{l}\text { Molar Ratio } \\
\text { Oxalate:Fe } \\
\text { (Dissolved) }\end{array}$ & $\begin{array}{c}\text { \% } \mathrm{Fe}_{2} \mathrm{O}_{3} \\
\text { Dissolved } \\
\text { (ICP-ES) }\end{array}$ & $\begin{array}{c}\text { Final } \\
\text { pH }^{\mathbf{b}}\end{array}$ \\
\hline 0.22 & 0.00 & 0.22 & 0.00 & 147.5 & 0.0616 & 1.8 & 71.9 & 1.10 \\
\hline 0.22 & 0.08 & 0.14 & 0.00 & 147.6 & 0.0470 & 2.4 & 54.9 & 2.06 \\
\hline 0.22 & 0.11 & 0.11 & 0.00 & 150.4 & 0.0407 & 2.7 & 48.5 & $2.65^{*}$ \\
\hline 0.22 & 0.15 & 0.07 & 0.00 & 152.6 & 0.0378 & 2.9 & 45.7 & $3.09 *$ \\
\hline 0.22 & 0.20 & 0.02 & 0.00 & 153.6 & 0.0358 & 3.0 & 43.7 & $4.07^{*}$ \\
\hline 0.22 & 0.22 & 0.00 & 0.00 & 152.3 & 0.0310 & 3.5 & 37.5 & $5.17^{*}$ \\
\hline
\end{tabular}

atest durations: 30 days for samples without $\mathrm{pH}$ control, 41 days for samples with $\mathrm{pH}$ control

b $3 \mathrm{M}$ nitric acid used for $\mathrm{pH}$ control; asterisk indicates samples for which $\mathrm{pH}$ was controlled 
[262248lowbkg.raw] MH_FTF040932_XRD Low BKG Slide Hay

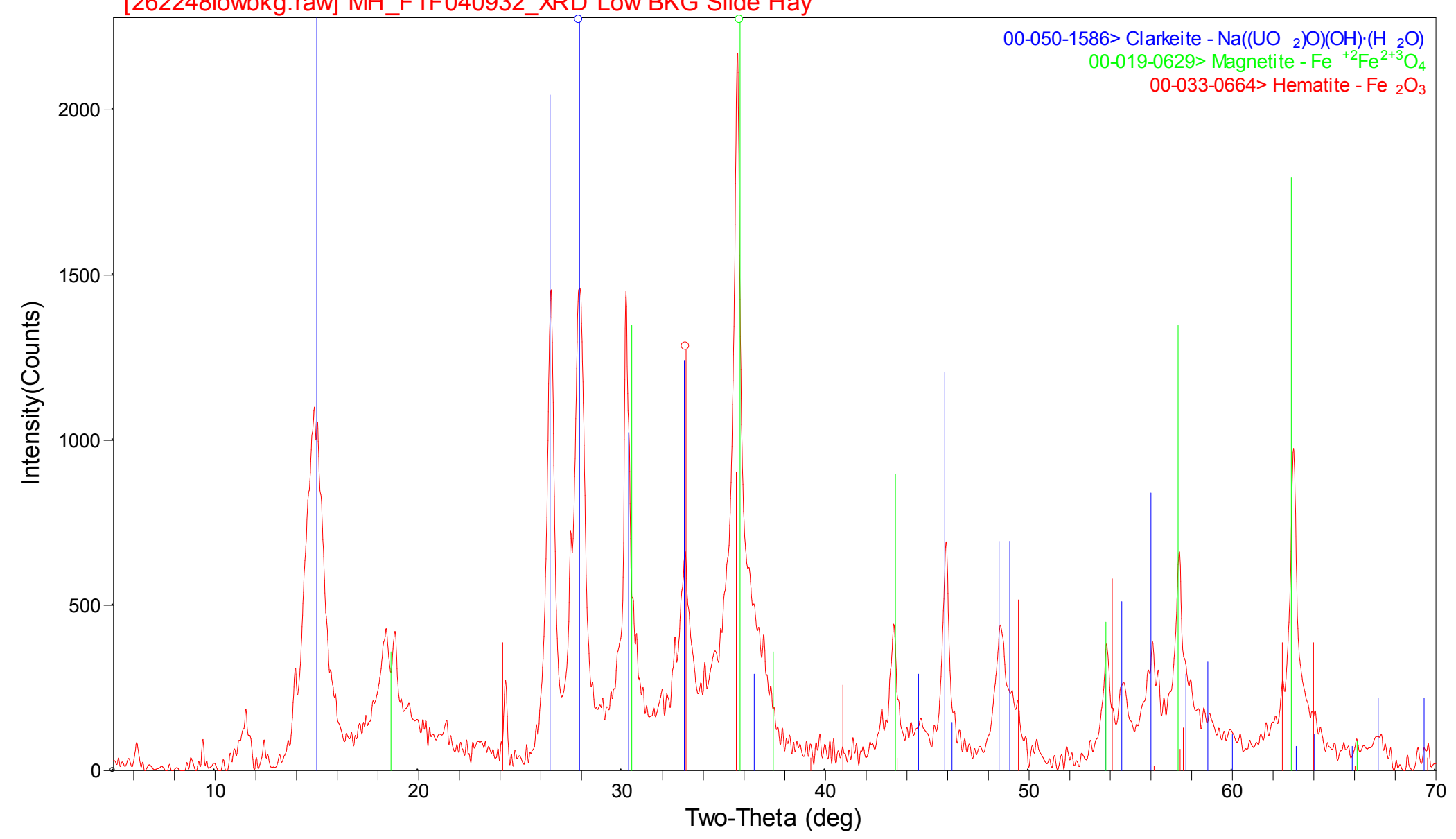

Figure 4.1 XRD Analysis of SRS Tank 4F Sludge

$-39-$ 


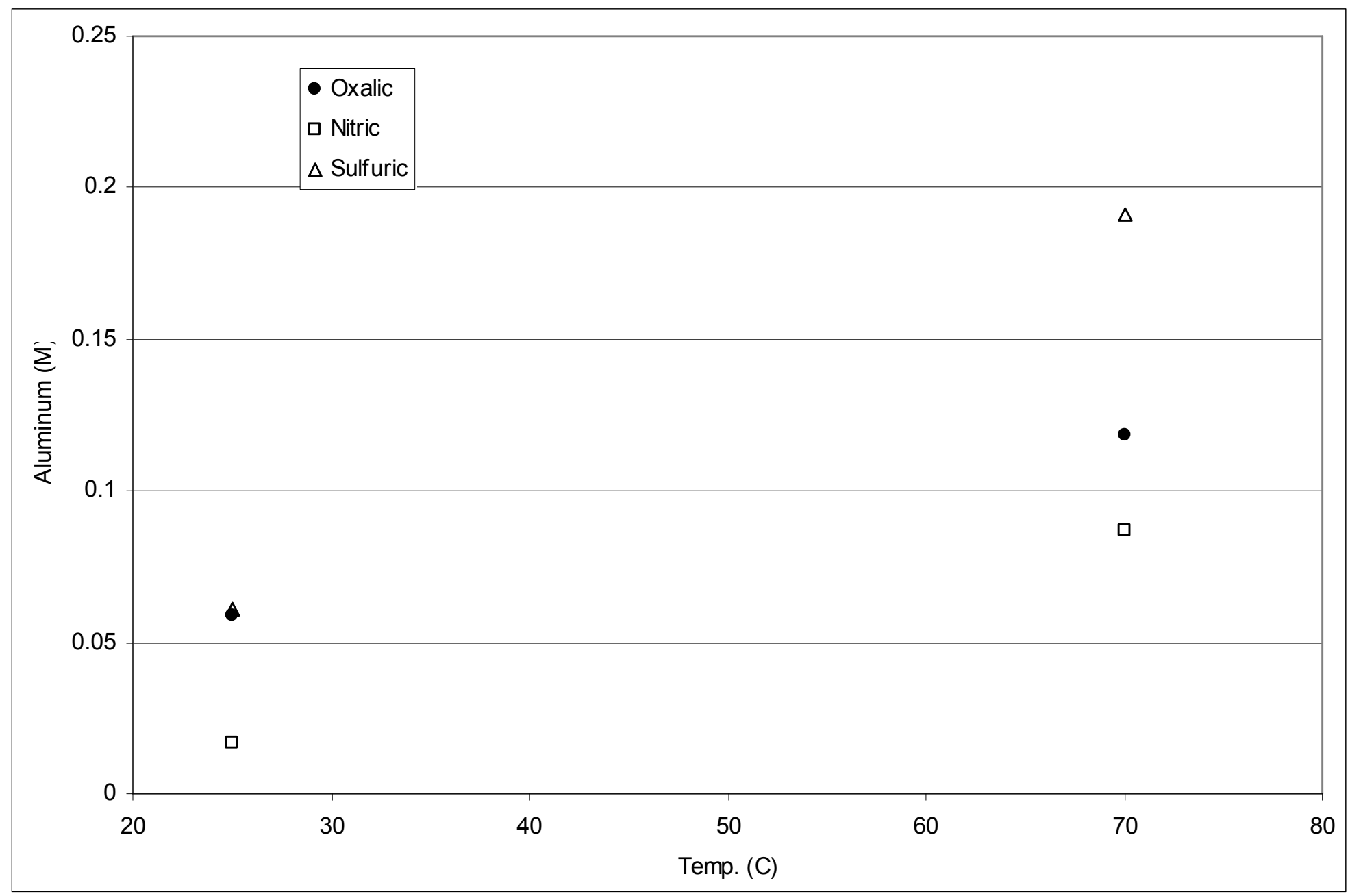

Figure 4.2 Gibbsite Solubility in $0.125 \mathrm{M}$ Acids versus Temperature.

$-40-$ 


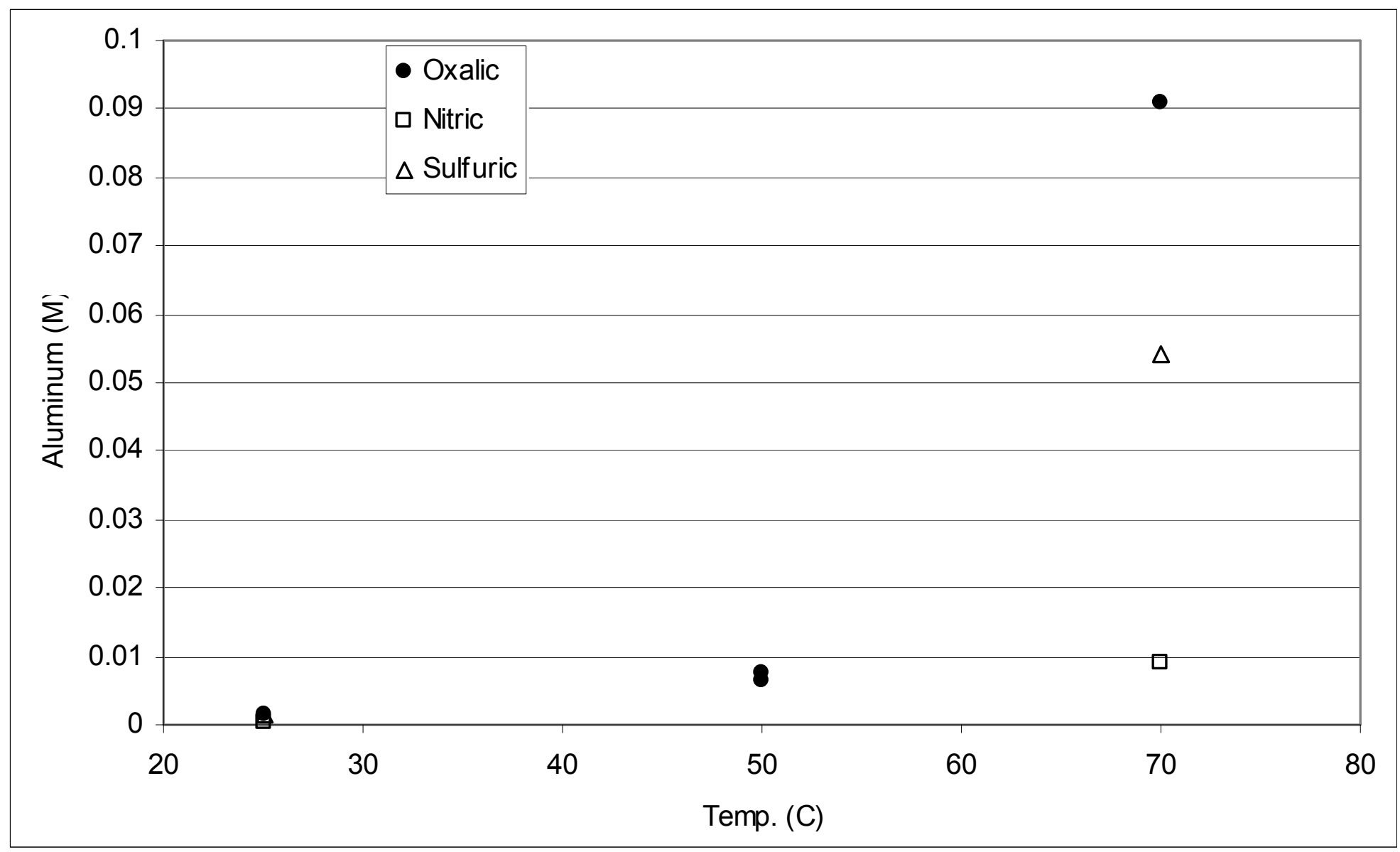

Figure 4.3 Boehmite Solubility in 0.125 M Acids versus Temperature. 


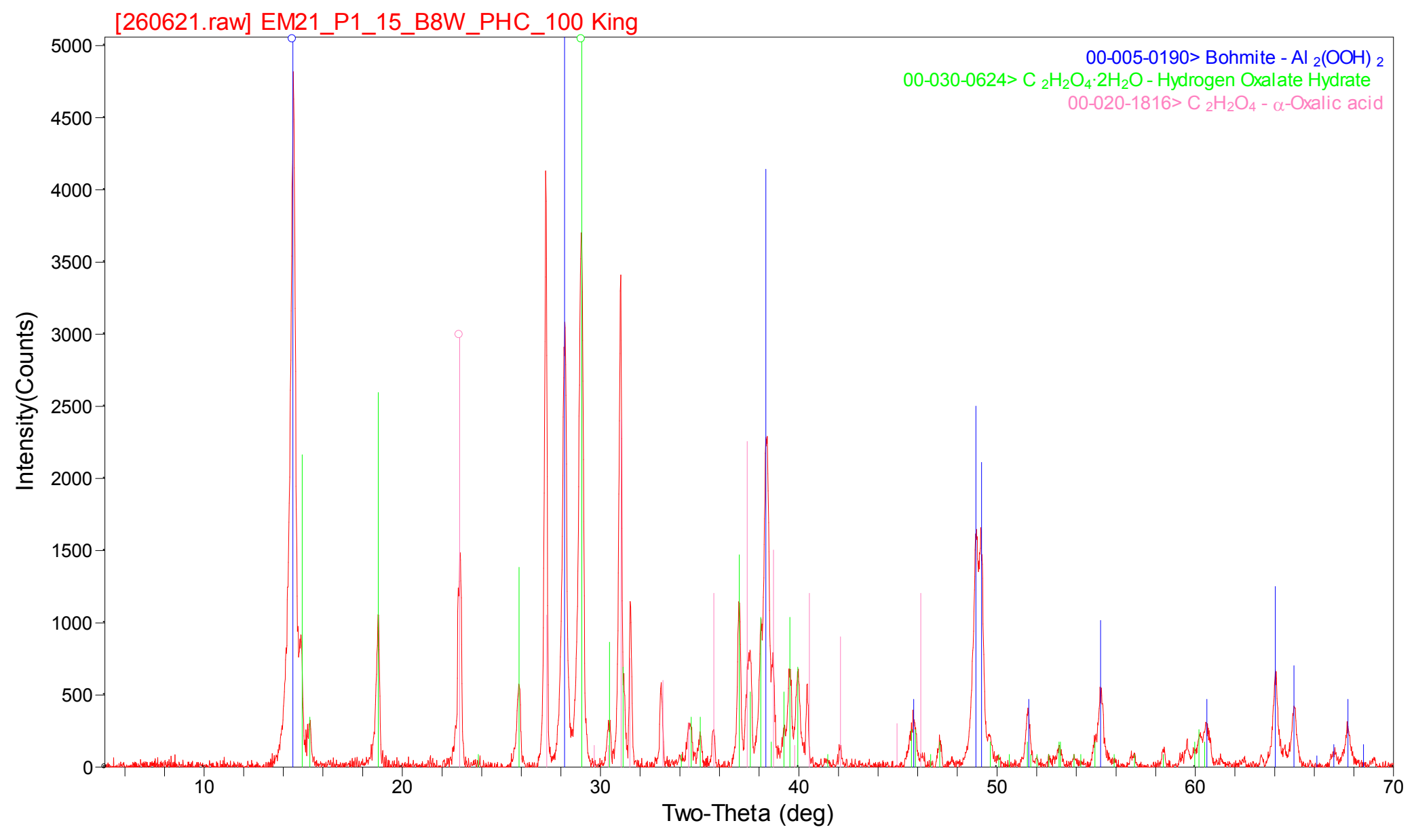

Figure 4.4 XRD Analysis of Residual Boehmite Solids After Contact with 8 wt. \% OA

$-42-$ 


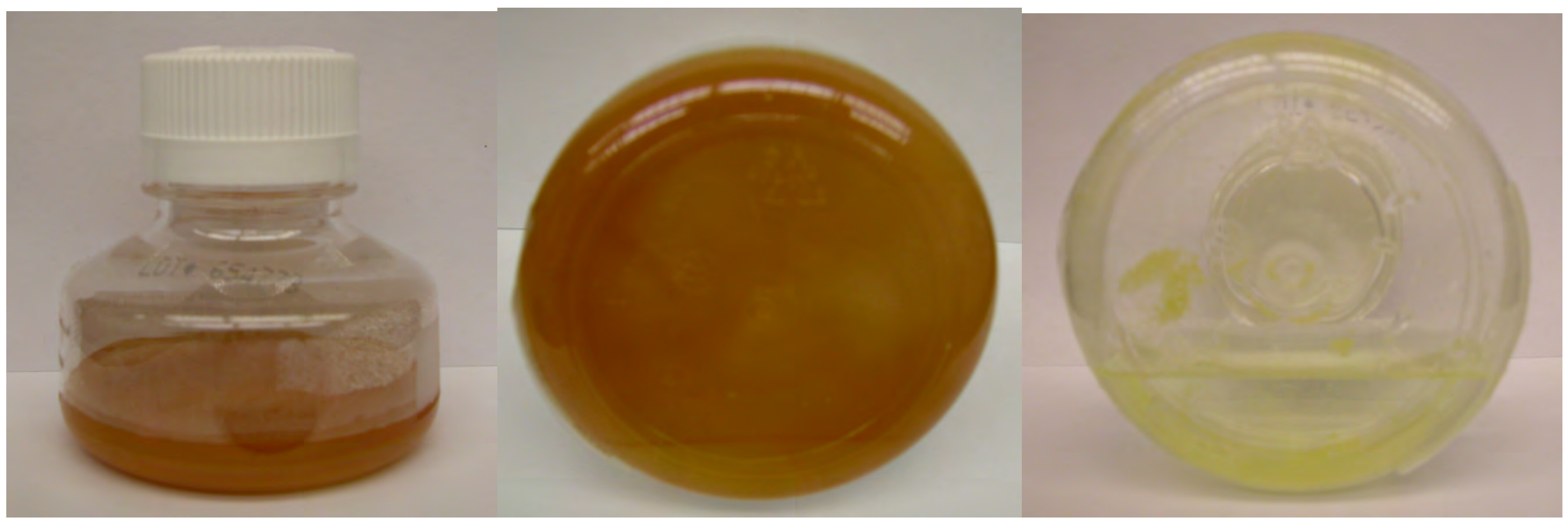

Figure 4.5 Solids formed after light exposure from $\mathrm{Fe}_{2}\left(\mathrm{C}_{2} \mathrm{O}_{4}\right)_{3}$ dissolved in water (left and center) and 8 wt. \% OA (right). 


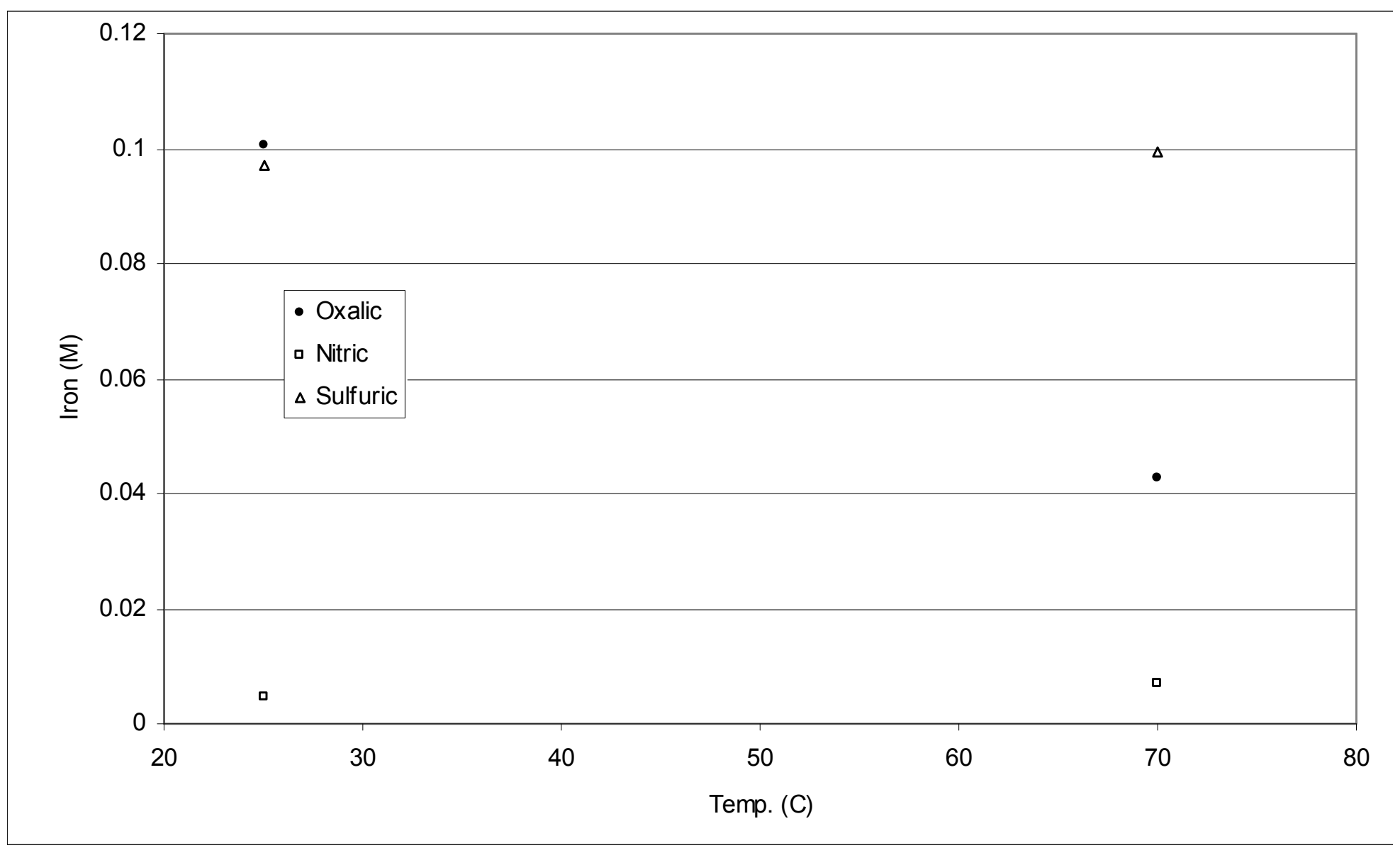

Figure 4.6 Magnetite Solubility in Various Acids versus Temperature.

$-44-$ 


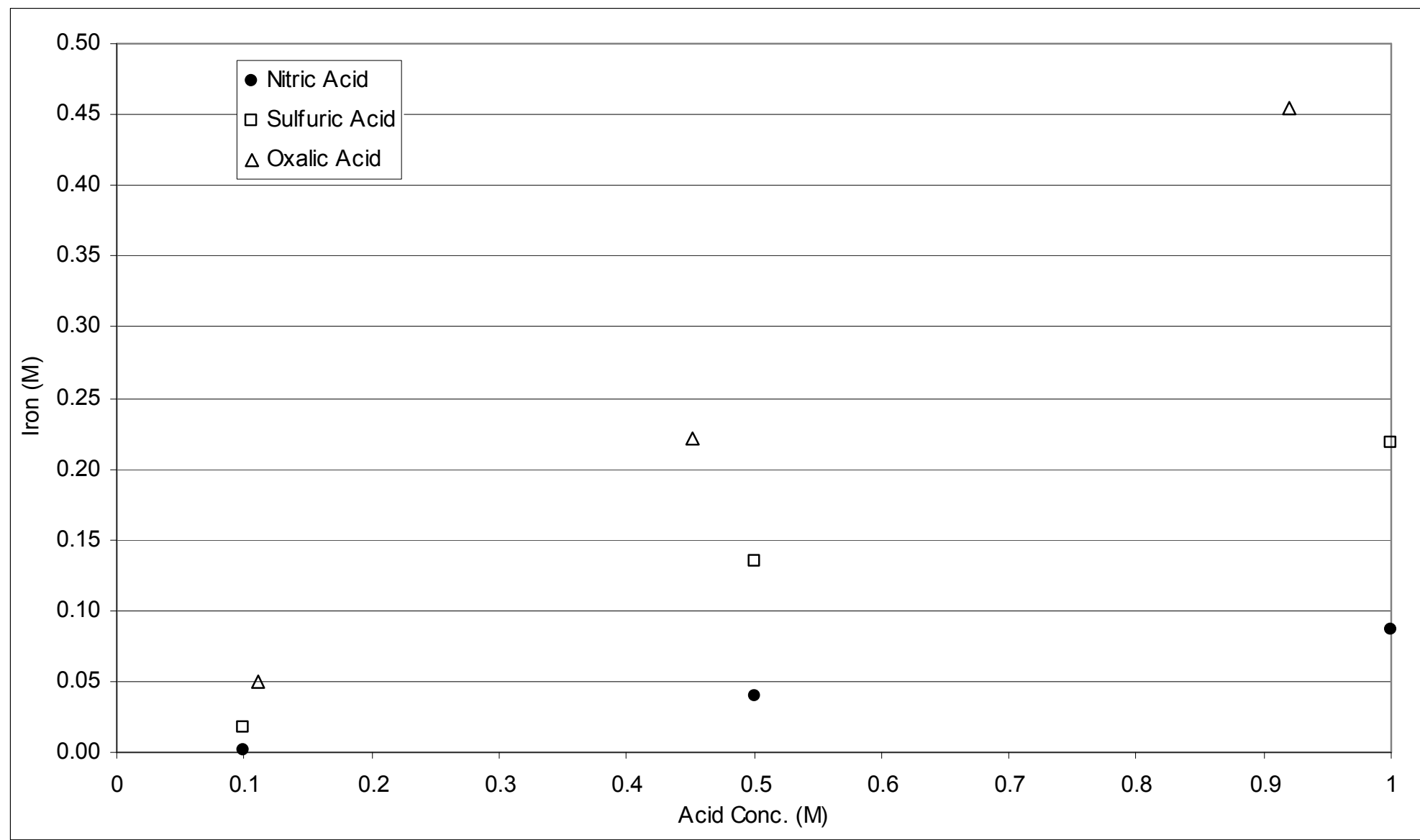

Figure 4.7 Hematite Solubility in Various Acids versus Concentration at $50{ }^{\circ} \mathrm{C}$ without pH Control.

$-45-$ 


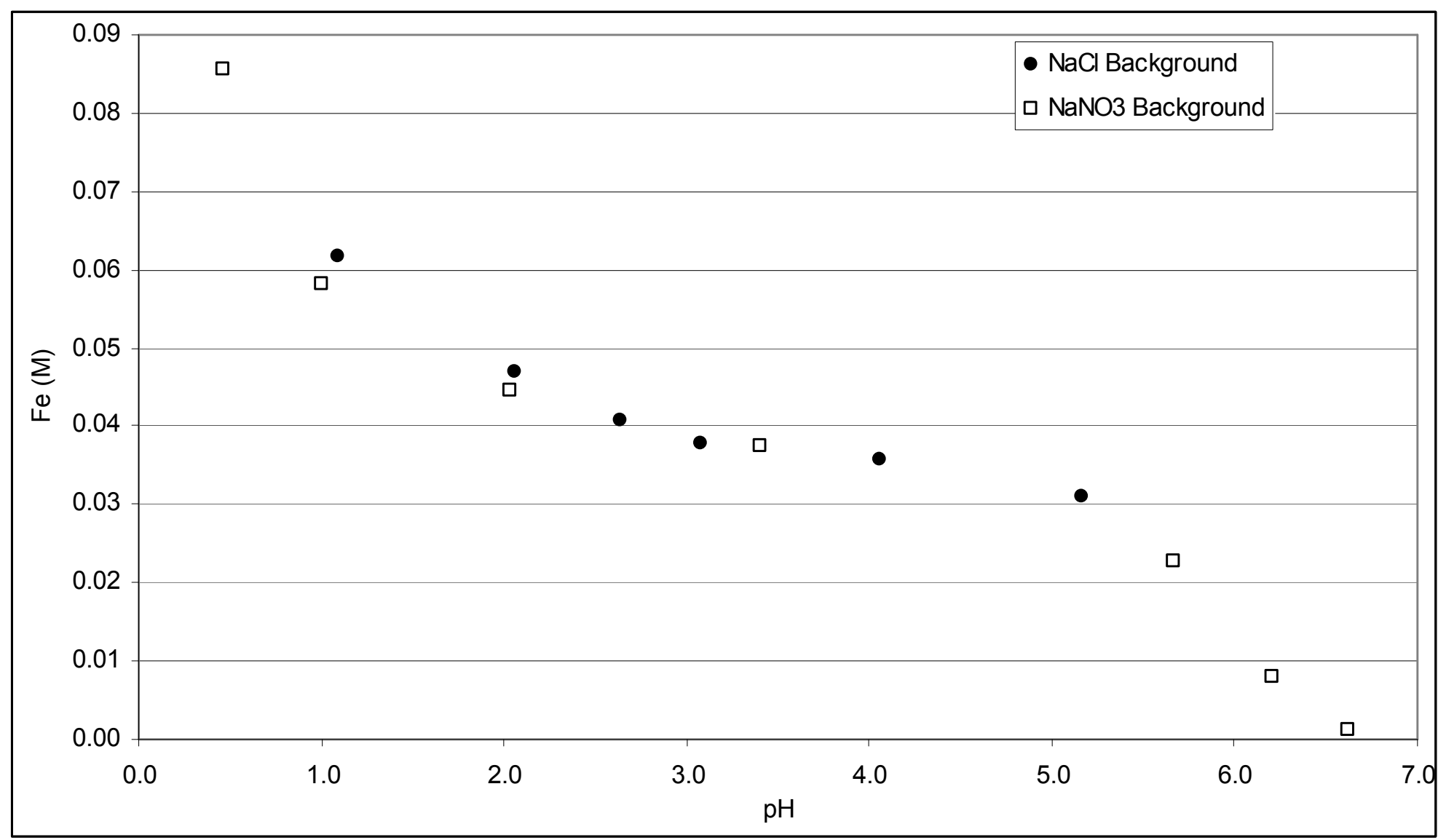

Figure 4.8 Hematite Solubility versus pH in 1 wt. \% Oxalic Acid 


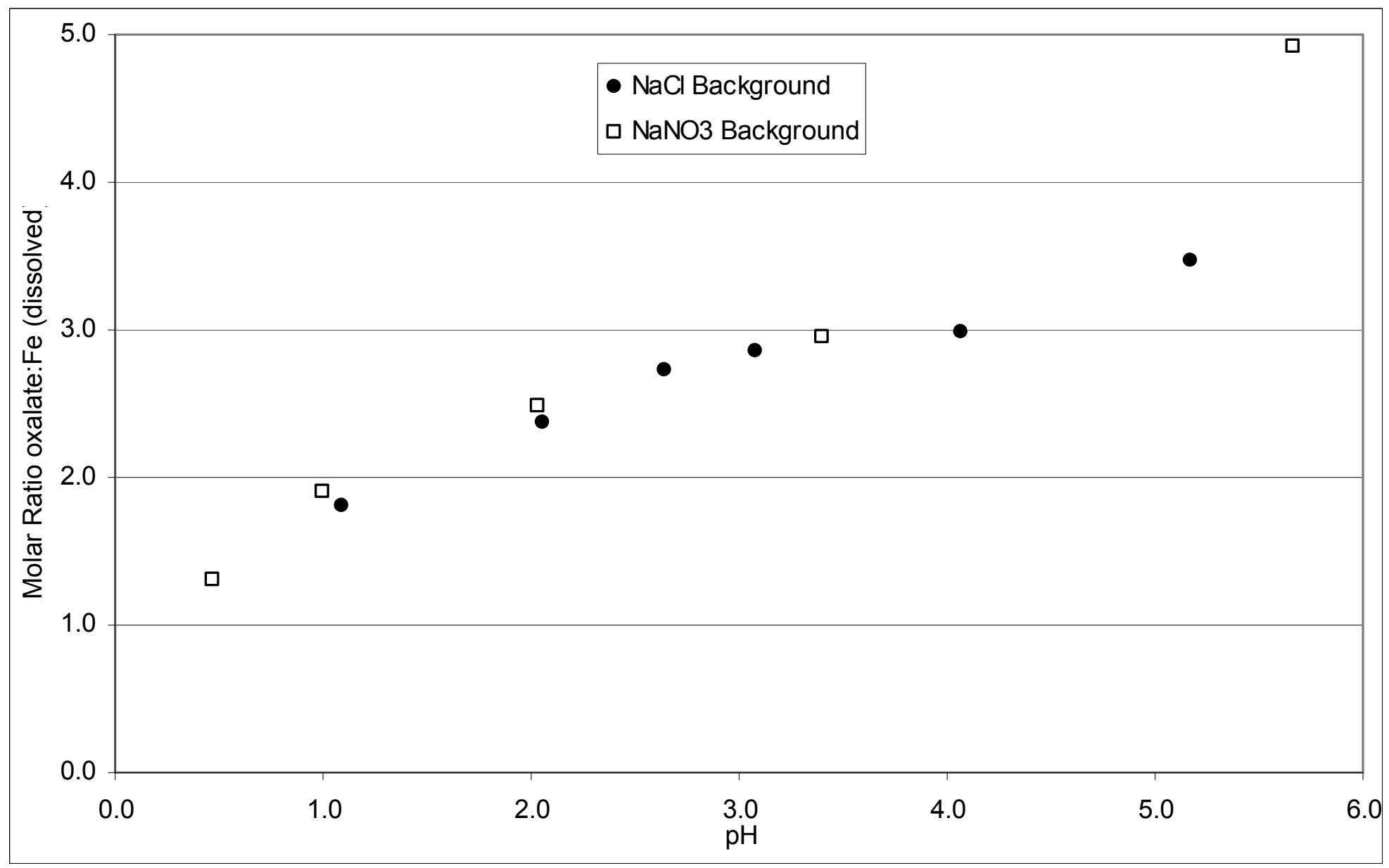

Figure 4.9 Soluble Oxalate:Iron Molar Ratio for Hematite versus pH in 1 wt. \% Oxalic Acid 


\subsection{THERMODYNAMIC MODELING OF SOLUBILITY TESTS}

A model was developed using the OLI Systems Inc, Environmental Simulation Program (ESP) version 8.1 to evaluate the ability of the software to predict the experimental results shown in Section 4.0. The model contained two sequential Mix blocks with the first block combining an acid solution stream with a solids only stream of the mineral phase of interest. The output of this first Mix block became an input to the second Mix block. The second Mix block allowed addition of an acid or base solution to adjust $\mathrm{pH}$ of the mixture from the first Mix block. Figure 5.1 shows a schematic of the ESP model. This model construct seemed the most direct way to simulate the methodology used in the experiments. The chemistry model for the simulations included the GEOCHEM database as the source for the iron compounds hematite and magnetite.

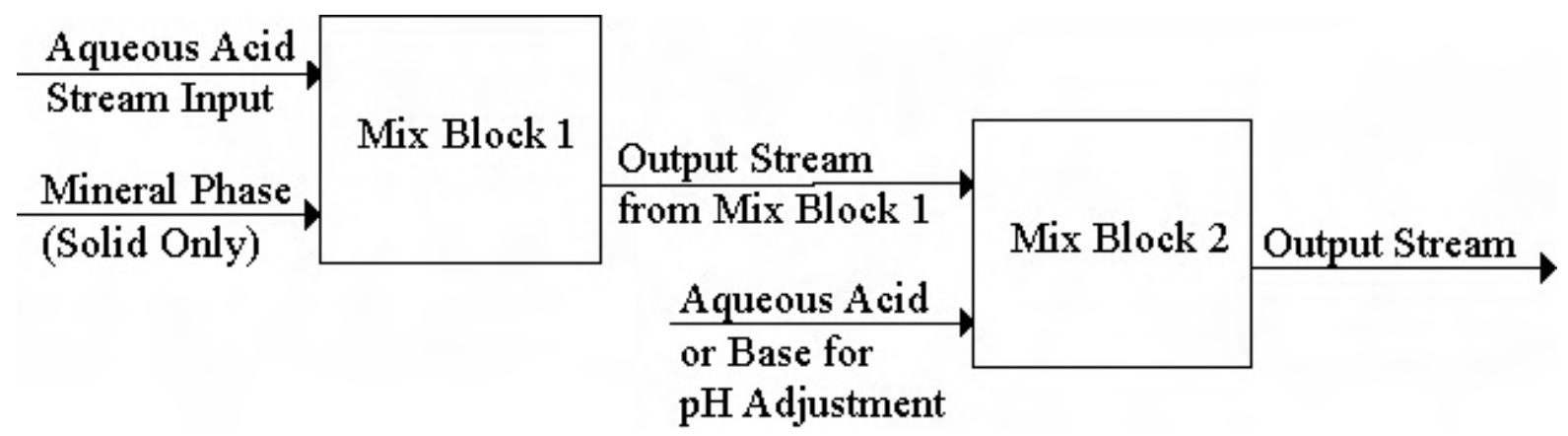

Figure 5.1 Schematic of ESP Model

\subsection{MODEL PREDICTIONS COMPARED TO EXPERIMENTAL DATA}

Tables 5.1 through 5.8 show the results of the thermodynamic modeling compared with the experimentally obtained data. In general the tests with oxalic acid and nitric acid used $3 \mathrm{M}$ nitric acid to control the $\mathrm{pH}$, while $3 \mathrm{M}$ sulfuric acid was used for the sulfuric acid test. Modeling results that show $100 \%$ dissolution do not reflect a solution composition saturated in iron. In some cases, additional solids were added during the modeling run to determine the saturated iron concentration.

Tables 5.1 through 5.4 compare the model predictions with the experimental data for a group of tests contacting $0.125 \mathrm{M}$ acids (oxalic acid, nitric acid, and sulfuric acid) with pure phases of hematite, magnetite, boehmite, and gibbsite while maintaining a $\mathrm{pH}$ of 1 . In all cases the model over-predicts the solubility of the pure metal phases in the acids. At least part of the explanation for the variance between the model predictions and the experimental data results from the considerably high solubility of the metal phases in nitric and sulfuric predicted by the model. Additionally, the $3 \mathrm{M}$ nitric acid and sulfuric acid added for $\mathrm{pH}$ control raised the 
nitric acid and sulfuric acid concentrations well above the $0.125 \mathrm{M}$ of the original acid solution.

In Table 5.5, hematite was contacted with three concentrations of nitric and sulfuric acid at $50{ }^{\circ} \mathrm{C}$ with no additional acid added for $\mathrm{pH}$ control. The model over-predicts the solubility of hematite in nitric acid at all three concentrations by a factor of $\sim 2$. The model predictions for the sulfuric acid tests under-predicted the iron concentration for the $0.125 \mathrm{M}$ sulfuric acid test and over-predicted the iron concentration for the $0.5 \mathrm{M}$ and $1 \mathrm{M}$ tests versus the experimental data.

Table 5.6 shows the predicted and experimentally derived solubility of hematite in three concentrations of oxalic acid with and without $\mathrm{pH}$ control at $50{ }^{\circ} \mathrm{C}$. Again, $3 \mathrm{M}$ nitric acid was used to control the $\mathrm{pH}$ of the oxalic acid solution. The model prediction for the soluble iron concentration from dissolved hematite in $0.11 \mathrm{M}$ oxalic acid of $0.071 \mathrm{M}$ shows reasonably good agreement with the experimentally determined concentration of $0.062 \mathrm{M}$. With the $\mathrm{pH}$ of the solution lowered to 1.0, the model predicts the soluble iron concentration increases to $0.106 \mathrm{M}$, again showing good agreement with the experimental value of $0.103 \mathrm{M}$ at a mass ratio of 38 . Additionally, at higher mass ratios with $0.11 \mathrm{M}$ oxalic acid, the model prediction versus experimental data shows good agreement with no $\mathrm{pH}$ control. With the $\mathrm{pH}$ controlled to 1 , the experimentally determined iron concentrations do not increase to $\sim 0.1 \mathrm{M}$ but remain at $\sim 0.060 \mathrm{M}$. At higher mass ratios, nearly all of the hematite was dissolved in the laboratory test $(80-92 \%$ dissolved). If some portion of the hematite material used in the experiments was more refractory, the data in Table 5.6 may indicate that the tests controlled to a $\mathrm{pH}$ of 1 simply ran out of dissolvable hematite at the higher mass ratios (i.e., when the $\%$ dissolved approached 90\%).

Tables 5.7 and 5.8 compare the model predictions to experimental data for tests investigating the effects of $\mathrm{pH}$ on hematite solubility in oxalic acid. The data shown in Table 5.7 represents a set of tests where a solution of defined $\mathrm{pH}$ was contacted with hematite at a mass ratio of 150 with no further acid additions to maintain a particular $\mathrm{pH}$. Table 5.8 contains data from identical tests using the same defined $\mathrm{pH}$ solutions; however, in this case the $\mathrm{pH}$ was controlled to a defined endpoint by the addition of $3 \mathrm{M}$ nitric acid. The modeling results agree well with the experimental data in both tables with the exception of a few points at low $\mathrm{pH}$ (i.e., where larger amounts of $3 \mathrm{M}$ nitric acid were added to obtain the desired $\mathrm{pH}$ ). Figures 5.1 and 5.2 show the model's prediction of the solubility of hematite in 1 and $8 \mathrm{wt} \%$ oxalic acid as a function of $\mathrm{pH}$. Figures 5.3 and 5.4 graphically show the data in Tables 5.7 and 5.8 respectively. As discussed in the previous section, these graphs emphasize the importance of $\mathrm{pH}$ control for the dissolution of iron-based sludge solids. 
Table 5.1 Comparison of Experimental Data with Modeling Results: Hematite Solubility in 0.125 M Acids at $25{ }^{\circ} \mathrm{C}$

\begin{tabular}{|c|c|c|c|c|c|c|c|c|c|}
\hline Acid & $\begin{array}{c}\text { Data } \\
\text { Source }\end{array}$ & $\begin{array}{c}\text { Temp. } \\
{ }^{\circ} \mathrm{C}\end{array}$ & $\begin{array}{c}\text { Initial } \\
\text { Acid } \\
\text { Conc. } \\
\text { M } \\
\end{array}$ & $\begin{array}{c}\text { Initial } \\
\text { Mass } \\
\text { Ratio } \\
\text { (liq./solid) }\end{array}$ & $\begin{array}{c}\text { Molar Ratio } \\
\text { Anion:Fe } \\
\text { (Dissolved) }\end{array}$ & $\begin{array}{c}\text { Final } \\
\text { Fe } \\
\text { Conc. } \\
\text { M } \\
\end{array}$ & $\begin{array}{c}\% \text { Fe } \\
\text { Dissolved }\end{array}$ & $\begin{array}{c}\text { Final } \\
\text { pH }\end{array}$ & $\begin{array}{c}\text { Acid Added } \\
\text { for pH } \\
(\mathrm{mmol})\end{array}$ \\
\hline Oxalic & Model & 25 & 0.125 & 100 & 1.1 & 0.114 & $100 \%$ & 1.00 & 13.8 \\
\hline Oxalic & Model & 25 & 0.125 & $63^{*}$ & 0.7 & 0.169 & $99.9 \%$ & 1.00 & 16.3 \\
\hline Oxalic & Experiment & 25 & 0.125 & 106 & 1.7 & 0.070 & $58.5 \%$ & 1.05 & 9.0 \\
\hline Nitric & Model & 25 & $0.125^{\mathrm{c}}$ & 100 & 5.0 & 0.074 & $64.0 \%$ & 1.00 & 13.9 \\
\hline Nitric & Experiment & 25 & 0.125 & 102 & 69 & 0.0026 & $2.1 \%$ & 1.00 & 3.0 \\
\hline Sulfuric & Model & 25 & 0.125 & 100 & 3.1 & 0.116 & $100 \%$ & 1.00 & 13.4 \\
\hline Sulfuric & Experiment & 25 & 0.125 & 102 & 4.9 & 0.037 & $29.9 \%$ & 1.14 & 3.4 \\
\hline
\end{tabular}

*Additional solids added to determine saturated iron concentration 
Table 5.2 Comparison of Experimental Data with Modeling Results: Magnetite Solubility in $0.125 \mathrm{M}^{\mathrm{Acids}}$ at $25^{\circ} \mathrm{C}$ and $70^{\circ} \mathrm{C}$

\begin{tabular}{|c|c|c|c|c|c|c|c|c|c|}
\hline Acid & $\begin{array}{c}\text { Data } \\
\text { Source }\end{array}$ & $\begin{array}{c}\text { Temp. } \\
{ }^{\circ} \mathrm{C}\end{array}$ & $\begin{array}{c}\text { Initial } \\
\text { Acid } \\
\text { Conc. } \\
\text { M } \\
\end{array}$ & $\begin{array}{c}\text { Initial } \\
\text { Mass } \\
\text { Ratio } \\
\text { (liq./solid) }\end{array}$ & $\begin{array}{c}\text { Molar Ratio } \\
\text { Anion:Fe } \\
\text { (Dissolved) }\end{array}$ & $\begin{array}{c}\text { Final } \\
\text { Fe } \\
\text { Conc. } \\
\text { M }\end{array}$ & $\begin{array}{c}\text { \%Fe } \\
\text { Dissolved }\end{array}$ & $\begin{array}{c}\text { Final } \\
\text { pH }\end{array}$ & $\begin{array}{c}\text { Acid } \\
\text { Added } \\
\text { for pH } \\
\text { (mmol) }\end{array}$ \\
\hline Oxalic & Model & 25 & 0.125 & 100 & 1.1 & 0.119 & $100.0 \%$ & 1.0 & 13.0 \\
\hline Oxalic & Model & 25 & 0.125 & $39 *$ & 0.5 & 0.257 & $99.9 \%$ & 1.0 & 16.1 \\
\hline Oxalic & Experiment & 25 & 0.125 & 100 & 1.1 & 0.101 & $84.0 \%$ & 1.2 & 10.8 \\
\hline Oxalic & Model & 70 & 0.125 & 100. & 1.0 & 0.117 & $100.0 \%$ & 1.0 & 13.0 \\
\hline Oxalic & Experiment & 70 & 0.125 & 115 & 2.8 & 0.043 & $39.4 \%$ & 1.3 & 6.1 \\
\hline Nitric & Model & 25 & 0.125 & $100^{\mathrm{c}}$ & 4.0 & 0.115 & $100.0 \%$ & 1.0 & 19.6 \\
\hline Nitric & Experiment & 25 & 0.125 & 100 & 34.5 & 0.0045 & $3.5 \%$ & 1.2 & 1.6 \\
\hline Nitric & Model & 70 & 0.125 & 100 & 5.4 & 0.042 & $34.6 \%$ & 1.0 & 5.8 \\
\hline Nitric & Experiment & 70 & 0.125 & 114 & 17.9 & 0.007 & $6.2 \%$ & 1.2 & 0.09 \\
\hline Sulfuric & Model & 25 & 0.125 & 100 & 2.8 & 0.120 & $100.0 \%$ & 1.0 & 12.2 \\
\hline Sulfuric & Experiment & 25 & 0.125 & 100 & 2.4 & 0.097 & $78.8 \%$ & 1.3 & 5.8 \\
\hline Sulfuric & Model & 70 & 0.125 & 100 & 3.1 & 0.116 & $100.0 \%$ & 1.0 & 13.4 \\
\hline Sulfuric & Experiment & 70 & 0.125 & 115 & 1.9 & 0.099 & $90.7 \%$ & 1.3 & 4.9 \\
\hline
\end{tabular}

*Additional solids added to determine saturated iron concentration 
SRNL-STI-2009-00791, REV. 0

Table 5.3 Comparison of Experimental Data with Modeling Results: Gibbsite Solubility in 0.125 M Acids at $25^{\circ} \mathrm{C}$ and $70^{\circ} \mathrm{C}$

\begin{tabular}{|c|c|c|c|c|c|c|c|c|c|}
\hline Acid & Data Source & $\begin{array}{c}\text { Temp. } \\
{ }^{\circ} \mathrm{C}\end{array}$ & $\begin{array}{c}\text { Initial } \\
\text { Acid } \\
\text { Conc. } \\
\text { M } \\
\end{array}$ & $\begin{array}{c}\text { Initial } \\
\text { Mass } \\
\text { Ratio } \\
\text { (liq./solid) } \\
\end{array}$ & $\begin{array}{c}\text { Molar Ratio } \\
\text { Anion:Al } \\
\text { (Dissolved) }\end{array}$ & $\begin{array}{c}\text { Final } \\
\text { Al } \\
\text { Conc. } \\
\text { M } \\
\end{array}$ & $\begin{array}{c}\text { \%Al } \\
\text { Dissolved }\end{array}$ & $\begin{array}{c}\text { Final } \\
\text { pH }\end{array}$ & $\begin{array}{c}\text { Acid } \\
\text { Added } \\
\text { for pH } \\
(\mathrm{mmol}) \\
\end{array}$ \\
\hline Oxalic & Model & 25 & 0.125 & 100 & 1.1 & 0.111 & $100.0 \%$ & 1.0 & 25.1 \\
\hline Oxalic & Experiment & 25 & 0.125 & 100 & 2.0 & 0.059 & $48.6 \%$ & 0.8 & 9.0 \\
\hline Oxalic & Model & 70 & 0.125 & 100 & 1.1 & 0.108 & $100.0 \%$ & 1.0 & 26.2 \\
\hline Oxalic & Experiment & 70 & 0.125 & 93 & 1.0 & 0.118 & $91.6 \%$ & 1.3 & 10.3 \\
\hline Nitric & Model & 25 & 0.125 & 100 & 4.4 & 0.112 & $100.0 \%$ & 1.0 & 21.7 \\
\hline Nitric & Experiment & 25 & 0.125 & 100 & 14.6 & 0.017 & $13.5 \%$ & 0.9 & 6.5 \\
\hline Nitric & Model & 70 & 0.125 & 100 & 4.5 & 0.110 & $100.0 \%$ & 1.0 & 22.3 \\
\hline Nitric & Experiment & 70 & 0.125 & 113 & 3.3 & 0.087 & $81.8 \%$ & 1.2 & 9.1 \\
\hline Sulfuric & Model & 25 & 0.125 & 100 & 2.8 & 0.119 & $100.0 \%$ & 1.0 & 11.8 \\
\hline Sulfuric & Experiment & 25 & 0.125 & 100 & 4.3 & 0.061 & $50.0 \%$ & 0.9 & 7.6 \\
\hline Sulfuric & Model & 70 & 0.125 & 100 & 3.4 & 0.114 & $100.0 \%$ & 1.0 & 15.3 \\
\hline Sulfuric & Experiment & 70 & 0.125 & 70 & 1.6 & 0.191 & $111.4 \%$ & 1.4 & 9.6 \\
\hline
\end{tabular}


SRNL-STI-2009-00791, REV. 0

Table 5.4 Comparison of Experimental Data with Modeling Results: Boehmite Solubility in 0.125 M Acids at $25^{\circ} \mathrm{C}$ and $70{ }^{\circ} \mathrm{C}$

\begin{tabular}{|l|c|c|c|c|c|c|c|c|c|}
\hline Acid & Data Source & $\begin{array}{c}\text { Temp. } \\
\mathbf{}_{\mathbf{O}} \mathbf{C}\end{array}$ & $\begin{array}{c}\text { Initial } \\
\text { Acid } \\
\text { Conc. } \\
\mathbf{M}\end{array}$ & $\begin{array}{c}\text { Initial } \\
\text { Mass } \\
\text { Ratio } \\
\text { (liq./solid) }\end{array}$ & $\begin{array}{c}\text { Molar Ratio } \\
\text { Anion:Al } \\
\text { (Dissolved) }\end{array}$ & $\begin{array}{c}\text { Final } \\
\text { Al } \\
\text { Conc. } \\
\mathbf{M}\end{array}$ & $\begin{array}{c}\text { Acid } \\
\text { \%Al } \\
\text { Dissolved }\end{array}$ & $\begin{array}{c}\text { Final } \\
\text { pH }\end{array}$ & $\begin{array}{c}\text { Added } \\
\text { for pH } \\
\text { (mmol) }\end{array}$ \\
\hline Oxalic & Model & 25 & 0.125 & 100 & 0.9 & 0.140 & $100.0 \%$ & 1.0 & 31.1 \\
\hline Oxalic & Experiment & 25 & 0.125 & 100 & 72.7 & 0.0017 & $1.0 \%$ & 1.3 & 4.8 \\
\hline Oxalic & Model & 70 & 0.125 & 100 & 0.9 & 0.136 & $100.0 \%$ & 1.0 & 32.4 \\
\hline Oxalic & Experiment & 70 & 0.125 & 104 & 1.4 & 0.091 & $58.0 \%$ & 1.3 & 2.5 \\
\hline Nitric & Model & 25 & 0.125 & 100 & 4.1 & 0.141 & $100.0 \%$ & 1.0 & 27.9 \\
\hline Nitric & Experiment & 25 & 0.125 & 100 & 394.9 & 0.0003 & $0.2 \%$ & 1.3 & 0 \\
\hline Nitric & Model & 70 & 0.125 & 100 & 4.2 & 0.138 & $100.0 \%$ & 1.0 & 28.6 \\
\hline Nitric & Experiment & 70 & 0.125 & 105 & 13.7 & 0.0091 & $5.7 \%$ & 1.2 & 0 \\
\hline Sulfuric & Model & 25 & 0.125 & 100 & 2.6 & 0.151 & $100.0 \%$ & 1.0 & 15.3 \\
\hline Sulfuric & Experiment & 25 & 0.125 & 100 & 93.2 & 0.0014 & $0.5 \%$ & 1.3 & 0.2 \\
\hline Sulfuric & Model & 70 & 0.125 & 100 & 3.1 & 0.145 & $100.0 \%$ & 1.0 & 19.5 \\
\hline Sulfuric & Experiment & 70 & 0.125 & 105 & 2.3 & 0.054 & $34.1 \%$ & 1.3 & 0 \\
\hline
\end{tabular}


Table 5.5 Comparison of Experimental Data with Modeling Results: Hematite Solubility in Nitric and Sulfuric Acids at Constant Phase Ratios at $25^{\circ} \mathrm{C}$ and $70{ }^{\circ} \mathrm{C}$

\begin{tabular}{|l|c|c|c|c|c|c|c|}
\hline & & Temp. & $\begin{array}{c}\text { Initial } \\
\text { Acid } \\
\text { Conc. } \\
\text { Acid }\end{array}$ & $\begin{array}{c}\text { Initial } \\
\text { Mass } \\
\text { Ratio } \\
\text { (liq./solid) }\end{array}$ & $\begin{array}{c}\text { Final } \\
\text { Fe } \\
\text { Conc. } \\
\text { M }\end{array}$ & $\begin{array}{c}\text { MFe } \\
\text { Dissolved }\end{array}$ & $\begin{array}{c}\text { Final } \\
\text { pH }\end{array}$ \\
\hline Nitric & Model & 50 & 0.125 & 100 & 0.003 & $2.1 \%$ & 1.1 \\
\hline Nitric & Experiment & 50 & 0.125 & 101 & 0.0017 & $1.4 \%$ & 1.0 \\
\hline Nitric & Model & 50 & 0.5 & 100 & 0.069 & $54.8 \%$ & 0.7 \\
\hline Nitric & Experiment & 50 & 0.5 & 101 & 0.039 & $31.3 \%$ & 0.5 \\
\hline Nitric* & Model & 50 & 1.0 & 65 & 0.194 & $99.9 \%$ & 0.6 \\
\hline Nitric & Experiment & 50 & 1.0 & 101 & 0.086 & $66.8 \%$ & 0.2 \\
\hline Sulfuric & Model & 50 & 0.125 & 100 & 0.008 & $6.2 \%$ & 1.0 \\
\hline Sulfuric & Experiment & 50 & 0.125 & 100 & 0.017 & $13.5 \%$ & 1.2 \\
\hline Sulfuric* & Model & 50 & 0.5 & 85 & 0.151 & $99.9 \%$ & 1.0 \\
\hline Sulfuric & Experiment & 50 & 0.5 & 80 & 0.135 & $83.8 \%$ & 0.8 \\
\hline Sulfuric* & Model & 50 & 1.0 & 34 & 0.383 & $99.9 \%$ & 1.0 \\
\hline Sulfuric & Experiment & 50 & 1.0 & 51 & 0.218 & $83.1 \%$ & 0.6 \\
\hline
\end{tabular}

* Initial mass ratio was 100 for all experiments and modeling runs. Additional hematite solids were added in some cases to determine the saturated iron concentration. 
SRNL-STI-2009-00791, REV. 0

Table 5.6 Comparison of Experimental Data with Modeling Results: Hematite Solubility in Oxalic Acid with Varying Phase/Molar Ratios at $50{ }^{\circ} \mathrm{C}$ with and without $\mathrm{pH}$ Control

\begin{tabular}{|c|c|c|c|c|c|c|c|c|}
\hline $\begin{array}{c}\text { Initial } \\
\text { Acid Conc. } \\
\mathbf{M} \\
\end{array}$ & Data Source & $\begin{array}{c}\text { pH } \\
\text { Control? }\end{array}$ & $\begin{array}{c}\text { Initial } \\
\text { Mass Ratio } \\
\text { (liq./solid) }\end{array}$ & $\begin{array}{c}\text { Molar Ratio } \\
\text { Anion:Fe } \\
\text { (Dissolved) }\end{array}$ & $\begin{array}{c}\text { Final } \\
\text { Fe Conc. } \\
M \\
\end{array}$ & $\begin{array}{c}\text { \%Fe } \\
\text { Dissolved }\end{array}$ & $\begin{array}{c}\text { Final } \\
\text { pH }\end{array}$ & $\begin{array}{c}\text { Acid Added } \\
\text { for pH } \\
(\mathrm{mmol})\end{array}$ \\
\hline 0.11 & Model & No & 38 & 1.6 & 0.071 & $21.6 \%$ & 2.2 & 0.0 \\
\hline 0.11 & Experiment & No & 38 & 1.8 & 0.062 & $18.4 \%$ & 1.8 & 0.0 \\
\hline 0.11 & Model & Yes & 38 & 1.1 & 0.106 & $35.0 \%$ & 1.0 & 5.2 \\
\hline 0.11 & Experiment & Yes & 38 & 0.9 & 0.103 & $36.6 \%$ & 0.9 & 10.5 \\
\hline 0.11 & Model & No & 150 & 1.6 & 0.071 & $85.9 \%$ & 2.2 & 0.0 \\
\hline 0.11 & Experiment & No & 150 & 1.9 & 0.059 & $70.2 \%$ & 1.5 & 0.0 \\
\hline 0.11 & Model & Yes & $107 *$ & 1.1 & 0.106 & $99.8 \%$ & 1.0 & 10.4 \\
\hline 0.11 & Experiment & Yes & 150 & 1.6 & 0.063 & $81.3 \%$ & 1.0 & 10.5 \\
\hline 0.11 & Model & No & $174^{*}$ & 1.6 & 0.071 & $99.9 \%$ & 2.2 & 0.0 \\
\hline 0.11 & Experiment & No & $210 *$ & 2.2 & 0.052 & $87.1 \%$ & 1.4 & 0.0 \\
\hline 0.11 & Model & Yes & $107 *$ & 1.1 & 0.106 & $99.9 \%$ & 1.0 & 21.0 \\
\hline 0.11 & Experiment & Yes & $228 *$ & 2.1 & 0.050 & $89.9 \%$ & 0.9 & 13.5 \\
\hline 0.45 & Model & No & $43 *$ & 1.5 & 0.294 & $99.98 \%$ & 2.0 & 0.0 \\
\hline 0.45 & Experiment & No & $53 *$ & 2.0 & 0.222 & $91.1 \%$ & 1.0 & 0.0 \\
\hline 0.45 & Model & Yes & $28 *$ & 1.2 & 0.369 & $99.99 \%$ & 1.0 & 24.1 \\
\hline 0.45 & Experiment & Yes & $54 *$ & 2.1 & 0.219 & $91.7 \%$ & 0.9 & 0.75 \\
\hline 0.92 & Model & No & $22 *$ & 1.6 & 0.596 & $99.97 \%$ & 1.9 & 0.0 \\
\hline 0.92 & Experiment & No & $26^{*}$ & 2.0 & 0.454 & $92.1 \%$ & 0.8 & 0.0 \\
\hline 0.92 & Model & Yes & 14 & 1.4 & 0.645 & $99.99 \%$ & 1.0 & 20.2 \\
\hline
\end{tabular}

* Initial mass ratios changed due to the addition of hematite solids to determine the saturated iron concentration. 
Table 5.7 Comparison of Experimental Data with Modeling Results: Hematite Solubility in 1 wt\% Oxalic Acid with NaNO Background Salt and Constant Phase Ratio Over a Range of $\mathrm{pH}$ at $50{ }^{\circ} \mathrm{C}$

\begin{tabular}{|c|c|c|c|c|c|c|c|c|c|}
\hline Acid & Data Source & $\begin{array}{c}\text { Initial } \\
{\left[\mathrm{Na}^{+}\right]} \\
\text {Conc. } \\
\mathrm{M} \\
\end{array}$ & $\begin{array}{c}\text { Initial } \\
{\left[\mathrm{OH}^{-}\right]} \\
\text {Conc. } \\
\mathrm{M} \\
\end{array}$ & $\begin{array}{c}\text { Initial } \\
{\left[\mathrm{NO}_{3}^{-}\right]} \\
\text {Conc. } \\
\mathrm{M} \\
\end{array}$ & $\begin{array}{c}\text { Initial } \\
\text { Mass } \\
\text { Ratio } \\
\text { (liq./solid) }\end{array}$ & $\begin{array}{c}\text { Molar Ratio } \\
\text { Anion:Fe } \\
\text { (Dissolved) }\end{array}$ & $\begin{array}{c}\text { Final Fe } \\
\text { Conc. } \\
\mathbf{M} \\
\end{array}$ & $\begin{array}{c}\% \text { Fe } \\
\text { Dissolved }\end{array}$ & $\begin{array}{c}\text { Final } \\
\text { pH }\end{array}$ \\
\hline Oxalic & Model & 0.220 & 0.00 & 0.72 & 150 & 1.3 & 0.085 & $100.0 \%$ & 0.5 \\
\hline Oxalic & Model & 0.220 & 0.00 & 0.72 & $84^{*}$ & 0.7 & 0.151 & $99.9 \%$ & 0.7 \\
\hline Oxalic & Experiment & 0.22 & 0.00 & 0.72 & 150 & 1.3 & 0.086 & $84.5 \%$ & 0.5 \\
\hline Oxalic & Model & 0.219 & 0.00 & 0.219 & 150 & 1.6 & 0.071 & $84.5 \%$ & 2.2 \\
\hline Oxalic & Experiment & 0.22 & 0.00 & 0.22 & 151 & 1.9 & 0.058 & $69.2 \%$ & 1.0 \\
\hline Oxalic & Model & 0.218 & 0.083 & 0.135 & 150 & 2.4 & 0.046 & $54.3 \%$ & 2.9 \\
\hline Oxalic & Experiment & 0.22 & 0.08 & 0.13 & 152 & 2.5 & 0.045 & $53.7 \%$ & 2.0 \\
\hline Oxalic & Model & 0.219 & 0.110 & 0.110 & 150 & 3.0 & 0.038 & $44.8 \%$ & 3.9 \\
\hline Oxalic & Experiment & 0.22 & 0.11 & 0.11 & 151 & 3.0 & 0.038 & $44.9 \%$ & 3.4 \\
\hline Oxalic & Experiment & 0.22 & 0.15 & 0.07 & 151 & 4.9 & 0.023 & $27.0 \%$ & 5.7 \\
\hline Oxalic & Model & 0.219 & 0.197 & 0.022 & 150 & 13.4 & 0.008 & $9.9 \%$ & 6.4 \\
\hline Oxalic & Experiment & 0.22 & 0.20 & 0.02 & 151 & 13.8 & 0.008 & $9.7 \%$ & 6.2 \\
\hline Oxalic & Model & 0.219 & 0.219 & 0.00 & 150 & 114.0 & 0.001 & $1.2 \%$ & 6.8 \\
\hline Oxalic & Experiment & 0.22 & 0.22 & 0.00 & 151 & 83.9 & 0.001 & $1.6 \%$ & 6.6 \\
\hline
\end{tabular}

*Additional solids added to determine saturated Fe concentration 
Table 5.8 Comparison of Experimental Data with Modeling Results: Hematite Solubility in 1 wt\% Oxalic Acid with NaCl Background Salt and Constant Phase Ratio Over a Range of $\mathrm{pH}$ at $50{ }^{\circ} \mathrm{C}$

\begin{tabular}{|c|c|c|c|c|c|c|c|c|c|c|}
\hline Acid & Data Source & $\begin{array}{c}\text { Initial } \\
{\left[\mathrm{Na}^{+}\right]} \\
\text {Conc. } \\
\mathrm{M}\end{array}$ & $\begin{array}{c}\text { Initial } \\
\text { [OH'] } \\
\text { Conc. } \\
\text { M }\end{array}$ & $\begin{array}{c}\text { Initial } \\
{\left[\mathrm{Cl}^{-}\right]} \\
\text {Conc. } \\
\mathrm{M}\end{array}$ & $\begin{array}{c}\text { Initial } \\
\text { Mass } \\
\text { Ratio } \\
\text { (liq./solid) }\end{array}$ & $\begin{array}{c}\text { Molar Ratio } \\
\text { Anion:Fe } \\
\text { (Dissolved) }\end{array}$ & $\begin{array}{c}\text { Final Fe } \\
\text { Conc. } \\
\mathbf{M}\end{array}$ & $\begin{array}{c}\text { \%Fe } \\
\text { Dissolved }\end{array}$ & $\begin{array}{c}\text { Final } \\
\text { pH }\end{array}$ & $\begin{array}{c}\text { Added } \\
\text { Acid for } \\
\text { pH } \\
\text { (mmol) }\end{array}$ \\
\hline Oxalic & Model & 0.219 & 0.00 & 0.219 & 150 & 1.4 & 0.079 & $100 \%$ & 1.0 & 18.2 \\
\hline Oxalic & Model & 0.219 & 0.00 & 0.219 & $108 *$ & 1.1 & 0.106 & $99.9 \%$ & 1.0 & 20.2 \\
\hline Oxalic & Experiment & 0.22 & 0.00 & 0.22 & 148 & 1.8 & 0.062 & $71.9 \%$ & 1.1 & 0.0 \\
\hline Oxalic & Model & 0.218 & 0.083 & 0.135 & 150 & 1.4 & 0.080 & $100 \%$ & 2.0 & 12.7 \\
\hline Oxalic & Model & 0.218 & 0.083 & 0.135 & $146^{*}$ & 1.4 & 0.082 & $99.9 \%$ & 2.0 & 13.0 \\
\hline Oxalic & Experiment & 0.22 & 0.08 & 0.14 & 148 & 2.4 & 0.047 & $54.9 \%$ & 2.1 & 0.0 \\
\hline Oxalic & Model & 0.219 & 0.11 & 0.11 & 150 & 2.0 & 0.055 & $67.3 \%$ & 2.5 & 6.1 \\
\hline Oxalic & Experiment & 0.22 & 0.11 & 0.11 & 150 & 2.7 & 0.041 & $48.5 \%$ & 2.7 & 0.4 \\
\hline Oxalic & Model & 0.219 & 0.153 & 0.066 & 150 & 2.6 & 0.043 & $52.0 \%$ & 3.0 & 6.3 \\
\hline Oxalic & Experiment & 0.22 & 0.15 & 0.07 & 153 & 2.9 & 0.038 & $45.7 \%$ & 3.1 & 2.2 \\
\hline Oxalic & Model & 0.219 & 0.197 & 0.022 & 150 & 3.1 & 0.036 & $44.8 \%$ & 4.0 & 8.8 \\
\hline Oxalic & Experiment & 0.22 & 0.20 & 0.02 & 154 & 3.0 & 0.036 & $43.7 \%$ & 4.1 & 4.0 \\
\hline Oxalic & Model & 0.219 & 0.219 & 0.00 & 150 & 3.3 & 0.034 & $42.2 \%$ & 5.0 & 10.3 \\
\hline Oxalic & Experiment & 0.22 & 0.22 & 0.00 & 152 & 3.5 & 0.031 & $37.5 \%$ & 5.2 & 3.6 \\
\hline
\end{tabular}

*Additional solids added to determine saturated Fe concentration 
Hematite Solubility in $1 \mathrm{wt} \%$ Oxalic Acid as a Function of pH

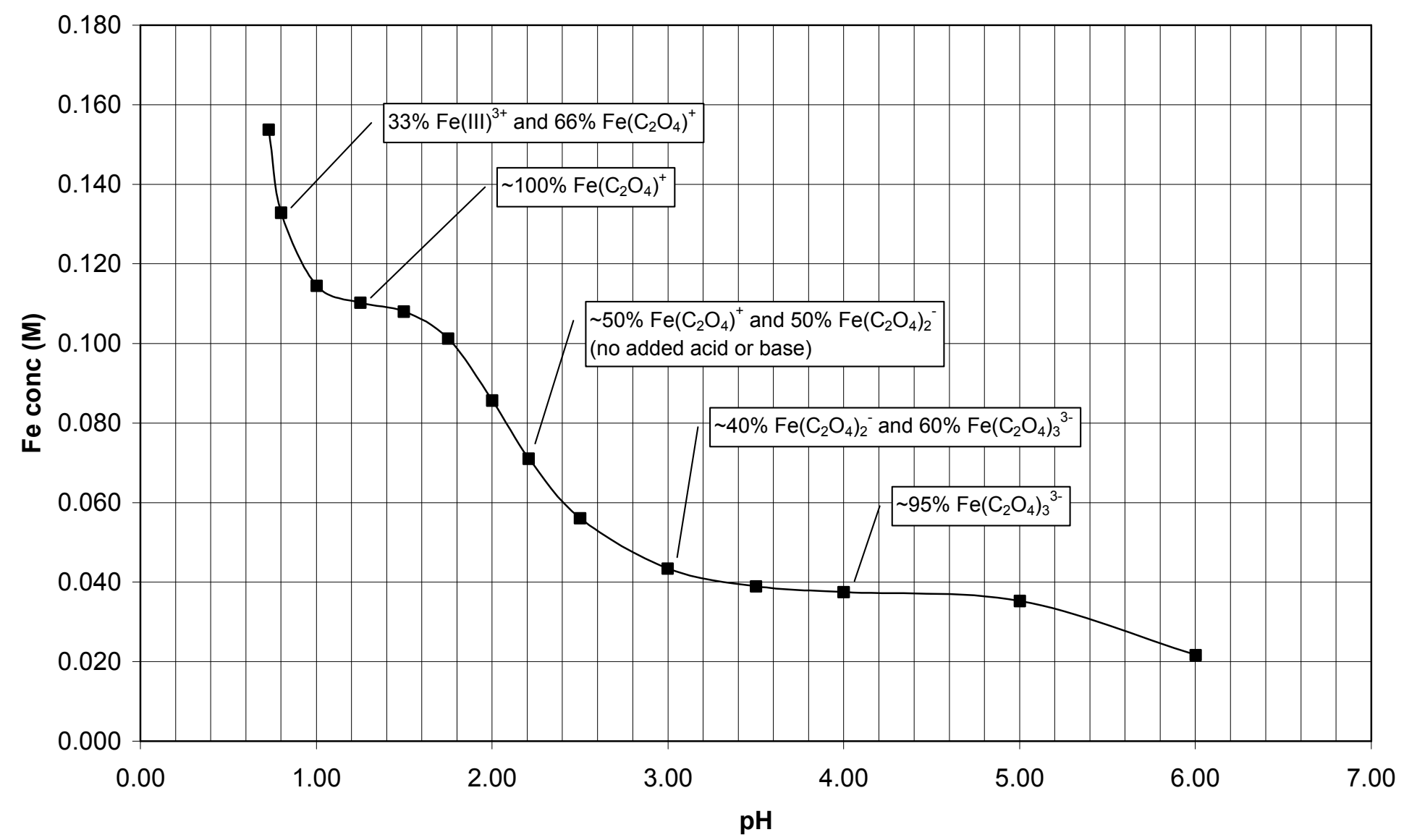

Figure 5.2 Model Predictions of Hematite Solubility in 1 wt\% Oxalic Acid 


\section{Hematite Solubility in $\mathbf{8} \mathbf{w t} \%$ Oxalic Acid as a Function of $\mathrm{pH}$}

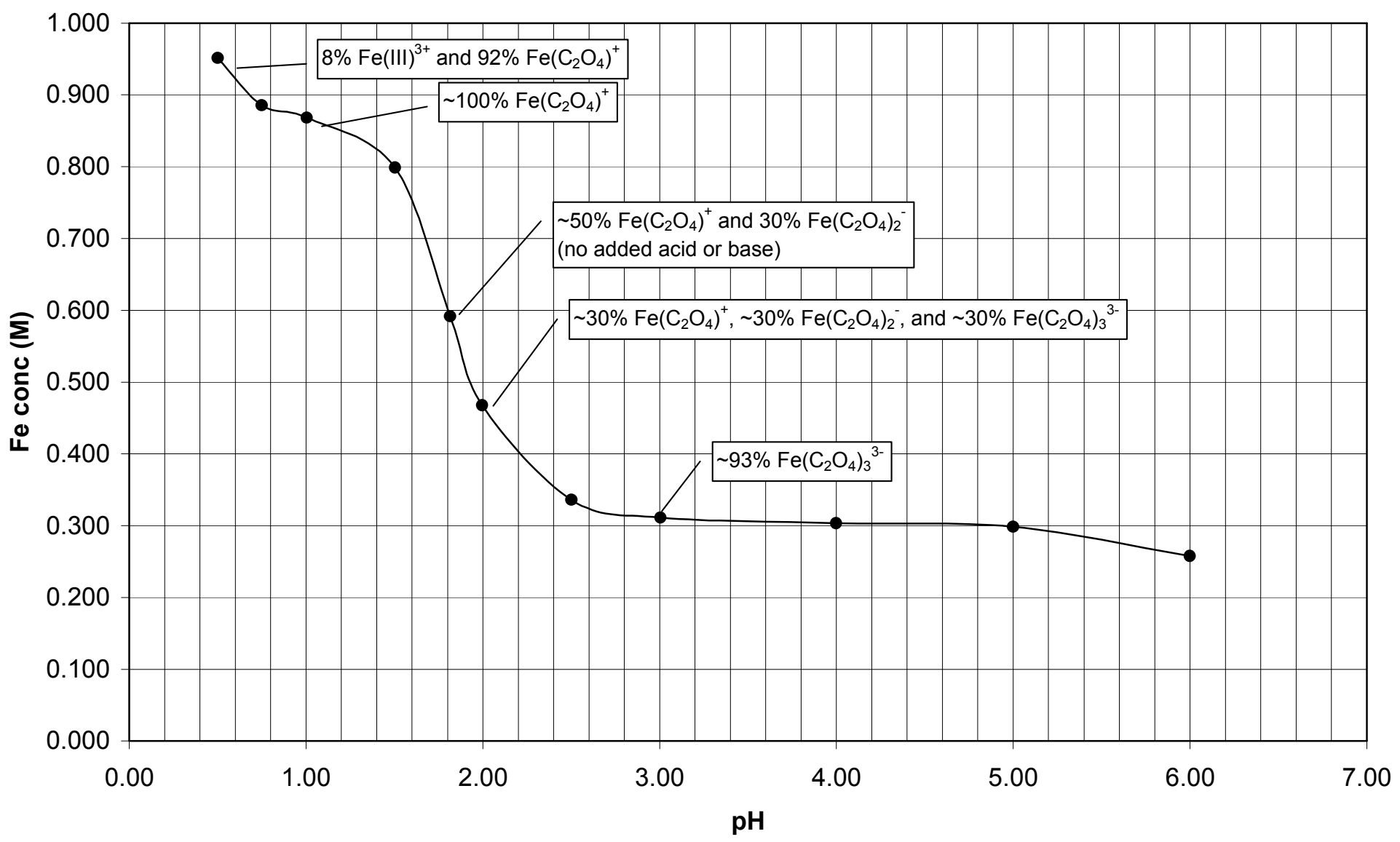

Figure 5.3 Model Predictions of Hematite Solubility in 8 wt\% Oxalic Acid 
Hematite Solubility in $1 \mathrm{wt} \%$ Oxalic Acid as a Function of $\mathrm{pH}$

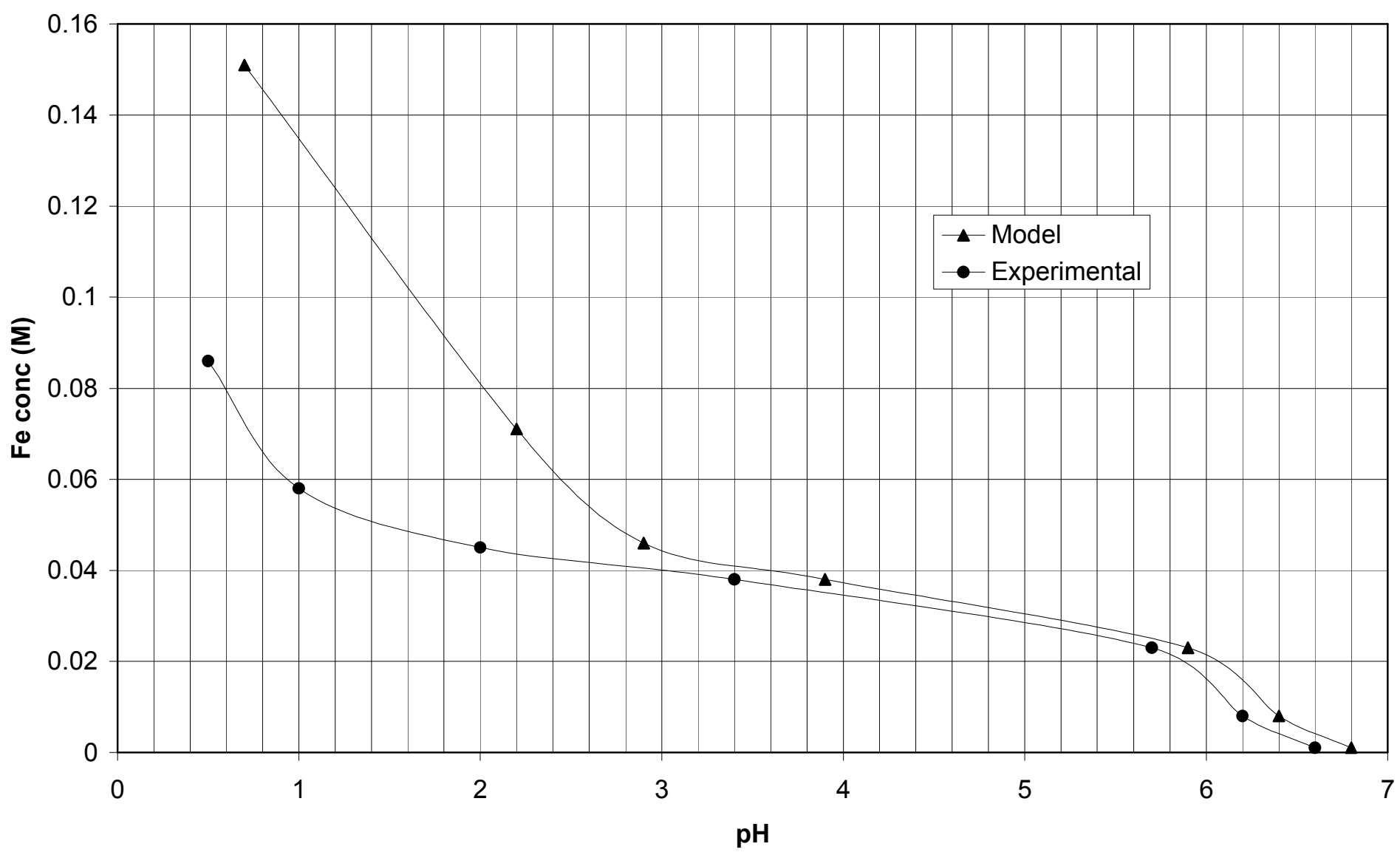

Figure 5.4 Hematite Solubility in 1 wt\% Oxalic Acid-Model Predictions and Experimental Data-No pH Control 
Hematite Solubility in $1 \mathrm{wt} \%$ Oxalic Acid as a Function of pH

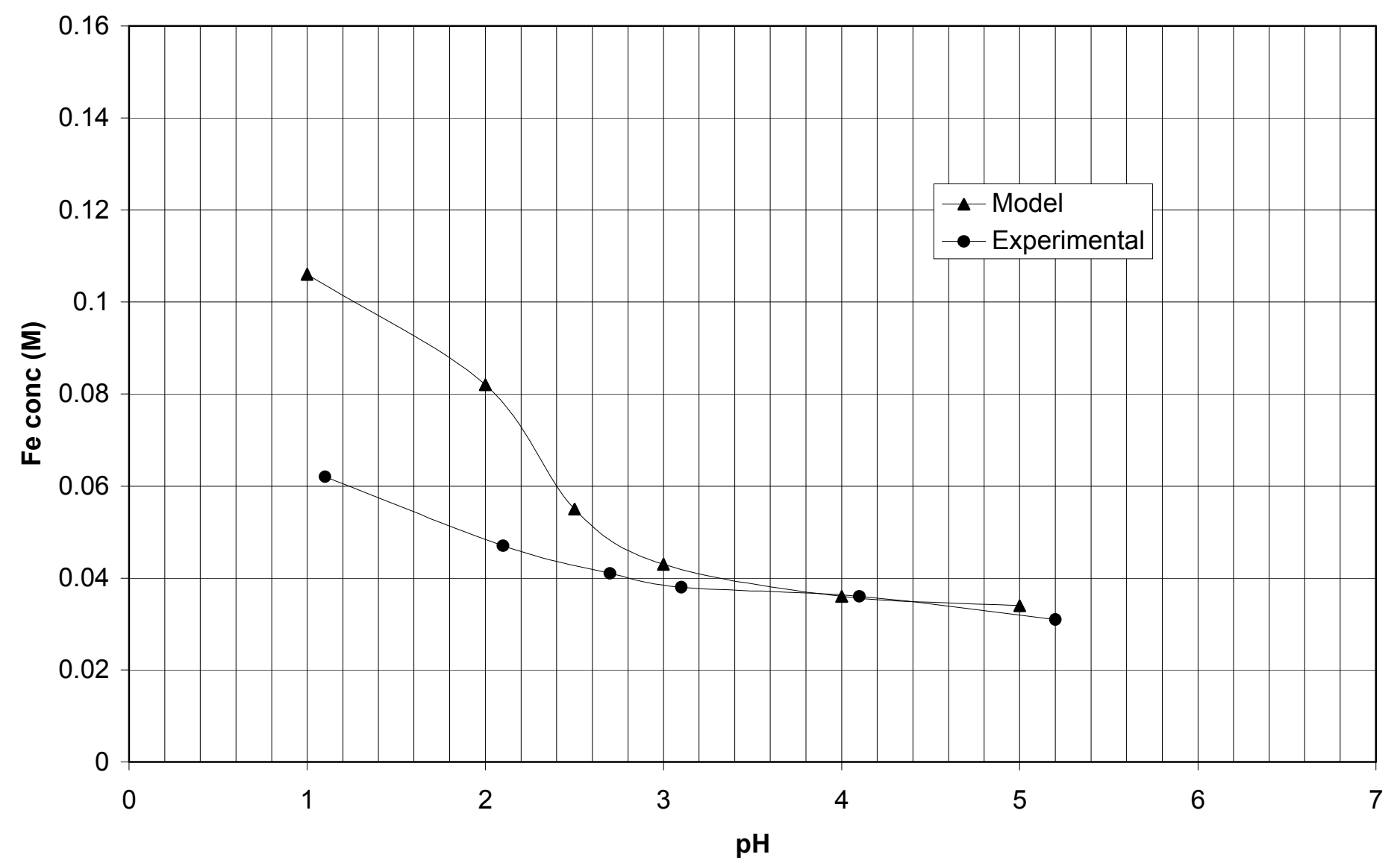

Figure 5.5 Hematite Solubility in 1 wt\% Oxalic Acid-Model Predictions and Experimental Data-pH Control 


\subsection{CONCLUSIONS}

Solubility tests were conducted using non-radioactive, pure metal phases known to be the primary phases present in High Level Waste sludge. The metal phases studied included the aluminum phases gibbsite and boehmite and the iron phases magnetite and hematite. Hematite and boehmite are expected to be the most difficult iron and aluminum phases to dissolve. These mineral phases have been identified in both SRS and Hanford High Level Waste sludge. Acids evaluated for dissolution included oxalic, nitric, and sulfuric acids. The results of the solubility tests indicate that oxalic and sulfuric acids are more effective for the dissolution of the primary sludge phases. For boehmite, elevated temperature will be required to promote effective phase dissolution in the acids studied.

Literature reviews, thermodynamic modeling, and experimental results have all confirmed that $\mathrm{pH}$ control using a supplemental proton source (additional acid) is critical for minimization of oxalic acid usage during the dissolution of hematite. Hematite dissolution is significantly impacted by $\mathrm{pH}$, partially due to changes in speciation with $\mathrm{pH}$. With $\mathrm{pH}$ control, iron concentrations as high as $0.103 \mathrm{M}$ have been observed experimentally with hematite in $0.11 \mathrm{M}$ oxalic acid. This is consistent with the formation of a 1:1 (iron:oxalate) complex. The solubility of hematite in oxalic acid has been confirmed to increase by a factor of 3 when the final solution $\mathrm{pH}$ decreases from 5 to below 1 . This is consistent with literature predictions of a shift in speciation from a $1: 3$ to a $1: 1$ complex as the $\mathrm{pH}$ is lowered. The results emphasize the importance of $\mathrm{pH}$ control in optimizing hematite dissolution in oxalic acid and may explain the somewhat limited success observed during recent attempts to remove sludge heels from SRS Tanks 5F and 6F using oxalic acid.

Based on the results of the solubility tests conducted, the following additional conclusions can be drawn.

- Primary aluminum and iron phases observed in High Level Waste sludge include gibbsite $\left(\mathrm{AlOH}_{3}\right)$, boehmite $(\mathrm{AlOOH})$, magnetite $\left(\mathrm{Fe}_{3} \mathrm{O}_{4}\right)$, and hematite $\left(\mathrm{Fe}_{2} \mathrm{O}_{3}\right)$.

- Effective dissolution of the aluminum phases gibbsite and boehmite in acid requires elevated temperatures near $70^{\circ} \mathrm{C}$.

- Hematite dissolution in oxalic acid is a stoichiometric process dependant upon the provision of sufficient oxalate molar equivalents to complex the iron and sufficient $\mathrm{H}^{+}$to promote the dissolution reaction.

- The optimal utilization of oxalic acid for hematite dissolution requires an additional proton source, such as nitric acid, and a $\mathrm{pH}$ of $\leq 1$. In the absence of a supplemental proton source, greater than stoichiometric amounts of oxalate are required. Corrosion studies will be needed to determine the effects of these conditions on tank walls.

- Solution $\mathrm{pH}$ control dramatically effects the efficiency of hematite dissolution in oxalic acid with $\mathrm{pH}$ values $\leq 1$ being preferred due to the formation of a 1:1 iron:oxalate complex. Above $\mathrm{pH} 3$, hematite dissolution significantly decreases.

- Magnetite is generally more soluble than hematite in all acids tested.

- Gibbsite is generally more soluble than the boehmite form of aluminum in all acids tested. 
- Other Fe(III) phases in oxalic acid should behave similarly to hematite, although supplemental acid requirements should be lower for mixed oxy/hydroxide phases such as $\mathrm{Fe}(\mathrm{O}) \mathrm{OH}$.

- The OLI Thermodynamic Model is a useful tool for the prediction of equilibrium iron concentrations, but predictions must be experimentally verified.

- The OLI model appears to over predict the solubility of the iron and aluminum phases studied in mineral acids.

- The minimization of oxalate consumption during sludge heel chemical cleaning is possible through the use of other acids for neutralization and $\mathrm{pH}$ control.

- Solution $\mathrm{pH}$ control should be considered in future chemical cleaning efforts for the removal of sludge heels.

Table 6.1 summarizes the experimentally determined solubilities of the aluminum phases, gibbsite and boehmite, and the iron phases, magnetite and hematite, used in the basic studies program. 
Table 6.1 Solubilities of Primary Metal Phases in Oxalic, Nitric, and Sulfuric Acids.

\begin{tabular}{|c|c|c|c|}
\hline Metal Phase $^{\text {a }}$ & Acid $^{\text {b }}$ & Temp. $\left({ }^{\circ} \mathrm{C}\right)$ & Equilibrium Al or $\mathrm{Fe}(\mathrm{M})$ \\
\hline gibbsite & oxalic & 25 & 0.059 \\
\hline gibbsite & oxalic & 70 & 0.118 \\
\hline gibbsite & nitric & 25 & 0.017 \\
\hline gibbsite & nitric & 70 & 0.087 \\
\hline gibbsite & sulfuric & 25 & 0.061 \\
\hline gibbsite & sulfuric & 70 & 0.191 \\
\hline boehmite & oxalic & 25 & 0.0017 \\
\hline boehmite & oxalic & 70 & 0.0910 \\
\hline boehmite & nitric & 25 & 0.0003 \\
\hline boehmite & nitric & 70 & 0.0091 \\
\hline boehmite & sulfuric & 25 & 0.0014 \\
\hline boehmite & sulfuric & 70 & 0.0541 \\
\hline magnetite & oxalic & 25 & 0.1005 \\
\hline magnetite & oxalic & 70 & 0.0427 \\
\hline magnetite & nitric & 25 & 0.0045 \\
\hline magnetite & nitric & 70 & 0.0070 \\
\hline magnetite & sulfuric & 25 & 0.0972 \\
\hline magnetite & sulfuric & 70 & 0.0993 \\
\hline hematite & oxalic & 25 & 0.0695 \\
\hline hematite & oxalic & 70 & $--^{c}$ \\
\hline hematite & nitric & 25 & 0.0026 \\
\hline hematite & nitric & 70 & $--^{c}$ \\
\hline hematite & sulfuric & 25 & 0.0370 \\
\hline hematite & sulfuric & 70 & $--^{c}$ \\
\hline
\end{tabular}

${ }^{a}$ gibbsite $=\mathrm{Al}(\mathrm{OH})_{3}$, boehmite $=\mathrm{AlOOH}$, magnetite $=\mathrm{Fe}_{3} \mathrm{O}_{4}$, hematite $=\mathrm{Fe}_{2} \mathrm{O}_{3}$

binitial contact acids are those listed at $0.125 \mathrm{M}$; however nitric acid was added for $\mathrm{pH}$ control in samples involving initial contact with oxalic and nitric, and sulfuric acid was added for $\mathrm{pH}$ control for samples involving initial contact with sulfuric, final solution $\mathrm{pH}$ values ranged from 0.8 to 1.4

${ }^{c}$ it is expected that this data will be included in the report before issue 


\subsection{PATH FORWARD}

The results provided in this report are preliminary in nature and are intended to provide a summary of progress made with regard to testing and understanding sludge dissolution chemistry (particularly in oxalic acid solution). Additional work is planned based on these results. Other testing that may be conducted in the next phase of the work is listed below.

- $\quad$ solubility testing of other representative iron, aluminum, manganese, and uranium phases

- $\mathrm{pH}$ effects on hematite dissolution in more concentrated oxalic acid ( $>1$ wt. \%)

- dissolution kinetics tests in oxalic acid

- solubility tests with other complexing organic acids (formic, acetic, citric, etc.) with $\mathrm{pH}$ control

- development of dissolution schemes targeting metals with low solubility in oxalic acid $(\mathrm{Pu}, \mathrm{Mn}, \mathrm{Ni}$, etc.) including the use of alternative complexants such as EDTA (implementation may be contingent on complexant susceptibility to destruction)

- further evaluation of acid mixtures for dissolution such as nitric/oxalic or sulfuric/oxalic

- comparison of the effectiveness of caustic versus acid dissolution of aluminum phases

- development of strategies to minimize oxalic acid usage during sludge dissolution

- real tank sludge waste solubility testing using optimized conditions

- further characterization of mineral phases in tank sludge samples to increase confidence in the phases targeted for the basic studies program and for the development of more representative simulants

- sludge simulant development to produce simulants that better mimic the solubility measured in real waste sludge samples

- solubility testing of refined sludge simulants

- corrosion studies of optimized dissolution conditions and mixtures of oxalic acid with nitric or sulfuric acid. 


\subsection{REFERENCES}

1. Adu-Wusu, K.; Barnes, M. J.; Bibler, N. E.; Cantrell, J. R.; Fondeur, F. F.; Hamm, B. A.; Herman. C. C.; Hobbs, D. T.; Ketusky, E. T.; Singleton, M.; Stallings, M. E.; Stevens, W. E.; Wiersma, B. J. Waste Tank Heel Chemical Cleaning Summary, WSRC-TR-2003-00401, Rev. 0, Savannah River Site, September 2003.

2. Ketusky, E. T. Determination of An Alternative Technology for HLW Tank Chemical Cleaning, WSRC-STI-2002007-00587, Rev. 0, Savannah River Site, October 2007.

3. Hay, M. S.; Koopman, D. C. Review of Alternative Enhanced Chemical Cleaning Options for SRS Waste Tanks, SRNL-STI-2009-00500, Rev. 0, Savannah River National Laboratory, August 2009.

4. Martino, C. J. Evaluation of Alternative Chemical Cleaning and Enhanced Chemical Cleaning Methods, SRNL-L3100-2009-00118, Rev. 0, Savannah River National Laboratory, June 2009.

5. Bertholdt, H. O.; Bege, D. Method for Disposing of a Solution Containing an Organic Acid, US Patent 5,958,247, Sept. 28, 1999.

6. Poirier, M. R., Fink, S. D., Analysis of Solids Remaining Following Chemical Cleaning of Tank 5F, SRNL-STI-2009-00492, December, 2009.

7. Poirier, M. R., Fink, S. D., Analysis of Samples from Tank 6 F Chemical Cleaning, SRNL-STI-2009-00493, February, 2010.

8. Reboul, S. H., Hay, M. S., Ziegler, K. E., Stone, M. E., Tank 12 Sludge Characterization and Aluminum Dissolution Demonstration, WSRC-TR-2004-00180, Rev. 0, Savannah River Site March 2004.

9. Lee, S. O., Dissolution of Iron Oxides by Oxalic Acid, Doctoral Thesis, The University of New South Wales, Sydney, Australia, September 2005.

10. Adu-Wusu, K.; McCabe, D. J. Aluminum Dissolution and Sludge Settling, WSRCSTI-2008-00208, Rev. 0, Savannah River National Laboratory, April 2008.

11. Poirier, M. R. Recipe for Simulated Tank $8 F$ Sludge Containing No RCRA Metals or Halides, WSRC-TR-2005-00045, Rev. 0, Savannah River Site, January 2005.

12. Lambert, D. P., Analysis of June 2009 Tank 7 3-L Sample, SRNL-L3100-2009-00232, Rev. 1, Savannah River National Laboratory, September 2009.

13. Hay, M.S.; Analysis of Tank $19 F$ Solids by X-ray Diffraction, SRT-LWP-97-111, Rev. 0, Savannah River National Laboratory, September 1997. 
14. Hay, M.S.; Bibler, N.E., Characterization and Sludge Washing Studies of Tank 42H Sludge, WSRC-RP-94-730, Rev. 0, Savannah River National Laboratory, July 1994.

15. Herman, C. C., Fonduer, F. F., Click, D. R., Stone, M. E., Initial Results for SRNL Characterization and Settling Testing of Tank 51 - Sludge Batch 4, SRNL-ITS-200500272, Rev. 0, Savannah River National Laboratory, December 2005.

16. Lide, D. R., CRC Handbook of Chemistry and Physics, $71^{\text {st }}$ Edition, CRC Press, Inc. 1990. 